Cochrane Database of Systematic Reviews

\title{
Gemcitabine-based chemotherapy for advanced biliary tract
} carcinomas (Review)

Abdel-Rahman O, Elsayed Z, Elhalawani H

Abdel-Rahman O, Elsayed Z, Elhalawani H.

Gemcitabine-based chemotherapy for advanced biliary tract carcinomas.

Cochrane Database of Systematic Reviews 2018, Issue 4. Art. No.: CD011746.

DOI: 10.1002/14651858.CD011746.pub2.

www.cochranelibrary.com 
TABLE OF CONTENTS

ABSTRACT

PLAIN LANGUAGE SUMMARY

SUMMARY OF FINDINGS

BACKGROUND

OBJECTIVES

METHODS

RESULTS

Figure 1.

Figure 2.

Figure 3.

Figure 4.

DISCUSSION

AUTHORS' CONCLUSIONS

ACKNOWLEDGEMENTS

REFERENCES

CHARACTERISTICS OF STUDIES

DATA AND ANALYSES

Analysis 1.1. Comparison 1 Gemcitabine plus vandetanib versus vandetanib alone, Outcome 1 Serious adverse events. .........

Analysis 1.2. Comparison 1 Gemcitabine plus vandetanib versus vandetanib alone, Outcome 2 Overall response rate. ............

Analysis 1.3. Comparison 1 Gemcitabine plus vandetanib versus vandetanib alone, Outcome 3 Grade $1-4$ anaemia. ..............

Analysis 1.4. Comparison 1 Gemcitabine plus vandetanib versus vandetanib alone, Outcome 4 Grade $3-4$ anaemia. ..............

Analysis 1.5. Comparison 1 Gemcitabine plus vandetanib versus vandetanib alone, Outcome 5 Grade 1 - 4 neutropenia. ........

Analysis 1.6. Comparison 1 Gemcitabine plus vandetanib versus vandetanib alone, Outcome 6 Grade 3 - 4 neutropenia. ........

Analysis 2.1. Comparison 2 Gemcitabine versus vandetanib, Outcome 1 Serious adverse events.

Analysis 2.2. Comparison 2 Gemcitabine versus vandetanib, Outcome 2 Overall response rate.

Analysis 2.3. Comparison 2 Gemcitabine versus vandetanib, Outcome 3 Grade 1 - 4 anaemia.

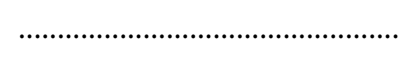

Analysis 2.4. Comparison 2 Gemcitabine versus vandetanib, Outcome 4 Grade 3 - 4 anaemia.

Analysis 2.5. Comparison 2 Gemcitabine versus vandetanib, Outcome 5 Grade 1 - 4 neutropenia.

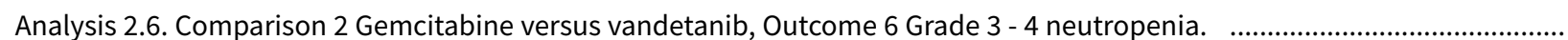

Analysis 3.1. Comparison 3 Gemcitabine plus cisplatin versus S-1 plus cisplatin, Outcome 1 All-cause mortality at one year. ...

Analysis 3.2. Comparison 3 Gemcitabine plus cisplatin versus S-1 plus cisplatin, Outcome 2 Overall response rate. .................

Analysis 3.3. Comparison 3 Gemcitabine plus cisplatin versus S-1 plus cisplatin, Outcome 3 Grade 1 - 4 anaemia. ..................

Analysis 3.4. Comparison 3 Gemcitabine plus cisplatin versus S-1 plus cisplatin, Outcome 4 Grade 3 - 4 anaemia. ...................

Analysis 3.5. Comparison 3 Gemcitabine plus cisplatin versus S-1 plus cisplatin, Outcome 5 Grade 1 - 4 thrombocytopenia. ....

Analysis 3.6. Comparison 3 Gemcitabine plus cisplatin versus S-1 plus cisplatin, Outcome 6 Grade 3 - 4 thrombocytopenia. ....

Analysis 3.7. Comparison 3 Gemcitabine plus cisplatin versus S-1 plus cisplatin, Outcome 7 Grade 1 - 4 neutropenia. .............

Analysis 3.8. Comparison 3 Gemcitabine plus cisplatin versus S-1 plus cisplatin, Outcome 8 Grade 3 - 4 neutropenia. .............

Analysis 3.9. Comparison 3 Gemcitabine plus cisplatin versus S-1 plus cisplatin, Outcome 9 Febrile neutropenia. ...................

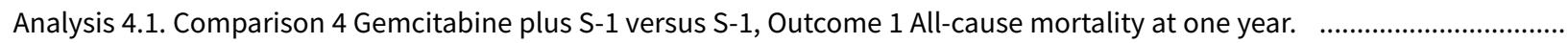

Analysis 4.2. Comparison 4 Gemcitabine plus S-1 versus S-1, Outcome 2 Serious adverse events.

Analysis 4.3. Comparison 4 Gemcitabine plus S-1 versus S-1, Outcome 3 Overall response rate.

Analysis 4.4. Comparison 4 Gemcitabine plus S-1 versus S-1, Outcome 4 Grade 1 - 4 anaemia.

Analysis 4.5. Comparison 4 Gemcitabine plus S-1 versus S-1, Outcome 5 Grade 3 - 4 anaemia.

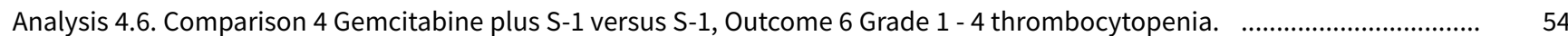

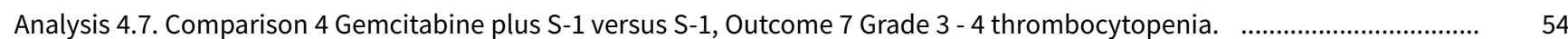

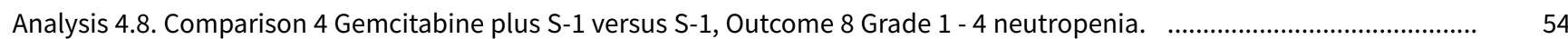

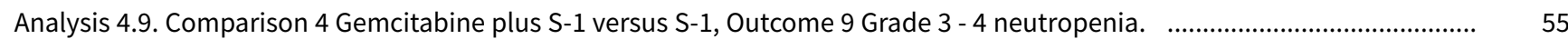

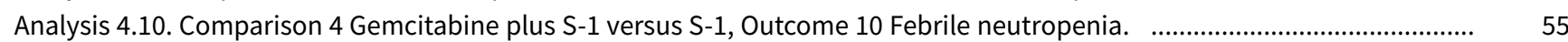

Analysis 5.1. Comparison 5 Gemcitabine plus oxaliplatin versus best supportive care, Outcome 1 All-cause mortality at one 55 year.

Analysis 5.2. Comparison 5 Gemcitabine plus oxaliplatin versus best supportive care, Outcome 2 Overall response rate. ......... 
Analysis 6.1. Comparison 6 Gemcitabine plus oxaliplatin versus fluorouracil plus folinic acid, Outcome 1 All-cause mortality at one year.

Analysis 6.2. Comparison 6 Gemcitabine plus oxaliplatin versus fluorouracil plus folinic acid, Outcome 2 Overall response rate. Analysis 7.1. Comparison 7 Gemcitabine plus oxaliplatin versus 5-fluorouracil plus cisplatin plus radiotherapy, Outcome 1 Allcause mortality at one year.

Analysis 7.2. Comparison 7 Gemcitabine plus oxaliplatin versus 5-fluorouracil plus cisplatin plus radiotherapy, Outcome 2 Serious adverse events.

Analysis 7.3. Comparison 7 Gemcitabine plus oxaliplatin versus 5-fluorouracil plus cisplatin plus radiotherapy, Outcome $3 \mathrm{Grade}$ 3 - 4 neutropenia.

Analysis 8.1. Comparison 8 Gemcitabine plus mitomycin C versus capecitabine plus mitomycin C, Outcome 1 All-cause mortality at one year.

Analysis 8.2. Comparison 8 Gemcitabine plus mitomycin C versus capecitabine plus mitomycin C, Outcome 2 Overall response rate.

Analysis 8.3. Comparison 8 Gemcitabine plus mitomycin C versus capecitabine plus mitomycin C, Outcome 3 Grade 1 - 4 thrombocytopenia.

Analysis 8.4. Comparison 8 Gemcitabine plus mitomycin C versus capecitabine plus mitomycin C, Outcome 4 Grade 3 - 4 thrombocytopenia.

ADDITIONAL TABLES

APPENDICES

CONTRIBUTIONS OF AUTHORS 
[Intervention Review]

\section{Gemcitabine-based chemotherapy for advanced biliary tract carcinomas}

Omar Abdel-Rahman'1,2, Zeinab Elsayed ${ }^{2}$, Hesham Elhalawani ${ }^{3}$

1Department of Oncology, University of Calgary and Tom Baker Cancer Center, Calgary, Canada. ${ }^{2}$ Clinical Oncology, Faculty of Medicine, Ain Shams University, Cairo, Egypt. ${ }^{3}$ Department of Radiation Oncology, The University of Texas MD Anderson Cancer Center, Houston, Texas, USA

Contact: Omar Abdel-Rahman, Department of Oncology, University of Calgary and Tom Baker Cancer Center, Calgary, Alberta, T2N 4N1, Canada.omar.abdelrhman@med.asu.edu.eg, omar.abdelsalam@ahs.ca.

Editorial group: Cochrane Hepato-Biliary Group.

Publication status and date: New, published in Issue 4, 2018.

Citation: Abdel-Rahman O, Elsayed Z, Elhalawani H. Gemcitabine-based chemotherapy for advanced biliary tract carcinomas. Cochrane Database of Systematic Reviews 2018, Issue 4. Art. No.: CD011746. DOI: 10.1002/14651858.CD011746.pub2.

Copyright @ 2018 The Cochrane Collaboration. Published by John Wiley \& Sons, Ltd.

\section{A B S T R A C T}

\section{Background}

Biliary tract cancers are a group of rare heterogeneous malignant tumours. They include intrahepatic and extrahepatic cholangiocarcinomas, gallbladder carcinomas, and ampullary carcinomas. Surgery remains the optimal modality of therapy leading to long-term survival for people diagnosed with resectable biliary tract carcinomas. Unfortunately, most people with biliary tract carcinomas are diagnosed with either unresectable locally-advanced or metastatic disease, and they are only suitable for palliative chemotherapy or supportive care.

\section{Objectives}

To assess the benefits and harms of intravenous administration of gemcitabine monotherapy or gemcitabine-based chemotherapy versus placebo, or no intervention, or other treatments (excluding gemcitabine) in adults with advanced biliary tract carcinomas.

\section{Search methods}

We performed electronic searches in the Cochrane Hepato-Biliary Group Controlled Trials Register, CENTRAL, MEDLINE, Embase, LILACS, Science Citation Index Expanded, and Conference Proceedings Citation Index - Science up to June 2017. We also checked reference lists of primary original studies and review articles manually, for further related articles (cross-references).

\section{Selection criteria}

Eligible studies include randomised clinical trials, irrespective of language or publication status, comparing intravenous administration of gemcitabine monotherapy or gemcitabine-based combination to placebo, to no intervention, or to treatments other than gemcitabine.

\section{Data collection and analysis}

We used standard methodological procedures expected by Cochrane. We assessed risks of bias of the included trials using definitions of predefined bias risk domains, and presented the review results incorporating the methodological quality of the trials using GRADE.

\section{Main results}

We included seven published randomised clinical trials with 600 participants. All included trials were at high risk of bias, and we rated the evidence as very low quality. Cointerventions were equally applied in three trials (gemcitabine plus S-1 (a combination of tegafur, gimeracil, and oteracil) versus S-1 monotherapy; gemcitabine plus S-1 versus gemcitabine monotherapy versus S-1 monotherapy; and gemcitabine plus vandetanib versus gemcitabine plus placebo versus vandetanib monotherapy), while four trials compared gemcitabine plus cisplatin versus S-1 plus cisplatin; gemcitabine plus mitomycin C versus capecitabine plus mitomycin C; gemcitabine plus oxaliplatin versus chemoradiotherapy; and gemcitabine plus oxaliplatin versus 5 -fluorouracil plus folinic acid versus best supportive care. The seven 
trials were conducted in India, Japan, France, China, Austria, South Korea, and Italy. The median age of the participants in the seven trials was between 50 and 60 years, and the male/female ratios were comparable in most of the trials. Based on these seven trials, we established eight comparisons. We could not perform all planned analyses in all comparisons because of insufficient data.

\section{Gemcitabine versus vandetanib}

One three-arm trial compared gemcitabine versus vandetanib versus both drugs in combination. It reported no data for mortality, healthrelated quality of life, or tumour progression outcomes. We rated the increased risk of serious adverse events, anaemia, and overall response rate as very low-certainty evidence.

\section{Gemcitabine plus cisplatin versus S-1 plus cisplatin}

From one trial of 96 participants, we found very low-certainty evidence that gemcitabine can lower the risk of mortality at one year when used with cisplatin versus S-1 plus cisplatin (risk ratio (RR) $0.76,95 \%$ confidence interval $(\mathrm{Cl}) 0.58$ to $0.98 ; \mathrm{P}=0.04$; participants $=96$ ). The trial did not report data for serious adverse events, quality of life, or tumour response outcomes. There is very low-certainty evidence that gemcitabine plus cisplatin combination leads to a higher risk of high-grade thrombocytopenia compared with S-1 plus cisplatin combination (RR 5.28, $95 \% \mathrm{Cl} 1.23$ to $22.55 ; \mathrm{P}=0.02$; participants $=96$ ).

\section{Gemcitabine plus S-1 versus S-1}

From two trials enrolling 151 participants, we found no difference between the two groups in terms of risk of mortality at one year or risk of serious adverse events. Gemcitabine plus S-1 combination was associated with a higher overall response rate compared with S-1 alone (RR 2.46, 95\% Cl 1.27 to 4.75; $\mathrm{P}=0.007$; participants $=140$; trials $=2 ; \mathrm{I}^{2}=0 \%$; very low certainty of evidence). Neither of the trials reported data for health-related quality of life or time to progression of the tumour.

\section{Gemcitabine plus oxaliplatin versus 5 -fluorouracil plus folinic acid versus best supportive care}

One three-arm trial compared gemcitabine plus oxaliplatin versus 5-fluorouracil plus folinic acid versus best supportive care. It reported no data for serious adverse events, health-related quality of life, or tumour progression. We rated the evidence for mortality and for overall response rate as of very low certainty.

\section{Gemcitabine plus oxaliplatin versus 5-fluorouracil plus cisplatin plus radiotherapy}

One trial of 34 participants compared gemcitabine plus oxaliplatin versus 5-fluorouracil plus cisplatin plus radiotherapy. It reported no data for quality of life, overall response rate, or tumour progression outcomes. We rated the evidence for mortality and serious adverse events as of very low certainty.

\section{Gemcitabine plus mitomycin C versus capecitabine plus mitomycin C}

One trial of 51 participants compared gemcitabine plus mitomycin C versus capecitabine plus mitomycin C. It reported no data for serious adverse events, quality of life, or tumour progression. We rated the evidence for mortality, overall response rate and thrombocytopenia as of very low certainty.

We also identified three ongoing trials evaluating outcomes of interest for our review, which we can incorporate in future updates.

For-profit bias: there was a high risk of for-profit bias in two trials (because of industry sponsorship) while there was a low risk of for-profit bias in another three trials, and unclear risk in two trials.

\section{Authors' conclusions}

In adults with advanced biliary tract carcinomas, the effects of gemcitabine or gemcitabine-based chemotherapy are uncertain on mortality and overall response compared with a range of inactive or active controls. The very low certainty of evidence is due to risk of bias, lack of information in the analyses and hence large imprecision, and possible publication bias. The confidence intervals do not rule out meaningful benefits or lack of effect of gemcitabine in all comparisons but one on mortality where gemcitabine plus cisplatin is compared with S-1 plus cisplatin. Gemcitabine-based regimens showed an increase in non-serious adverse events (particularly haematological toxicities). Further randomised clinical trials are mandatory, to further explore the best therapeutic options for adults with advanced biliary tract carcinomas.

\section{PLAIN LANGUAGE SUMMARY}

\section{Gemcitabine-containing chemotherapy for people with advanced bile duct cancer}

\section{Review question}

What are the benefits and harms of gemcitabine-based chemotherapy versus placebo or no intervention or gemcitabine-based chemotherapy versus chemotherapy without gemcitabine in people with advanced bile duct cancer?

\section{Background}

Bile duct cancer (starting in the bile duct) is an uncommon malignant tumour. In most people, bile duct cancer is diagnosed at an advanced stage. For them, treatment options include drugs (chemotherapy). Gemcitabine is a drug used to treat certain types of cancerous tumours, including advanced bile duct cancer. Gemcitabine is an active chemotherapy drug, and in combination with cisplatin has been the accepted standard treatment in this disease. 


\section{Study characteristics}

The review authors searched published medical articles to clarify the role of gemcitabine (given by injection into a vein) compared with placebo (an inactive substance or preparation used as a control intervention in an experiment), or with no intervention, or with nongemcitabine chemotherapy combinations in the treatment of people with advanced bile duct cancer. The review authors looked for randomised clinical trials, where people were allocated at random to one of two or more treatments groups, in order to perform statistical analysis from which to draw conclusions about the intervention. The evidence is current to June 2017.

\section{Key results}

The review authors found seven randomised clinical trials, and judged all of them to be at high risk of bias. These trials randomised 600 people with advanced bile duct cancer. The majority of these trials suggested that there were no demonstrable differences in either benefits or harms between gemcitabine-containing chemotherapy regimens compared with non-gemcitabine chemotherapy combinations. Only one trial, comparing gemcitabine plus cisplatin versus S-1 plus cisplatin suggested that gemcitabine-containing regimens might decrease death. The review authors identified three ongoing randomised clinical trials.

As far as funding goes, two of the seven trials were sponsored by the pharmaceutical industry, three were not sponsored by the industry, and the remaining two trials provided no information about funding.

\section{Quality of the evidence and conclusions}

The evidence obtained from the seven low-quality randomised trials was insufficient to prove whether or not gemcitabine-containing combinations are better than non-gemcitabine-containing combinations for people with advanced bile duct cancer. Moreover, gemcitabine-based combinations showed an increase in non-serious adverse events, particularly haematological toxicities (damage to blood and body tissues). More randomised clinical trials are needed. 


\section{SUMMARY OF FINDINGS}

\section{Summary of findings for the main comparison. Gemcitabine plus vandetanib compared with vandetanib for advanced biliary tract carcinomas}

Gemcitabine plus vandetanib compared with vandetanib for advanced biliary tract carcinomas

Patient or population: people with advanced biliary tract carcinomas

Setting: specialist hospitals

Intervention: gemcitabine plus vandetanib

Comparison: vandetanib

\begin{tabular}{|c|c|c|c|c|c|c|}
\hline \multirow[t]{2}{*}{ Outcomes } & \multicolumn{2}{|c|}{ Anticipated absolute effects* $(95 \% \mathrm{Cl})$} & \multirow{2}{*}{$\begin{array}{l}\text { Relative effect } \\
(95 \% \mathrm{CI})\end{array}$} & \multirow{2}{*}{$\begin{array}{l}\text { № of partici- } \\
\text { pants } \\
\text { (studies) }\end{array}$} & \multirow{2}{*}{$\begin{array}{l}\text { Certainty of } \\
\text { the evidence } \\
\text { (GRADE) }\end{array}$} & \multirow[t]{2}{*}{ Comments } \\
\hline & $\begin{array}{l}\text { Risk with vande- } \\
\text { tanib }\end{array}$ & $\begin{array}{l}\text { Risk with gemcitabine plus van- } \\
\text { detanib }\end{array}$ & & & & \\
\hline All-cause mortality at 1 year & Not reported & & & & & \\
\hline Serious adverse events & Study population & & $\begin{array}{l}\text { RR } 0.95 \\
\text { (0.52 to } 1.74)\end{array}$ & $\begin{array}{l}117 \\
(1 \mathrm{RCT})\end{array}$ & $\begin{array}{l}\oplus \odot \odot \ominus \\
\text { VERY LOW } 1\end{array}$ & \\
\hline Health-related quality of life & Not reported & & & & & \\
\hline \multirow[t]{2}{*}{ Overall response rate } & \multicolumn{2}{|l|}{ Study population } & \multirow{2}{*}{$\begin{array}{l}\text { RR } 5.40 \\
\text { (1.25 to } 23.29 \text { ) }\end{array}$} & \multirow{2}{*}{$\begin{array}{l}113 \\
(1 \mathrm{RCT})\end{array}$} & \multirow{2}{*}{$\begin{array}{l}\oplus \ominus \ominus \odot \\
\text { VERY LOW1 }\end{array}$} & \\
\hline & 36 per 1000 & $\begin{array}{l}193 \text { per } 1000 \\
\text { ( } 45 \text { to } 832 \text { ) }\end{array}$ & & & & \\
\hline \multirow[t]{2}{*}{ Grade 1 - 4 anaemia } & Study population & & \multirow{2}{*}{$\begin{array}{l}\text { RR } 7.12 \\
\text { (0.90 to } 56.08)\end{array}$} & \multirow{2}{*}{$\begin{array}{l}117 \\
(1 \mathrm{RCT})\end{array}$} & \multirow{2}{*}{$\begin{array}{l}\oplus \ominus \ominus \ominus \\
\text { VERY LOW1 }\end{array}$} & \\
\hline & 17 per 1000 & $\begin{array}{l}121 \text { per } 1000 \\
\text { (15 to } 951)\end{array}$ & & & & \\
\hline
\end{tabular}

${ }^{*}$ The risk in the intervention group (and its 95\% confidence interval) is based on the assumed risk in the comparison group and the relative effect of the intervention (and its $95 \% \mathrm{Cl}$ ).

CI: Confidence interval; RR: Risk ratio; $\mathbf{R C T}$ : randomised clinical trial 


\begin{tabular}{|c|c|c|c|c|c|c|}
\hline \multicolumn{7}{|c|}{$\begin{array}{l}\text { High certainty: We are very confident that the true effect lies close to that of the estimate of the effect. } \\
\text { Moderate certainty: We are moderately confident in the effect estimate: The true effect is likely to be close to the estimate of the effect, but there is a possibility that it is } \\
\text { substantially different. } \\
\text { Low certainty: Our confidence in the effect estimate is limited: The true effect may be substantially different from the estimate of the effect. } \\
\text { Very low certainty: We have very little confidence in the effect estimate: The true effect is likely to be substantially different from the estimate of effect. }\end{array}$} \\
\hline \multicolumn{7}{|c|}{$\begin{array}{l}\text { 1Downgraded three levels }(-3) \text { because of i) within-study risk of bias due to high risk of bias; ii) publication bias could not be assessed; iii) imprecision due to small number of } \\
\text { trials (one trial) }\end{array}$} \\
\hline \multicolumn{7}{|c|}{ Gemcitabine compared with vandetanib for advanced biliary tract carcinomas } \\
\hline \multicolumn{7}{|c|}{$\begin{array}{l}\text { Patient or population: people with advanced biliary tract carcinomas } \\
\text { Setting: specialist hospitals } \\
\text { Intervention: gemcitabine } \\
\text { Comparison: vandetanib }\end{array}$} \\
\hline \multirow[t]{3}{*}{ Outcomes } & \multicolumn{2}{|c|}{ Illustrative comparative risks* $(95 \% \mathrm{Cl})$} & \multirow{3}{*}{$\begin{array}{l}\text { Relative effect } \\
(95 \% \mathrm{Cl})\end{array}$} & \multirow{3}{*}{$\begin{array}{l}\text { No of Partici- } \\
\text { pants } \\
\text { (studies) }\end{array}$} & \multirow{3}{*}{$\begin{array}{l}\text { Quality of the } \\
\text { evidence } \\
\text { (GRADE) }\end{array}$} & \multirow[t]{3}{*}{ Comments } \\
\hline & Assumed risk & Corresponding risk & & & & \\
\hline & $\begin{array}{l}\text { Risk with vande- } \\
\text { tanib }\end{array}$ & Risk with gemcitabine & & & & \\
\hline All-cause mortality at 1 year & \multicolumn{4}{|l|}{ Not reported } & & \\
\hline Serious adverse events & 271 per 1000 & $\begin{array}{l}214 \text { per } 1000 \\
\text { (111 to } 412)\end{array}$ & RR 0.79 (0.41 to 1.52$)$ & $\begin{array}{l}115 \\
(1 \mathrm{RCT})\end{array}$ & $\begin{array}{l}\oplus \odot \odot \odot \\
\text { VERY LOW1 }\end{array}$ & \\
\hline Helath-related quality of life & \multicolumn{4}{|l|}{ Not reported } & & \\
\hline Overall response rate & 36 per 1000 & $\begin{array}{l}135 \text { per } 1000 \\
(29 \text { to } 619)\end{array}$ & $\begin{array}{l}\text { RR } 3.77 \text { (0.82 to } \\
17.33)\end{array}$ & $\begin{array}{l}108 \\
(1 \mathrm{RCT})\end{array}$ & $\begin{array}{l}\oplus \odot \odot \odot \\
\text { VERY LOW } 1\end{array}$ & \\
\hline Time to progression of the tumour & \multicolumn{4}{|l|}{ Not reported } & & \\
\hline Grade 1 - 4 anaemia & 17 per 1000 & $\begin{array}{l}125 \text { per } 1000 \\
\text { (16 to } 984)\end{array}$ & $\begin{array}{l}\text { RR } 7.38 \text { (0.94 to } \\
58.05)\end{array}$ & $\begin{array}{l}115 \\
(1 \mathrm{RCT})\end{array}$ & $\begin{array}{l}\oplus \odot \odot \odot \\
\text { VERY LOW } 1\end{array}$ & \\
\hline
\end{tabular}




\begin{tabular}{|c|c|c|c|c|c|c|}
\hline \multicolumn{7}{|c|}{$\begin{array}{l}{ }^{\star} \text { The basis for the assumed risk (e.g. the median control group risk across studies) is provided in footnotes. The corresponding risk (and its } 95 \% \text { confidence interval) is } \\
\text { based on the assumed risk in the comparison group and the relative effect of the intervention (and its } 95 \% \mathrm{Cl} \text { ). } \\
\text { Cl: Confidence interval; RR: Risk ratio; RCT: randomised clinical trial }\end{array}$} \\
\hline \multicolumn{7}{|c|}{$\begin{array}{l}\text { GRADE Working Group grades of evidence } \\
\text { High quality: Further research is very unlikely to change our confidence in the estimate of effect. } \\
\text { Moderate quality: Further research is likely to have an important impact on our confidence in the estimate of effect and may change the estimate. } \\
\text { Low quality: Further research is very likely to have an important impact on our confidence in the estimate of effect and is likely to change the estimate. } \\
\text { Very low quality: We are very uncertain about the estimate. }\end{array}$} \\
\hline \multicolumn{7}{|c|}{$\begin{array}{l}\text { 1Downgraded three levels (-3) because of i) within-study risk of bias due to high risk of bias; ii) publication bias could not be assessed; iii) imprecision due to small number of } \\
\text { trials (one trial) }\end{array}$} \\
\hline \multicolumn{7}{|c|}{ Gemcitabine plus cisplatin compared with S-1 plus cisplatin for advanced biliary tract carcinomas } \\
\hline \multicolumn{7}{|c|}{$\begin{array}{l}\text { Patient or population: people with advanced biliary tract carcinomas } \\
\text { Setting: specialist hospitals } \\
\text { Intervention: gemcitabine plus cisplatin } \\
\text { Comparison: S-1 plus cisplatin }\end{array}$} \\
\hline \multirow[t]{2}{*}{ Outcomes } & \multicolumn{2}{|c|}{ Anticipated absolute effects* $(95 \% \mathrm{Cl})$} & \multirow{2}{*}{$\begin{array}{l}\text { Relative effect } \\
(95 \% \mathrm{Cl})\end{array}$} & \multirow{2}{*}{$\begin{array}{l}\text { No of partici- } \\
\text { pants } \\
\text { (studies) }\end{array}$} & \multirow{2}{*}{$\begin{array}{l}\text { Certainty of } \\
\text { the evidence } \\
\text { (GRADE) }\end{array}$} & \multirow[t]{2}{*}{ Comments } \\
\hline & $\begin{array}{l}\text { Risk with S- } \\
\text { cisplatin }\end{array}$ & $\begin{array}{l}\text { Risk with gemcitabine plus cis- } \\
\text { platin }\end{array}$ & & & & \\
\hline \multirow[t]{2}{*}{ All-cause mortality at 1 year } & Study popula & & \multirow{2}{*}{$\begin{array}{l}\text { RR } 0.76 \\
(0.58 \text { to } 0.98)\end{array}$} & \multirow{2}{*}{$\begin{array}{l}96 \\
(1 \mathrm{RCT})\end{array}$} & \multirow{2}{*}{\multicolumn{2}{|c|}{$\begin{array}{l}\oplus \odot \odot \odot \\
\text { VERY LOW1 }\end{array}$}} \\
\hline & 809 per 1000 & $\begin{array}{l}614 \text { per } 1000 \\
\text { (469 to } 792)\end{array}$ & & & & \\
\hline Serious adverse events & Not reported & & & & & \\
\hline Health-related quality of life & Not reported & & & & & \\
\hline \multirow[t]{2}{*}{ Overall response rate } & Study popula & & \multirow{2}{*}{$\begin{array}{l}\text { RR } 0.82 \\
\text { (0.37 to } 1.82 \text { ) }\end{array}$} & \multirow{2}{*}{$\begin{array}{l}88 \\
(1 \mathrm{RCT})\end{array}$} & \multirow{2}{*}{\multicolumn{2}{|c|}{$\begin{array}{l}\oplus \odot \odot \odot \\
\text { VERY LOW } 1\end{array}$}} \\
\hline & 238 per 1000 & $\begin{array}{l}195 \text { per } 1000 \\
\text { (88 to } 433 \text { ) }\end{array}$ & & & & \\
\hline
\end{tabular}




\begin{tabular}{|c|c|c|c|c|c|c|}
\hline \multirow{3}{*}{\multicolumn{2}{|c|}{ 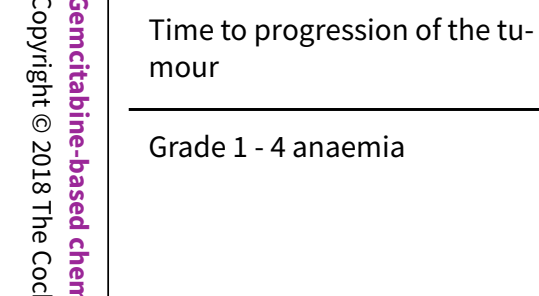 }} & \multicolumn{4}{|c|}{ Not reported } & \\
\hline & & \multicolumn{2}{|c|}{ Study population } & \multirow{2}{*}{$\begin{array}{l}\text { RR } 11.27 \\
\text { (4.41 to } 28.83 \text { ) }\end{array}$} & \multirow{2}{*}{$\begin{array}{l}96 \\
(1 \mathrm{RCT})\end{array}$} & \multirow{2}{*}{$\begin{array}{l}\oplus \ominus \ominus \ominus \\
\text { VERY LOW1 }\end{array}$} \\
\hline & & 85 per 1000 & $\begin{array}{l}959 \text { per } 1000 \\
\text { (375 to } 1000)\end{array}$ & & & \\
\hline
\end{tabular}

${ }^{\star}$ The risk in the intervention group (and its $95 \%$ confidence interval) is based on the assumed risk in the comparison group and the relative effect of the intervention (and its $95 \% \mathrm{Cl})$.

Cl: Confidence interval; RR: Risk ratio; RCT: randomised clinical trial

\section{GRADE Working Group grades of evidence}

High certainty: We are very confident that the true effect lies close to that of the estimate of the effect.

Moderate certainty: We are moderately confident in the effect estimate: The true effect is likely to be close to the estimate of the effect, but there is a possibility that it is substantially different.

Low certainty: Our confidence in the effect estimate is limited: The true effect may be substantially different from the estimate of the effect.

Very low certainty: We have very little confidence in the effect estimate: The true effect is likely to be substantially different from the estimate of effect.

1Downgraded three levels (-3) because of i) within-study risk of bias due to high risk of bias; ii) publication bias could not be assessed; iii) imprecision due to small number of trials (one trial)

\section{Summary of findings 4. Gemcitabine plus S-1 compared with S-1 for advanced biliary tract carcinomas}

\section{Gemcitabine plus S-1 compared with S-1 for advanced biliary tract carcinomas}

Patient or population: people with advanced biliary tract carcinomas

Setting: specialist hospitals

Intervention: gemcitabine plus S-1

Comparison: $\mathrm{S}-1$

\begin{tabular}{|c|c|c|c|c|c|c|}
\hline \multirow[t]{2}{*}{ Outcomes } & \multicolumn{2}{|c|}{ Anticipated absolute effects ${ }^{\star}(95 \% \mathrm{Cl})$} & \multirow{2}{*}{$\begin{array}{l}\text { Relative effect } \\
(95 \% \mathrm{Cl})\end{array}$} & \multirow{2}{*}{$\begin{array}{l}\text { № of partici- } \\
\text { pants } \\
\text { (studies) }\end{array}$} & \multirow{2}{*}{$\begin{array}{l}\text { Certainty of } \\
\text { the evidence } \\
\text { (GRADE) }\end{array}$} & \multirow[t]{2}{*}{ Comments } \\
\hline & Risk with S-1 & Risk with gemcitabine plus S-1 & & & & \\
\hline All-cause mortality at 1 year & 707 per 1000 & $\begin{array}{l}431 \text { per } 1000 \\
\text { (233 to } 799)\end{array}$ & $\begin{array}{l}\text { RR } 0.61 \\
\text { (0.33 to } 1.13 \text { ) }\end{array}$ & $\begin{array}{l}151 \\
\text { (2 RCTs) }\end{array}$ & $\begin{array}{l}\oplus \ominus \ominus \ominus \\
\text { VERY LOW } 1\end{array}$ & \\
\hline
\end{tabular}




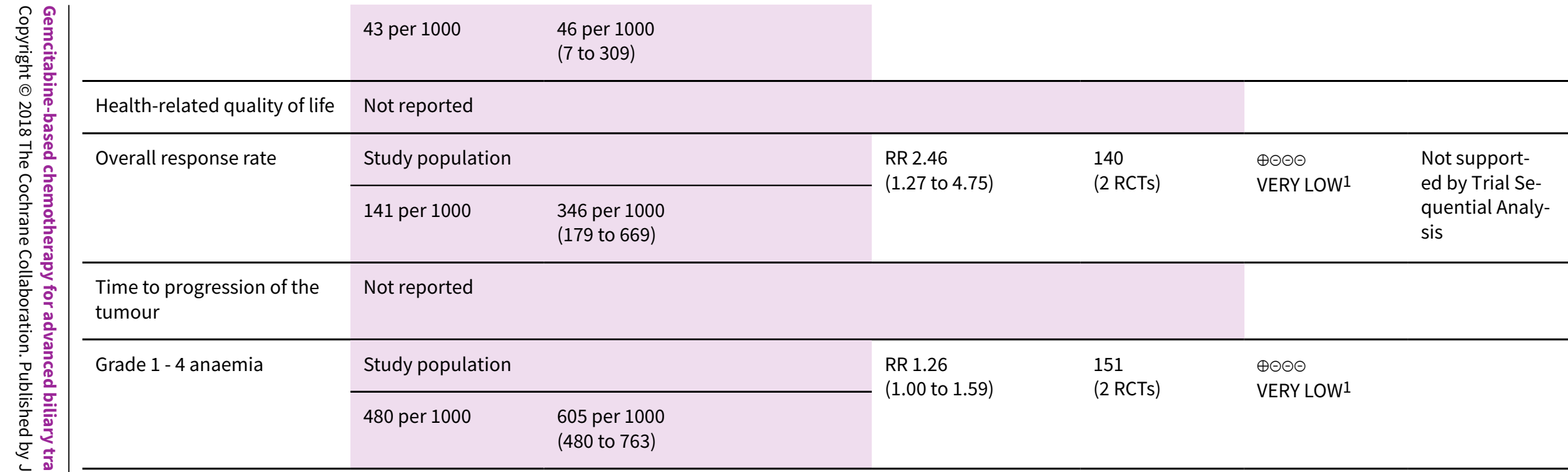

${ }^{\star}$ The risk in the intervention group (and its $95 \%$ confidence interval) is based on the assumed risk in the comparison group and the relative effect of the intervention (and its $95 \% \mathrm{Cl}$ ).

Cl: Confidence interval; RR: Risk ratio; RCT: randomised clinical trial

\section{GRADE Working Group grades of evidence}

High certainty: We are very confident that the true effect lies close to that of the estimate of the effect.

Moderate certainty: We are moderately confident in the effect estimate: The true effect is likely to be close to the estimate of the effect, but there is a possibility that it is substantially different.

Low certainty: Our confidence in the effect estimate is limited: The true effect may be substantially different from the estimate of the effect.

Very low certainty: We have very little confidence in the effect estimate: The true effect is likely to be substantially different from the estimate of effect.

${ }^{1}$ Downgraded three levels (-3) because of i) within-study risk of bias due to high risk of bias; ii) publication bias could not be assessed; iii) imprecision due to small number of trials (two trials)

\section{Summary of findings 5. Gemcitabine plus oxaliplatin compared with best supportive care for advanced biliary tract carcinomas}

Gemcitabine plus oxaliplatin compared with best supportive care for advanced biliary tract carcinomas

Patient or population: people with advanced biliary tract carcinomas

Setting: specialist hospitals

Intervention: gemcitabine plus oxaliplatin

Comparison: best supportive care 


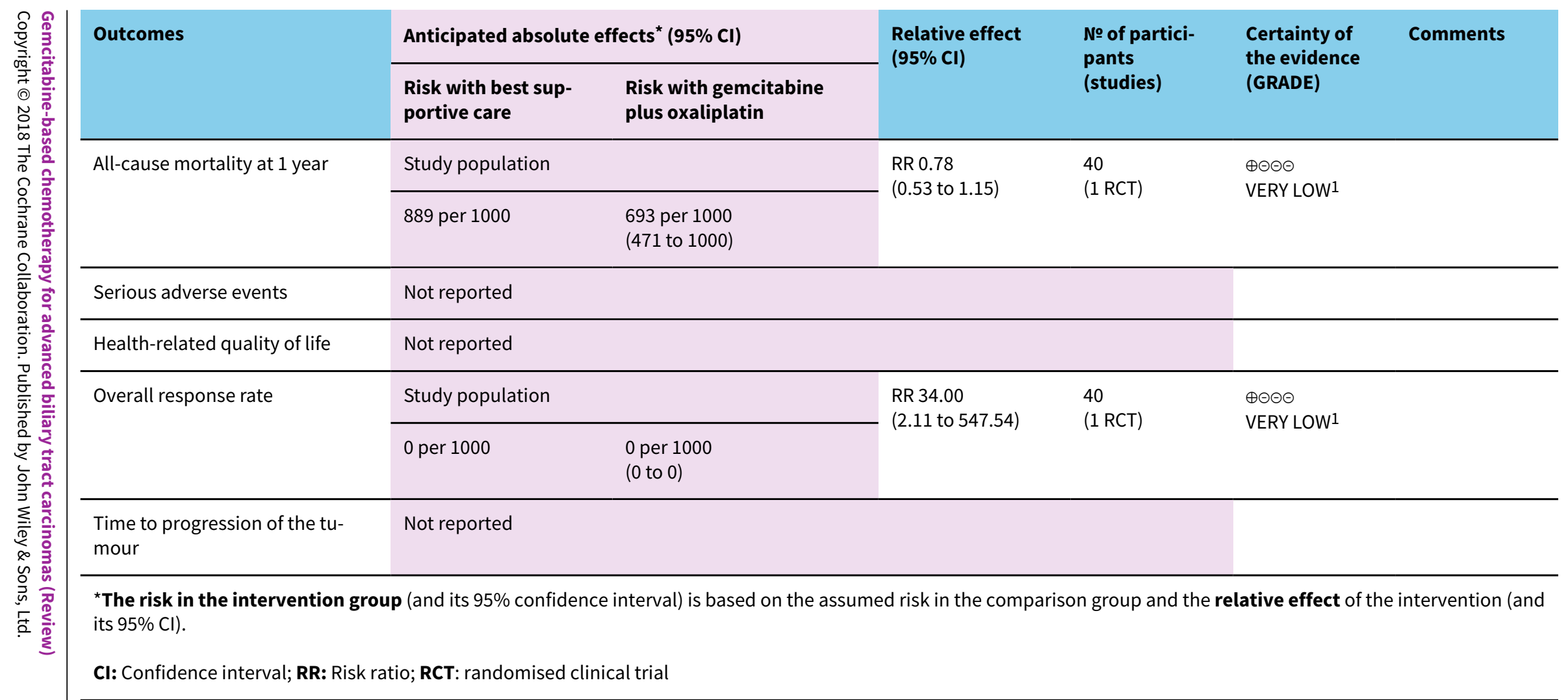

\section{GRADE Working Group grades of evidence}

High certainty: We are very confident that the true effect lies close to that of the estimate of the effect.

Moderate certainty: We are moderately confident in the effect estimate: The true effect is likely to be close to the estimate of the effect, but there is a possibility that it is substantially different.

Low certainty: Our confidence in the effect estimate is limited: The true effect may be substantially different from the estimate of the effect.

Very low certainty: We have very little confidence in the effect estimate: The true effect is likely to be substantially different from the estimate of effect.

1Downgraded three levels (-3) because of i) within-study risk of bias due to high risk of bias; ii) publication bias could not be assessed; iii) imprecision due to small number of trials (one trial)

Summary of findings 6. Gemcitabine plus oxaliplatin compared with 5-fluorouracil plus folinic acid for advanced biliary tract carcinomas

\section{Gemcitabine plus oxaliplatin compared with fluorouracil plus folinic acid for advanced biliary tract carcinomas}

Patient or population: people with advanced biliary tract carcinomas 
Setting: specialist hospitals

Intervention: gemcitabine plus oxaliplatin

Comparison: fluorouracil plus folinic acid

\begin{tabular}{|c|c|c|c|c|c|c|}
\hline \multirow[t]{2}{*}{ Outcomes } & \multicolumn{2}{|c|}{ Anticipated absolute effects* $(95 \% \mathrm{Cl})$} & \multirow{2}{*}{$\begin{array}{l}\text { Relative effect } \\
(95 \% \mathrm{Cl})\end{array}$} & \multirow{2}{*}{$\begin{array}{l}\text { № of partici- } \\
\text { pants } \\
\text { (studies) }\end{array}$} & \multirow{2}{*}{$\begin{array}{l}\text { Certainty of } \\
\text { the evidence } \\
\text { (GRADE) }\end{array}$} & \multirow[t]{2}{*}{ Comments } \\
\hline & $\begin{array}{l}\text { Risk with fluorouracil } \\
\text { plus folinic acid }\end{array}$ & $\begin{array}{l}\text { Risk with gemcitabine plus } \\
\text { oxaliplatin }\end{array}$ & & & & \\
\hline \multirow[t]{2}{*}{ All-cause mortality at 1 year } & \multicolumn{2}{|l|}{ Study population } & \multirow{2}{*}{$\begin{array}{l}\text { RR } 0.81 \\
\text { (0.55 to } 1.20)\end{array}$} & \multirow{2}{*}{$\begin{array}{l}41 \\
(1 \mathrm{RCT})\end{array}$} & \multirow{2}{*}{$\begin{array}{l}\oplus \odot \odot \ominus \\
\text { VERY LOW } 1\end{array}$} & \\
\hline & 857 per 1000 & $\begin{array}{l}694 \text { per } 1000 \\
(471 \text { to } 1000)\end{array}$ & & & & \\
\hline Serious adverse events & Not reported & & & & & \\
\hline Helath-related quality of life & Not reported & & & & & \\
\hline \multirow[t]{2}{*}{ Overall response rate } & Study population & & \multirow{2}{*}{$\begin{array}{l}\text { RR } 2.15 \\
\text { (0.64 to } 7.29)\end{array}$} & \multirow{2}{*}{$\begin{array}{l}41 \\
(1 \mathrm{RCT})\end{array}$} & \multirow{2}{*}{$\begin{array}{l}\oplus \odot \odot \odot \\
\text { VERY LOW } 1\end{array}$} & \\
\hline & 143 per 1000 & $\begin{array}{l}307 \text { per } 1000 \\
\text { (91 to } 1000)\end{array}$ & & & & \\
\hline $\begin{array}{l}\text { Time to progression of the tu- } \\
\text { mour }\end{array}$ & Not reported & & & & & \\
\hline
\end{tabular}

${ }^{\star}$ The risk in the intervention group (and its $95 \%$ confidence interval) is based on the assumed risk in the comparison group and the relative effect of the intervention (and its $95 \% \mathrm{Cl})$.

CI: Confidence interval; RR: Risk ratio; $\mathbf{R C T}$ : randomised clinical trial

\section{GRADE Working Group grades of evidence}

High certainty: We are very confident that the true effect lies close to that of the estimate of the effect.

Moderate certainty: We are moderately confident in the effect estimate: The true effect is likely to be close to the estimate of the effect, but there is a possibility that it is substantially different.

Low certainty: Our confidence in the effect estimate is limited: The true effect may be substantially different from the estimate of the effect.

Very low certainty: We have very little confidence in the effect estimate: The true effect is likely to be substantially different from the estimate of effect.

1Downgraded three levels (-3) because of i) within-study risk of bias due to high risk of bias; ii) publication bias could not be assessed; iii) imprecision due to small number of trials (one trial) 
Summary of findings 7. Gemcitabine plus oxaliplatin compared with 5-fluorouracil plus cisplatin plus radiotherapy for advanced biliary tract carcinomas

Gemcitabine plus oxaliplatin compared with fluorouracil plus cisplatin plus radiotherapy for advanced biliary tract carcinomas

Patient or population: people with advanced biliary tract carcinomas

Setting: specialist hospitals

Intervention: gemcitabine plus oxaliplatin

Comparison: fluorouracil plus cisplatin plus radiotherapy

\begin{tabular}{|c|c|c|c|c|c|c|}
\hline \multirow[t]{2}{*}{ Outcomes } & \multicolumn{2}{|c|}{ Anticipated absolute effects ${ }^{\star}(95 \% \mathrm{Cl})$} & \multirow{2}{*}{$\begin{array}{l}\text { Relative effect } \\
(95 \% \mathrm{CI})\end{array}$} & \multirow{2}{*}{$\begin{array}{l}\text { № of partici- } \\
\text { pants } \\
\text { (studies) }\end{array}$} & \multirow{2}{*}{$\begin{array}{l}\text { Certainty of } \\
\text { the evidence } \\
\text { (GRADE) }\end{array}$} & \multirow[t]{2}{*}{ Comments } \\
\hline & $\begin{array}{l}\text { Risk with fluorouracil } \\
\text { and cisplatin plus radio- } \\
\text { therapy }\end{array}$ & $\begin{array}{l}\text { Risk with gemcitabine } \\
\text { plus oxaliplatin }\end{array}$ & & & & \\
\hline \multirow[t]{2}{*}{ All-cause mortality at 1 year } & Study population & & \multirow{2}{*}{$\begin{array}{l}\text { RR } 0.56 \\
\text { (0.21 to } 1.52)\end{array}$} & \multirow{2}{*}{$\begin{array}{l}34 \\
(1 \mathrm{RCT})\end{array}$} & \multirow{2}{*}{$\begin{array}{l}\oplus \ominus \ominus \ominus \\
\text { VERY LOW } 1\end{array}$} & \\
\hline & 444 per 1000 & $\begin{array}{l}249 \text { per } 1000 \\
\text { (93 to } 676)\end{array}$ & & & & \\
\hline \multirow[t]{2}{*}{ Serious adverse events } & Study population & & \multirow{2}{*}{$\begin{array}{l}\text { RR } 1.50 \\
\text { (0.66 to } 3.39)\end{array}$} & \multirow{2}{*}{$\begin{array}{l}34 \\
(1 \mathrm{RCT})\end{array}$} & \multirow{2}{*}{$\begin{array}{l}\oplus \ominus \ominus \ominus \\
\text { VERY LOW } 1\end{array}$} & \\
\hline & 333 per 1000 & $\begin{array}{l}500 \text { per } 1000 \\
(220 \text { to } 1000)\end{array}$ & & & & \\
\hline Health-related quality of life & Not reported & & & & & \\
\hline Overall response rate & Not reported & & & & & \\
\hline $\begin{array}{l}\text { Time to progression of the tu- } \\
\text { mour }\end{array}$ & Not reported & & & & & \\
\hline
\end{tabular}

${ }^{\star}$ The risk in the intervention group (and its $95 \%$ confidence interval) is based on the assumed risk in the comparison group and the relative effect of the intervention (and its $95 \% \mathrm{Cl})$.

CI: Confidence interval; RR: Risk ratio; RCT: randomised clinical trial

GRADE Working Group grades of evidence

High certainty: We are very confident that the true effect lies close to that of the estimate of the effect.

Moderate certainty: We are moderately confident in the effect estimate: The true effect is likely to be close to the estimate of the effect, but there is a possibility that it is

substantially different.

Low certainty: Our confidence in the effect estimate is limited: The true effect may be substantially different from the estimate of the effect.

Very low certainty: We have very little confidence in the effect estimate: The true effect is likely to be substantially different from the estimate of effect. 
1Downgraded three levels (-3) because of i) within-study risk of bias due to high risk of bias; ii) publication bias could not be assessed; iii) imprecision due to small number of trials (one trial)

\section{Summary of findings 8 . Gemcitabine plus mitomycin C compared with capecitabine plus mitomycin C for advanced biliary tract carcinomas}

Gemcitabine plus mitomycin C compared with mitomycin C plus capecitabine for advanced biliary tract carcinomas

Patient or population: people with advanced biliary tract carcinomas

Setting: specialist hospitals

Intervention: gemcitabine plus mitomycin C

Comparison: capecitabine plus mitomycin $C$

\begin{tabular}{|c|c|c|c|c|c|c|}
\hline \multirow[t]{2}{*}{ Outcomes } & \multicolumn{2}{|c|}{ Anticipated absolute effects ${ }^{\star}(95 \% \mathrm{Cl})$} & \multirow{2}{*}{$\begin{array}{l}\text { Relative effect } \\
(95 \% \mathrm{Cl})\end{array}$} & \multirow{2}{*}{$\begin{array}{l}\text { № of partici- } \\
\text { pants } \\
\text { (studies) }\end{array}$} & \multirow{2}{*}{$\begin{array}{l}\text { Certainty of } \\
\text { the evidence } \\
\text { (GRADE) }\end{array}$} & \multirow[t]{2}{*}{ Comments } \\
\hline & $\begin{array}{l}\text { Risk with } \\
\text { capecitabine plus } \\
\text { mitomycin C }\end{array}$ & $\begin{array}{l}\text { Risk with gemcitabine plus } \\
\text { mitomycin C }\end{array}$ & & & & \\
\hline \multirow[t]{2}{*}{ All-cause mortality at 1 year } & Study population & & \multirow{2}{*}{$\begin{array}{l}\text { RR } 1.14 \\
\text { (0.89 to } 1.48)\end{array}$} & \multirow{2}{*}{$\begin{array}{l}51 \\
(1 \mathrm{RCT})\end{array}$} & \multirow{2}{*}{$\begin{array}{l}\oplus \odot \odot \ominus \\
\text { VERY LOW } 1\end{array}$} & \\
\hline & 769 per 1000 & $\begin{array}{l}877 \text { per } 1000 \\
\text { (685 to } 1000)\end{array}$ & & & & \\
\hline Serious adverse events & Not reported & & & & & \\
\hline Health-related quality of life & Not reported & & & & & \\
\hline \multirow[t]{2}{*}{ Overall response rate } & Study population & & \multirow{2}{*}{$\begin{array}{l}\text { RR } 0.65 \\
\text { (0.25 to } 1.72)\end{array}$} & \multirow{2}{*}{$\begin{array}{l}51 \\
(1 \mathrm{RCT})\end{array}$} & \multirow{2}{*}{$\begin{array}{l}\oplus \odot \odot \ominus \\
\text { VERY LOW } 1\end{array}$} & \\
\hline & 308 per 1000 & $\begin{array}{l}200 \text { per } 1000 \\
\text { ( } 77 \text { to } 529)\end{array}$ & & & & \\
\hline $\begin{array}{l}\text { Time to progression of the tu- } \\
\text { mour }\end{array}$ & Not reported & & & & & \\
\hline \multirow[t]{2}{*}{ Grade 1 - 4 thrombocytopenia } & Study population & & \multirow{2}{*}{$\begin{array}{l}\text { RR } 0.56 \\
\text { (0.29 to } 1.06)\end{array}$} & \multirow{2}{*}{$\begin{array}{l}47 \\
(1 \mathrm{RCT})\end{array}$} & \multirow{2}{*}{$\begin{array}{l}\oplus \odot \odot \ominus \\
\text { VERY LOW1 }\end{array}$} & \\
\hline & 625 per 1000 & $\begin{array}{l}350 \text { per } 1000 \\
\text { (181 to } 663)\end{array}$ & & & & \\
\hline
\end{tabular}

${ }^{*}$ The risk in the intervention group (and its 95\% confidence interval) is based on the assumed risk in the comparison group and the relative effect of the intervention (and its $95 \% \mathrm{Cl}$ ). 


\section{GRADE Working Group grades of evidence}

High certainty: We are very confident that the true effect lies close to that of the estimate of the effect.

Moderate certainty: We are moderately confident in the effect estimate: The true effect is likely to be close to the estimate of the effect, but there is a possibility that it is substantially different.

Low certainty: Our confidence in the effect estimate is limited: The true effect may be substantially different from the estimate of the effect.

Very low certainty: We have very little confidence in the effect estimate: The true effect is likely to be substantially different from the estimate of effect.

1Downgraded three levels (-3) because of i) within-study risk of bias due to high risk of bias; ii) publication bias could not be assessed; iii) imprecision due to small number of trials (one trial) 


\section{B A C K G R O U N D}

\section{Description of the condition}

Biliary tract cancers are a group of rare heterogeneous malignant tumours. They include intrahepatic and extrahepatic cholangiocarcinomas, gallbladder carcinomas, and ampullary carcinomas (De Groen 1999). Although these malignancies are anatomically related and have similar metastatic patterns, each has a distinct clinical presentation, molecular pathology, and prognosis (Zhu 2010; Nakanuma 2015; Jain 2016).

The incidence and mortality rates of biliary tract cancers has changed in the world since the mid-1980s. Population-based data from the Surveillance Epidemiology and End Results (SEER) Program showed an increase in the incidence and mortality of intrahepatic cholangiocarcinoma in the USA (Patel 2001; Shaib 2004; Welzel 2006). Similar trends were also observed in the UK between 1971 and 2001. In the British population, a 12-fold increase in the incidence of intrahepatic cholangiocarcinoma and a marked decrease in the incidence of gallbladder carcinoma and extrahepatic cholangiocarcinoma were observed during this period (West 2001). Consistent with these trends, there was a global trend of an increasing mortality from intrahepatic cholangiocarcinoma and decreasing mortality from extrahepatic cholangiocarcinoma, in industrialised countries and in low-income countries (Patel 2002).

Gallbladder carcinoma is the most common and most aggressive cancer of the biliary tract. Worldwide, there is a prominent geographic variability in gallbladder carcinoma incidence that correlates with the prevalence of gallbladder stones. High incidences of gallbladder carcinoma are seen in South American countries, particularly Chile, Bolivia, and Ecuador, as well as some areas of India, Pakistan, Japan, and Korea (Strom 1995; Randi 2006). Conditions that are associated with chronic inflammation of the gallbladder are considered risk factors for gallbladder carcinoma. These include gallstone disease, porcelain gallbladder, gallbladder polyps, chronic Salmonella infection, congenital biliary cysts, and abnormal pancreaticobiliary duct junction (Zhu 2010).

Cholangiocarcinoma accounts for only $3 \%$ of all gastrointestinal carcinomas (Venook 2011). Population-based incidence data on cholangiocarcinoma are scanty and most cancer registries combine people with cholangiocarcinoma with people with other hepatobiliary malignancies, such as hepatocellular cancer and gallbladder carcinoma (Patel 2002; Khan 2008). Although there are many established risk factors for cholangiocarcinoma including parasitic infections, primary sclerosing cholangitis, biliary-duct cysts, hepatolithiasis, toxins, and hepatitis viruses-related cirrhosis (for intrahepatic cholangiocarcinoma) (Tyson 2011), in most people with cholangiocarcinoma no predisposing factor is identified (Chapman 1999). The prognosis of cholangiocarcinoma is poor, and incidence and mortality are almost similar (Tyson 2011).

The ampulla of Vater consists of the terminal portion of the common bile duct and main pancreatic duct, as well as a small segment of the duodenal mucosa (Westgaard 2008). Because of its small size, adenocarcinomas are relatively uncommon in comparison with those arising in the pancreas or common bile duct. They account for only $0.5 \%$ of all gastrointestinal malignancies, and cancers of the ampulla of Vater are usually reported in case-controlled studies from single or collaborating institutions
(Albores-Saavedra 2009). Although ampullary carcinomas are classified among biliary tract carcinomas, they are biologically and clinically distinct for their pathological, prognostic, and therapeutic features, and so the interpretation of study results in this specific patient subgroup have to be made cautiously.

Surgery remains the optimal modality of therapy leading to long-term survival for people diagnosed with resectable biliary tract carcinomas. Unfortunately, most people with biliary tract carcinomas are diagnosed with either unresectable locallyadvanced (stage III) or metastatic (stage IV) disease, and they are only suitable for palliative chemotherapy or supportive care (Lamarca 2014). The prognosis for such people is generally poor, resulting in a five-year survival of $5 \%$ to $15 \%$ (Anderson 2004; DeOliveira 2007).

\section{Description of the intervention}

Chemotherapeutic agents have been studied extensively in advanced biliary carcinomas. Gemcitabine, either as a single agent or in combination with other chemotherapeutic agents, has been extensively evaluated in several phase II studies in people with advanced biliary tract carcinomas (Gebbia 2001; Kubicka 2001; Penz 2001). Overall, objective response with gemcitabine alone ranges from $7 \%$ to $27 \%$, but median survival is only rarely longer than eight months (Park 2005; Suzuki 2010). One retrospective study of 304 people with unresectable biliary tract carcinoma compared the outcome for people who received gemcitabine alone to people who received a cisplatin-based regimen, a fluoropyrimidine-based regimen, or best supportive care. Gemcitabine seemed to be the most effective treatment, with a reduction in mortality of about $50 \%$ when compared with best supportive care (Yonemoto 2007). The results of a pooled analysis of 104 trials that included 2810 people with advanced biliary tract carcinoma showed that response and tumour control were higher for the subgroup of people who received gemcitabine and platinum-based agents. However, this tumour response did not translate into significant benefit in terms of either time to tumour progression or median overall survival (Eckel 2007; Eckel 2014).

The superiority of gemcitabine plus cisplatin over gemcitabine alone was shown in the randomised clinical phase III multicentre ABC-02 trial, which enrolled 410 people with locally-advanced or metastatic cholangiocarcinoma, gallbladder carcinoma, or ampullary carcinoma. Participants were randomly assigned to six courses of cisplatin $\left(25 \mathrm{mg} / \mathrm{m}^{2}\right)$ followed by gemcitabine $(1000 \mathrm{mg} /$ $\mathrm{m}^{2}$ ) on days one and eight, every 21 days, versus gemcitabine alone ( $1000 \mathrm{mg} / \mathrm{m}^{2}$ on days one, eight, and 15 every 28 days). At a median follow-up of 8.2 months, overall survival was significantly longer with gemcitabine plus cisplatin therapy (11.7 months with gemcitabine plus cisplatin versus 8.1 months gemcitabine alone), as well as median progression-free survival (eight months with gemcitabine plus cisplatin versus five months with gemcitabine alone). The proportion of participants with neutropenia was higher in the group receiving gemcitabine plus cisplatin. However, there was no significant difference in the proportion with neutropeniaassociated infections between the two treatment groups (Valle 2010; Valle 2014). Another smaller randomised clinical trial with 84 people with advanced biliary tract carcinoma reported a similar conclusion with a significantly longer overall survival with cisplatin plus gemcitabine compared with gemcitabine alone $(11.2$ months with gemcitabine plus cisplatin versus 7.7 months with 
gemcitabine alone) (Okusaka 2010). Other treatments which have been evaluated (with gemcitabine or compared to gemcitabinebased regimens) include other chemotherapeutics (e.g. cisplatin, carboplatin, fluoropyrimidines) and localised radiotherapy in combination with concurrent chemotherapy (for peoples with locally-advanced disease) (Chen 2016). Additionally, alternative therapeutic strategies besides systemic chemotherapy have been suggested, mainly for intrahepatic cholangiocarcinoma including intra-arterial chemotherapy, radioembolisation, and immune therapy (Schweitzer 2015). There is as yet no level-I evidence of a survival benefit for targeted therapy in advanced biliary tract carcinomas (Chen 2016)

\section{How the intervention might work}

Gemcitabine is a cell-cycle phase-specific chemotherapeutic agent. It primarily kills cells undergoing deoxyribonucleic acid (DNA) synthesis (S-phase) as well as blocking the progression of cells through the G1/S-phase boundary. Gemcitabine is metabolised intracellularly to the active diphosphate and triphosphate nucleotides. The cytotoxic effect of gemcitabine is due to a combination of the two actions by the diphosphate and the triphosphate nucleotides leading to inhibition of DNA synthesis (Mini 2006).

Gemcitabine has shown biological activities in a broad spectrum of solid tumours, including pancreatic cancers (Burris 1997). Because the biliary tract shares a common embryological origin with the exocrine pancreas, gemcitabine was considered as a reasonable therapeutic agent to be evaluated for the treatment of biliary tract cancers (Park 2005).

\section{Why it is important to do this review}

For advanced biliary tract carcinoma, systemic therapy is the mainstay of treatment for people who present with unresectable or metastatic disease. Progress has been made since the mid-2000s to identify the most effective chemotherapy regimens, with the recent recommendation of the combination of gemcitabine plus cisplatin as the standard schedule. This is based on the results of the ABC-02 trial (Valle 2010), and the identically-designed Japanese trial (Okusaka 2010). Both trials demonstrated a significantly longer overall survival with gemcitabine plus cisplatin compared with gemcitabine alone. However, gemcitabine plus cisplatin has not been directly compared with other non-gemcitabine-containing chemotherapy combinations in phase III trials. Comprehension of the molecular basis of cholangiocarcinogenesis and tumour progression has led to the testing of other chemotherapies in people with biliary tract carcinomas, demonstrating promising results (Marino 2013; Schweitzer 2015; Chen 2016). Although gemcitabine plus cisplatin is considered a standard option for advanced biliary cancer, exploration of other systemic therapy regimens in people with advanced biliary tract carcinomas is still needed, in order to improve outcomes for this disease. Moreover, the population of biliary tract carcinomas is heterogeneous, and because the incidence of biliary tract carcinoma is low, people with unresectable, metastatic or recurrent cancers are often enrolled in the same randomised clinical trial. Thus, the efficacy of gemcitabine-based chemotherapy in all clinical contexts and anatomical subsites needs detailed assessment.

\section{O B JECT IVES}

To assess the benefits and harms of intravenous administration of gemcitabine monotherapy or gemcitabine-based chemotherapy versus placebo, no intervention, or other treatments (excluding gemcitabine) in adults with advanced biliary tract carcinomas.

\section{MET HOD S}

\section{Criteria for considering studies for this review}

\section{Types of studies}

All randomised clinical trials, irrespective of language or publication status, comparing intravenous administration of gemcitabine monotherapy or gemcitabine-based combination therapy compared to placebo, to no intervention, or to treatments other than gemcitabine. We examined non-randomised studies retrieved with the searches for harmful effects only. We are aware that this may bias our review towards assessing benefits rather than harms.

\section{Types of participants}

All chemotherapy-naïve people with cytological or histopathological evidence of advanced (either unresectable or metastatic) biliary tract carcinomas (i.e. intra- and extrahepatic cholangiocarcinoma, gallbladder carcinoma, and ampullary carcinoma) who are without clinical evidence of active or former concurrent malignant diseases, and are older than 18 years. The definition of unresectable biliary tract carcinomas was according to the authors of the individual trials.

\section{Types of interventions}

Intravenous gemcitabine (monotherapy or combination therapy) versus placebo or no treatment, or treatments other than gemcitabine:

- gemcitabine-based chemotherapy versus placebo or no intervention;

- gemcitabine-based chemotherapy versus chemotherapy without gemcitabine.

\section{Types of outcome measures}

\section{Primary outcomes}

- All-cause mortality.

- Serious adverse events. We used the International Conference on Harmonisation (ICH) Guidelines for Good Clinical Practice's definition of a serious adverse event (ICH-GCP 1997); that is, any untoward medical occurrence that results in death, is lifethreatening, requires hospitalisation or prolongation of existing hospitalisation, results in persistent or significant disability or incapacity, or is a congenital anomaly or birth defect. We considered all other adverse events as non-serious (see below).

- Health-related quality of life: if reported in individual trials by the participants and if measured with validated instruments. 


\section{Secondary outcomes}

- Tumour response assessments (as recommended by the response evaluation in solid tumours criteria) using the following definitions of response (Eisenhauer 2009):

- complete response: disappearance of all target lesions. Any pathological lymph nodes (whether target or non-target) must have reduction in short axis to less than $10 \mathrm{~mm}$;

- partial response: at least a 30\% decrease in the sum of diameters of target lesions, taking as reference the baseline sum diameters;

- progressive disease: at least a $20 \%$ increase in the sum of diameters of target lesions, taking as reference the smallest sum on study (this includes the baseline sum if that is the smallest on study). In addition to the relative increase of $20 \%$, the sum must also demonstrate an absolute increase of at least $5 \mathrm{~mm}$. Note: the appearance of one or more new lesions is also considered progression;

- stable disease: neither sufficient shrinkage to qualify for partial response nor sufficient increase to qualify for progressive disease, taking as reference the smallest sum diameters while on study.

We combined complete response and partial response to evaluate the overall response rate. However, alternative criteria could have been added according to the choice of the trial authors.

- Time to progression of the tumour (reported as median time to progression).

- (Non-serious) adverse events.

\section{Search methods for identification of studies}

\section{Electronic searches}

We searched the Cochrane Hepato-Biliary Group Controlled Trials Register (Gluud 2018; June 2017), Cochrane Central Register of Controlled Trials (CENTRAL) in the Cochrane Library (2017, Issue 5), MEDLINE Ovid (1946 to June 2017), Embase Ovid (1974 to June 2017), LILACS (Bireme; 1982 to June 2017), Science Citation Index Expanded (Web of Science; 1900 to June 2017), and Conference Proceedings Citation Index - Science (Web of Science; 1990 to June 2017) (Royle 2003). Appendix 1 shows the search strategies used for the electronic searches. We also searched the www.clinicaltrials.gov register for additional studies and for ongoing studies. We added these to Characteristics of ongoing studies.

\section{Searching other resources}

We manually checked reference lists of the included studies and review articles for more trials of interest (cross-references).

\section{Data collection and analysis}

We conducted the review according to recommendations of Cochrane (Higgins 2011) and the Cochrane Hepato-Biliary Group Module (Gluud 2018). We performed the analyses using Review Manager 5 (RevMan 2014).

\section{Selection of studies}

Independently of each other, we identified the trials for inclusion. We have listed the excluded studies with the reasons for exclusion.
We excluded duplicate records based on consideration of titles and abstracts. We reviewed abstracts of the remaining articles. We conducted a review of the remaining articles for relevancy and reporting of outcomes of interest.

\section{Data extraction and management}

We individually extracted the required data. We extracted details of study population, interventions, and outcomes using a standardised data extraction form. This form included the following items:

- publication year;

- country;

- year of conduct of the trial;

- inclusion and exclusion criteria;

- sample size calculation performed or not;

- population characteristics, such as age and sex ratio;

- sample size reached or not;

- baseline characteristics including: Eastern Cooperative Oncology Group Performance Status; stage; and primary subsite of the tumour: intrahepatic and extrahepatic cholangiocarcinomas, gallbladder carcinomas, and ampullary carcinomas;

- outcomes (see Primary outcomes; Secondary outcomes);

- risk of bias (see Assessment of risk of bias in included studies);

- intention-to-treat analysis.

\section{Assessment of risk of bias in included studies}

Due to the risk of overestimation of beneficial intervention effects and underestimation of harmful intervention effects in randomised clinical trials of unclear or inadequate methodological quality (Schulz 1995; Moher 1998; Kjaergard 2001; Wood 2008; Savović 2012a; Savović 2012b; Lundh 2017), we assessed the influence of the risks of bias on our results. We used the domains with definitions provided below to assess the risks of bias in the included trials (Higgins 2011; Gluud 2018). In our assessment of the risks of bias, we included assessments of available information included in trial registrations unless the trial was registered after the trial was completed.

\section{Allocation sequence generation (selection bias)}

- Low risk of bias: sequence generation was achieved using computer random-number generation or a random-number table. Drawing lots, tossing a coin, shuffling cards, and throwing dice were adequate if performed by an independent person not otherwise involved in the trial.

- Unclear risk of bias: the method of sequence generation was not specified.

- High risk of bias: the sequence generation method was not random. We included such studies only for assessments of harms.

\section{Allocation concealment (selection bias)}

- Low risk of bias: the participant allocations could not have been foreseen in advance of or during enrolment. Allocation was controlled by a central and independent randomisation unit. The allocation sequence was unknown to the investigators 
(e.g. if the allocation sequence was hidden in sequentiallynumbered, opaque, and sealed envelopes).

- Unclear risk of bias: the method used to conceal the allocation was not described so that intervention allocations may have been foreseen in advance of or during enrolment.

- High risk of bias: the allocation sequence was likely to be known to the investigators who assigned the participants. We included such studies only for assessments of harms.

\section{Blinding of participants and personnel (performance bias)}

- Low risk of bias: it was mentioned that both the participants and personnel providing the interventions were blinded, and the method of blinding was described, so that knowledge of allocation was prevented during the trial.

- Unclear risk of bias: it was not mentioned if the trial was blinded, or the trial was described as blinded, but the method or extent of blinding was not described, so that knowledge of allocation was possible during the trial.

- High risk of bias: the trial was not blinded, so that the allocation was known during the trial. We included such studies only for assessments of harms.

\section{Blinding of outcome assessment (detection bias)}

- Low risk of bias: outcome assessment was carried out blinded for all relevant outcomes, and the method of blinding was described, so that knowledge of allocation was prevented.

- Unclear risk of bias: blinding of outcome assessment was not described, or the outcome assessment was described as blinded, but the method of blinding was not described, so that knowledge of allocation was possible.

- High risk of bias: outcome assessment was not blinded, so that the allocation was known to outcome assessors. We included such studies only for assessments of harms.

\section{Incomplete outcome data (attrition bias)}

- Low risk of bias: missing data were unlikely to make treatment effects depart from plausible values. Sufficient methods, such as multiple imputation, were employed to handle missing data.

- Unclear risk of bias: there was insufficient information to assess whether missing data in combination with the method used to handle missing data were likely to induce bias in the results.

- High risk of bias: the results were likely to be biased due to missing data.

\section{Selective outcome reporting (reporting bias)}

- Low risk: the trial reported the following predefined outcomes: all-cause mortality, serious adverse events, and tumour response (see Secondary outcomes). When the original trial protocol was available, the outcomes were those called for in that protocol. When the trial protocol was obtained from a trial registry (e.g. www.clinicaltrials.gov), the outcomes sought were those enumerated in the original protocol if the trial protocol was registered before or at the time that the trial was begun. If the trial protocol was registered after the trial was begun, we did not consider those outcomes to be reliable.

- Unclear risk: not all predefined outcomes were reported fully, or it was unclear whether data on these outcomes were recorded or not.

- High risk: one or more predefined outcomes were not reported.

\section{For-profit bias}

- Low risk of bias: the trial appeared to be free of industry sponsorship or other type of for-profit support that may manipulate the trial design, conduct or results.

- Unclear risk of bias: the trial may or may not be free of for-profit bias, as no information on clinical trial support or sponsorship was provided.

- High risk of bias: the trial was sponsored by industry or received other type of for-profit support.

\section{Other bias}

- Low risk of bias: the trial appeared to be free of other factors that could put it at risk of bias.

- Unclear risk of bias: the trial may or may not have been free of other factors that could put it at risk of bias.

- High risk of bias: there were other factors in the trial that could put it at risk of bias. We included such studies only for assessments of harms.

We judged trials to be at low overall risk of bias if rated as low risk of bias in all the above domains. We judged trials to be at high overall risk of bias if rated as unclear risk of bias or high risk of bias in one or more of the above domains.

We resolved any differences in opinion through discussion; in the case of unsettled disagreements, we planned to ask a member of the Cochrane Hepato-Biliary Group Editorial Team Office to adjudicate.

\section{Measures of treatment effect}

For dichotomous variables, we calculated the risk ratio (RR) with a $95 \%$ confidence interval $(\mathrm{CI})$. For continuous variables, we planned to calculate the mean difference (MD) or standardised mean difference (SMD) with its $95 \% \mathrm{Cl}$. Time-to-event data analyses are usually based on hazard ratios (HRs), so if these data were provided we planned to use the HR. If HR data were not provided, we planned to calculate the $\ln (\mathrm{HR})$ and its standard error indirectly, or we planned to use an Excel spreadsheet to obtain the exact HR (Parmar 1998).

\section{Unit of analysis issues}

The unit of analysis is the group of participants in each intervention group in the randomised clinical trials with a parallel-group design. In the case of cross-over trials, we used the data from the first trial period only. In case of trials with more than two intervention groups, we produced two different analyses, comparing the intervention group with the common control group.

\section{Dealing with missing data}

When we could not extract data from the text, we contacted the authors of the original publication to ask for missing information.

\section{Intention-to-treat analyses}

For the primary outcomes, we planned to include participants with incomplete or missing data in sensitivity analyses by imputing them according to the following scenarios (Hollis 1999):

- Extreme case analysis favouring the experimental intervention ('best-worse' case scenario): none of the dropouts/participants 
lost from the experimental group, but all of the dropouts/ participants lost from the control group experienced the outcome; we included all randomised participants in the denominator;

- Extreme case analysis favouring the control ('worst-best' case scenario): all dropouts/participants lost from the experimental group, but none from the control group experienced the outcome; we included all randomised participants in the denominator

However, because there was a low risk of attrition bias in most of the included trials, we did not do these analyses.

\section{Assessment of heterogeneity}

We used the $\mathrm{Chi}^{2}$ test to provide an indication of betweentrial heterogeneity. In addition, we quantified the degree of heterogeneity observed in the results using the 12 statistic, which can be interpreted as the percentage of variation observed between the trials attributable to between-trial differences rather than sampling error (chance).

We interpreted $\mathrm{I}^{2}$ values as follows:

- probably not important: $0 \%$ to $40 \%$;

- possible moderate heterogeneity: $30 \%$ to $60 \%$;

- possible substantial heterogeneity: $50 \%$ to $90 \%$;

- considerable heterogeneity: $75 \%$ to $100 \%$ (Higgins 2011).

\section{Assessment of reporting biases}

We carried out a comprehensive search in order to minimise the risk of publication bias. Because we did not identify enough trials for inclusion (10 trials), we did not use a funnel plot to explore bias (Egger 1997; Macaskill 2001).

\section{Data synthesis}

The review authors followed the instructions given in the Cochrane Handbook for Systematic Reviews of Interventions (Higgins 2011) and the Cochrane Hepato-Biliary Group Module (Gluud 2018).

\section{Meta-analysis}

We used random-effects model (DerSimonian 1986) and fixedeffect model (Mantel 1959; DeMets 1987) meta-analyses. In case of discrepancy between the two models (e.g. one giving a significant intervention effect, and the other no significant intervention effect), we reported both results; otherwise, we reported only the results from the meta-analysis model with the most conservative intervention effect (Jakobsen 2014).

\section{Trial Sequential Analysis}

We examined intervention effects with Trial Sequential Analysis (TSA) (Thorlund 2011; TSA 2011; Wetterslev 2017), in order to evaluate if intervention effects could be caused by random error ('play of chance') (Brok 2008; Wetterslev 2008; Brok 2009; Thorlund 2009, Wetterslev 2009; Thorlund 2010). However, we found TSA only suitable for one comparison out of the seven comparisons of the review.

We applied Trial Sequential Analysis as cumulative meta-analyses are at risk of producing random errors due to sparse data and repetitive testing of the accumulating data (Wetterslev 2008). To control for random errors, we calculated the required information size (i.e. the number of participants needed in a meta-analysis to detect or reject a certain intervention effect). The required information size calculation should also account for the diversity present in the meta-analysis (Wetterslev 2009). In our metaanalysis, the diversity-adjusted required information size was based on the event proportion in the control group; assumption of a plausible risk ratio reduction of $20 \%$ or the risk ratio reduction observed in the included trials at low risk of bias; a risk of type I error of $2.5 \%$, a risk of type II error of $10 \%$, and the assumed diversity of the meta-analysis. The underlying assumption of Trial Sequential Analysis is that testing for significance may be performed each time a new trial is added to the meta-analysis. We added the trials according to the year of publication, and, if more than one trial was published in a year, we added trials alphabetically according to the last name of the first author. On the basis of the diversity-adjusted required information size, we constructed trial sequential monitoring boundaries (Wetterslev 2008; Thorlund 2011). These boundaries determine the statistical inference one may draw regarding the cumulative meta-analysis that has not reached the required information size; if the cumulative Z-curve crosses the trial sequential monitoring boundary for benefit or harm before the diversity-adjusted required information size is reached, firm evidence may perhaps be established and further trials may be superfluous. On the contrary, if the boundary is not surpassed, it is most probably necessary to continue doing trials in order to detect or reject a certain intervention effect. That can be determined by assessing if the cumulative Z-curve crosses the trial sequential monitoring boundaries for futility.

\section{Subgroup analysis and investigation of heterogeneity}

We planned to perform a subgroup analysis comparing the intervention effect in:

- trials at low risk of bias compared to trials at high risk of bias;

- Eastern Cooperative Oncology Group Performance Score 0 compared to score 1 or 2;

- tumour site (cholangiocarcinoma, gallbladder carcinoma, ampullary carcinoma);

- tumour stage.

However, because of insufficient trial data, we could not perform all these subgroup analyses.

\section{Sensitivity analysis}

To assess the robustness of the eligibility criteria, in addition to the sensitivity analyses specified under Dealing with missing data, we planned to undertake sensitivity analyses that may explain our findings, including any observed heterogeneity. However, because of missing data, we could not perform this sensitivity analysis.

\section{'Summary of findings' tables}

We created 'Summary of findings' tables using GRADEpro (GRADEpro 2008; Table 1). We used the GRADE approach which appraises the certainty of evidence based on the extent to which one can be confident that an estimate of effect or association reflects the item being assessed. The certainty of evidence considers within-study risk of bias, indirectness of the evidence (population, intervention, control, outcomes), unexplained heterogeneity or inconsistency of results (including problems with subgroup analyses); imprecision of results (wide Cls 
as evaluated with Trial Sequential Analyses) (Jakobsen 2014), and risk of publication bias (Balshem 2011; Guyatt 2011a; Guyatt 2011b; Guyatt 2011c; Guyatt 2011d; Guyatt 2011e; Guyatt 2011f; Guyatt 2011g; Guyatt 2011h; Guyatt 2013a; Guyatt 2013b; Guyatt 2013c; Guyatt 2013d; Mustafa 2013; Guyatt 2017).

These grades are defined as follows.

- High certainty: We are very confident that the true effect lies close to that of the estimate of the effect.

- Moderate certainty: We are moderately confident in the effect estimate: the true effect is likely to be close to the estimate of the effect, but there is a possibility that it is substantially different.

- Low certainty: Our confidence in the effect estimate is limited: the true effect may be substantially different from the estimate of the effect.

- Very low certainty: We have very little confidence in the effect estimate: the true effect is likely to be substantially different from the estimate of effect.

\section{RESULTS}

\section{Description of studies}

\section{Results of the search}

We identified 3161 records from our database searches (Figure 1). Among the identified 3161 records, the number of duplicates that we found and removed was 620 records. Thus, the final number of records that we scanned was 2541. Based on the titles and abstracts of these records, we excluded 2521 records and further assessed the retrieved full-text paper publications of the remaining 20 records (Figure 1). We found seven randomised clinical trials described in seven publications which fulfilled the inclusion criteria of our systematic review (Kornek 2004; Sharma 2010; Kang 2012; Morizane 2013; Phelip 2014; Santoro 2015; Li 2016). Cointerventions (other than gemcitabine) were equally applied in three trials (Morizane 2013: gemcitabine plus S-1 versus S-1 alone; Santoro 2015: gemcitabine plus vandetanib versus vandetanib alone; Li 2016: gemcitabine plus S-1 versus S-1 alone), while in the other four trials co-interventions were unequally applied (Kornek 2004: gemcitabine plus mitomycin C versus capecitabine plus mitomycin C; Sharma 2010: gemcitabine plus oxaliplatin versus 5fluorouracil plus folinic acid versus best supportive care; Kang 2012: gemcitabine plus cisplatin versus S-1 plus cisplatin; Phelip 2014: gemcitabine plus oxaliplatin versus chemoradiotherapy protocol). The trials were set in single countries, conducted in India, Japan, France, Austria, South Korea, China, and Italy. The median age in the seven trials varied between 50 and 60 years and the numbers of included men and women were comparable in most of the trials. All the included trials were parallel-group trials. 
Figure 1. Study flow diagram

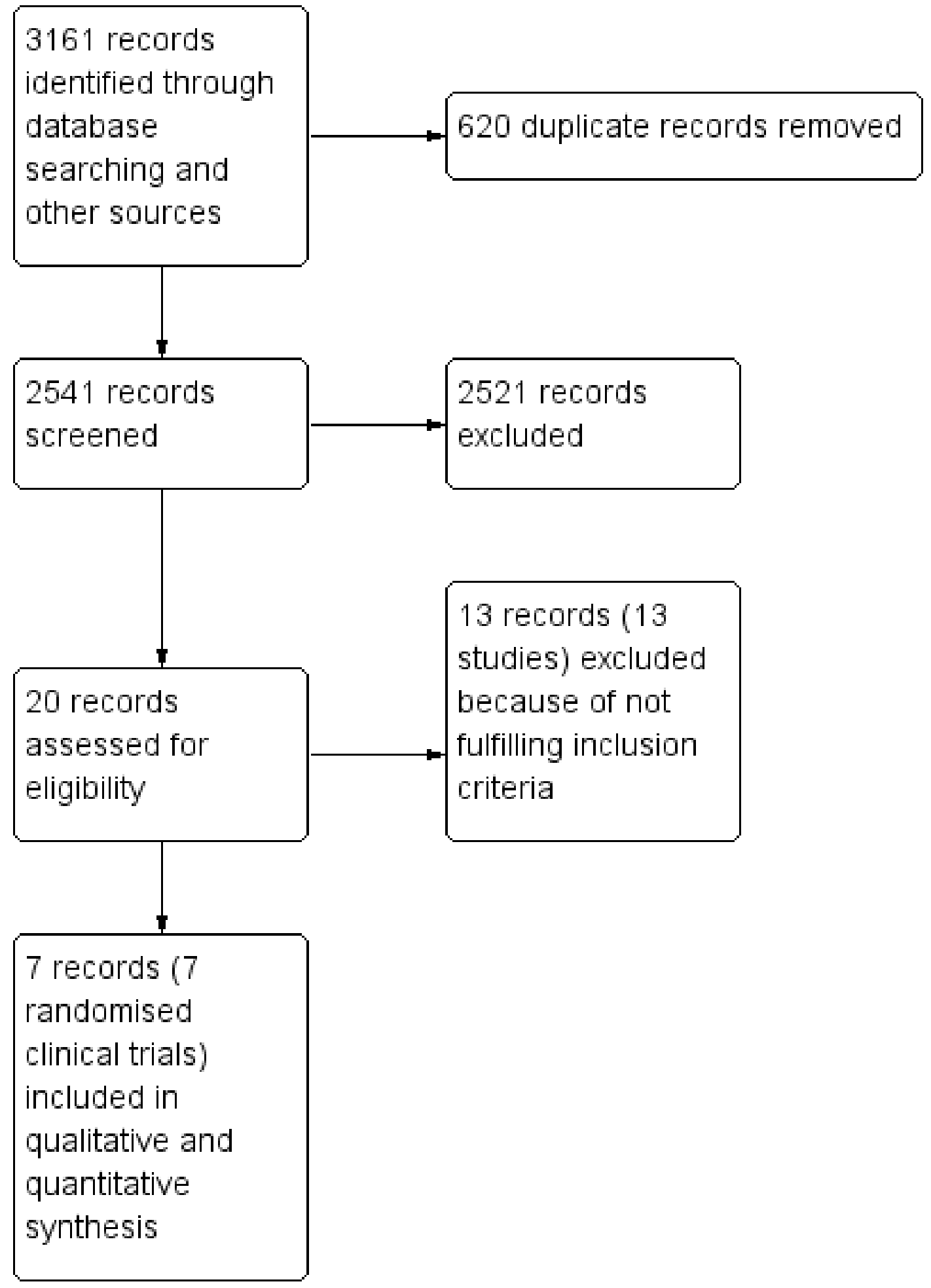

We excluded the remaining 13 publications as they did not fulfil the inclusion criteria of our review (Raderer 1999; Valle 2009; Okusaka 2010; Valle 2010; Lee 2012; Sasaki 2013; Malka 2014; Moehler 2014; Wan 2014; Chen 2015; Lee 2015; Valle 2015; Leone 2016). We also found three ongoing randomised trials of interest to our review (NCT01470443; NCT02591030; NCT03044587).

\section{Included studies}

\section{Included studies}

We included seven studies with a total of 600 participants in this systematic review (Characteristics of included studies). 
Santoro 2015 randomised 173 participants (recruited from October 2008 to September 2012) at 19 centres across Italy. The trial participants were randomised in a 1:1:1 ratio to three treatment groups: a comparator group of vandetanib $300 \mathrm{mg}$ monotherapy (group A), two intervention groups of vandetanib $100 \mathrm{mg}$ plus gemcitabine (group B), and gemcitabine plus placebo (group C). Planned outcomes were progression-free survival, overall survival, response rate, disease control rate, duration of response, performance status and safety outcomes. For data analysis purposes, both the gemcitabine plus vandetanib group and the gemcitabine plus placebo group were considered as the experimental intervention groups, and outcomes from each of these groups were compared against the vandetanib monotherapy (i.e. non-gemcitabine-containing comparator) control group.

Kang 2012 randomised 96 participants (enrolled from March 2008 to March 2009); 49 participants were randomised to the experimental intervention (gemcitabine $\left(1000 \mathrm{mg} / \mathrm{m}^{2} \mathrm{IV}\right.$ at $10 \mathrm{mg} / \mathrm{m}^{2} / \mathrm{min}$ on days 1 and 8) and cisplatin (60 mg/m² intravenously (IV) on day 1 ) every three weeks) and 47 participants to the control intervention (S-1 $\left(40 \mathrm{mg} / \mathrm{m}^{2}\right.$ orally twice a day on days 1 and 14) plus cisplatin (60 $\mathrm{mg} / \mathrm{m}^{2} \mathrm{IV}$ on day 1). Planned outcomes were progression-free survival, response rate, overall survival, and toxicity.

Morizane 2013 randomised 101 participants (from February 2009 to April 2010) to an experimental intervention of gemcitabine (gemcitabine: $1000 \mathrm{mg} / \mathrm{m}^{2}$, day 1 and day $8 ; \mathrm{S}-1: 60 \mathrm{mg} / \mathrm{m}^{2}$, twice daily on days 1 and 14, repeated every three weeks plus S-1 (a combination of tegafur, gimeracil, and oteracil); and a control intervention of S-1 $\left(80 \mathrm{mg} / \mathrm{m}^{2}\right.$, days 1 to 28 , given orally twice daily for four weeks, followed by a two-week rest, repeated every six weeks). Planned outcomes were progression-free survival, overall survival, response rate in participants with measurable lesions, the incidences of adverse events, and serious adverse events.

Li 2016 randomised 75 participants to three treatment groups: two control intervention groups of S-1 monotherapy (orally twice daily for 14 days, followed by a 14-day rest: group A) and gemcitabine monotherapy $\left(1000 \mathrm{mg} / \mathrm{m}^{2}\right.$ intravenously over 30 minutes on days 1,8 , and 15: group B), and one experimental intervention group of gemcitabine (in the same dose) plus S-1: group C. All participants were treated within a four-week cycle. Planned outcomes were overall survival, progression-free survival, objective response rate, and safety of chemotherapeutic agents. For data analysis purposes, the (gemcitabine/S-1) group was considered as the intervention group and we compared outcomes from this group against the S-1 monotherapy group (i.e. non-gemcitabine-containing comparator). We excluded the third group of gemcitabine/placebo from the analysis, following our protocol.

Sharma 2010 randomised 81 participants (from June 2006 to October 2008) into three groups, including two control intervention groups (group A: best supportive care (27 participants); group B: 5fluorouracil and folinic acid (28 participants)), and an experimental intervention group (group C: gemcitabine plus oxaliplatin (26 participants)), for a maximum of six cycles. Planned outcomes included progression-free survival, response rate, overall survival, and toxicity patterns. For our analysis, we divided the intervention group into two equal halves and compared each half with a different comparator group.

Phelip 2014 randomised 34 participants (between July 2006 and December 2010) with locally-advanced biliary tract cancers to an experimental intervention (16 participants in the gemcitabinebased chemotherapy group) and control intervention (18 participants in the chemoradiotherapy group). Chemoradiotherapy consisted of 5-fluorouracil infusion and cisplatin, and was given in association with radiotherapy (50 Gy), while gemcitabinebased chemotherapy consisted of gemcitabine combined with oxaliplatin (GEMOX) for six months. Planned outcomes were overall progression-free survival, overall survival, toxicity, rate of biliary complications, and duration of hospitalisation.

Kornek 2004 randomised 51 participants (enrolment dates were not reported in the published paper) to group A (experimental intervention): mitomycin $C 8 \mathrm{mg} / \mathrm{m}^{2}$ on day 1 in combination with gemcitabine $2000 \mathrm{mg} / \mathrm{m}^{2}$ on days 1 and 15 every four weeks; or group B (control intervention): mitomycin C $8 \mathrm{mg} / \mathrm{m}^{2}$ on day 1 plus capecitabine $2000 \mathrm{mg} / \mathrm{m}^{2} /$ day on days 1 and 14 , every four weeks. In both groups, chemotherapy was administered for six months, unless progression of disease occurred earlier. Planned outcomes were progression-free survival, response rate, overall survival, and treatment tolerance.

\section{Excluded studies}

We excluded 13 studies, as they did not fulfil our inclusion criteria (Characteristics of excluded studies). In Raderer 1999 study, the results of the prospectively-enrolled participants to the gemcitabine group were retrospectively compared to a patient cohort treated with 5-fluorouracil, leucovorin (LV) plus mitomycin C. Lee 2015 was a retrospective analysis of clinical data through reviewing medical records to compare the efficacy of gemcitabine-cisplatin versus capecitabine-cisplatin combination chemotherapy. In the three UK ABC trials (Valle 2009; Valle 2010; Valle 2015), gemcitabine was used in both groups of each of the three randomised trials. Similarly, the trials of Okusaka 2010; Lee 2012; Sasaki 2013; Malka 2014; Moehler 2014; Wan 2014; Chen 2015 and Leone 2016 used gemcitabine in both randomised groups of the trial.

\section{Risk of bias in included studies}

For graphical presentation of risk of bias of the included trials, see Figure 2 and Figure 3. 
Figure 2. Risk of bias graph: review authors' judgements about each risk of bias item presented as percentages across all included trials.

Random sequence generation (selection bias)

Allocation concealment (selection bias)

Blinding of participants and personnel (performance bias)

Blinding of outcome assessment (detection bias)

Incomplete outcome data (attrition bias)

Selective reporting (reporting bias)

For-profit bias

Other bias
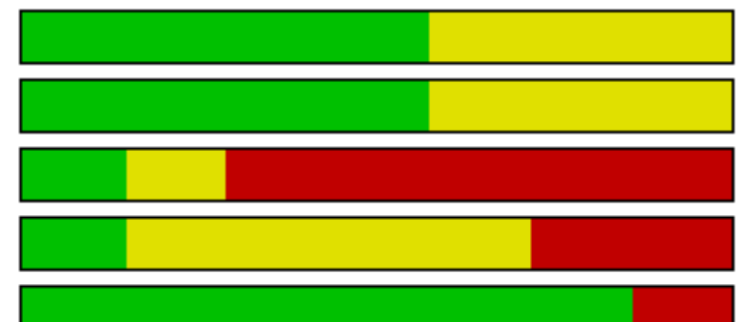

$$
\text { L }
$$
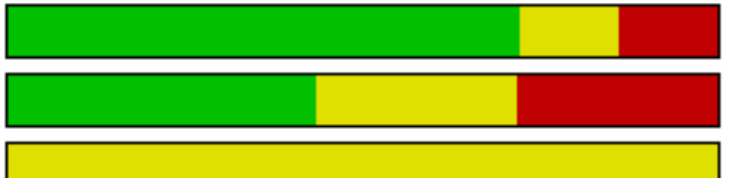

\begin{tabular}{|lllll}
\hline 1 & & 1 & & \\
\hline $0 \%$ & $25 \%$ & $50 \%$ & $75 \%$ & $100 \%$
\end{tabular}


Figure 3. Risk of bias summary: review authors' judgements about each risk of bias item for each included trial.

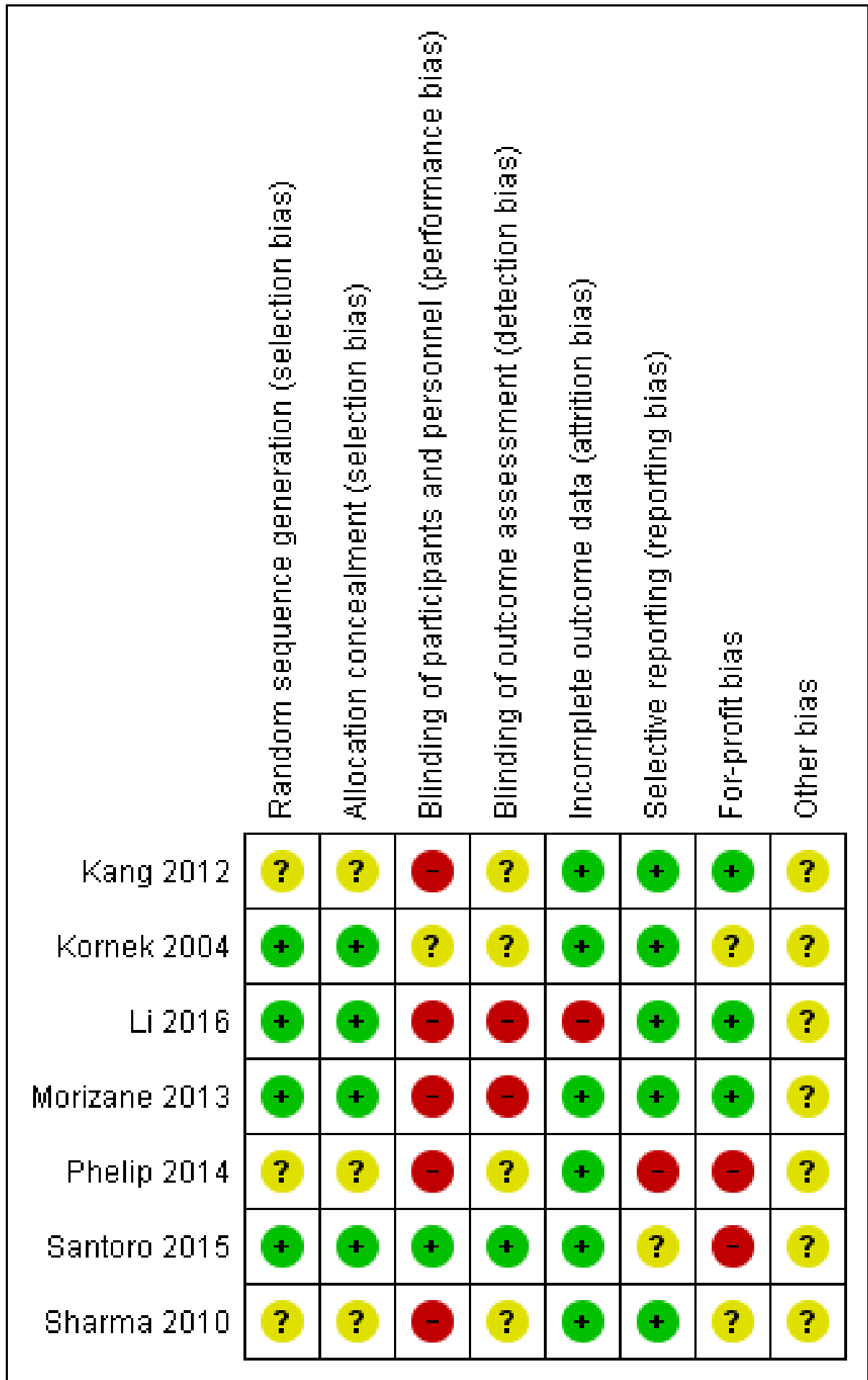

\section{Allocation}

Both allocation sequence generation and allocation concealment were clearly reported in four trials (Kornek 2004; Morizane 2013; Santoro 2015; Li 2016), while it was unclear in three trials (Sharma 2010; Kang 2012; Phelip 2014).

\section{Blinding}

Blinding of participants and personnel was clearly reported in the Santoro 2015 trial; unclearly reported in the Kornek 2004 trial; with a high risk of performance bias in Sharma 2010; Kang 2012; Morizane 2013; Phelip 2014 and Li 2016. Blinding of outcome assessment was clearly reported in the Santoro 2015 trial; unclearly 
reported by Kornek 2004; Kang 2012 and Phelip 2014; with a high risk of detection bias in Morizane 2013 and Li 2016.

\section{Incomplete outcome data}

There was a low risk of attrition bias in all included trials except for Li 2016, where we rated the risk of attrition bias as high.

\section{Selective reporting}

There was a low risk of reporting bias in all the included trials except for Phelip 2014, where we rated the risk of reporting bias as high, and except for Santoro 2015 where we rated the risk of reporting bias as unclear.

\section{For-profit bias}

There was a high risk of for-profit bias in Phelip 2014 and Santoro 2015 (because of industry sponsorship), while there was a low risk of for-profit bias in Kang 2012; Morizane 2013 and Li 2016, and unclear risk in Kornek 2004 and Sharma 2010 trials.

\section{Other potential sources of bias}

We found no evidence of other biases in the included trials.

Overall, we assessed all of the included trials at high risk of bias in at least one of the above domains; thus, all trials were considered at high overall risk of bias.

\section{Effects of interventions}

See: Summary of findings for the main comparison Gemcitabine plus vandetanib compared with vandetanib for advanced biliary tract carcinomas; Summary of findings 2 Gemcitabine versus vandetanib for advanced biliary tract carcinomas; Summary of findings 3 Gemcitabine plus cisplatin compared with S-1 plus cisplatin for advanced biliary tract carcinomas; Summary of findings 4 Gemcitabine plus S- 1 compared with S- 1 for advanced biliary tract carcinomas; Summary of findings $\mathbf{5}$ Gemcitabine plus oxaliplatin compared with best supportive care for advanced biliary tract carcinomas; Summary of findings 6 Gemcitabine plus oxaliplatin compared with 5-fluorouracil plus folinic acid for advanced biliary tract carcinomas; Summary of findings 7 Gemcitabine plus oxaliplatin compared with 5 -fluorouracil plus cisplatin plus radiotherapy for advanced biliary tract carcinomas; Summary of findings $\mathbf{8}$ Gemcitabine plus mitomycin C compared with capecitabine plus mitomycin C for advanced biliary tract carcinomas

\section{Gemcitabine plus vandetanib versus vandetanib alone}

One trial included data related to this comparison (Santoro 2015).

\section{All-cause mortality}

There was no mention of all-cause mortality in any of the groups of this comparison.

\section{Health-related quality of life}

There was no mention of health-related quality of life in any of the groups of this comparison.

\section{Serious adverse events}

In Santoro 2015, we found no overt differences between the treatment groups in the proportion of participants who experienced serious adverse events (16 participants $(27.1 \%)$ in the vandetanib monotherapy group and 15 participants $(25.9 \%)$ in the gemcitabine/vandetanib combination group). Types of serious adverse events reported in this trial included hepatic toxicities, haematological toxicities, and infections. Risk ratio (RR) for the probability of serious adverse events was 0.95 (95\% confidence interval $(\mathrm{Cl}) 0.52$ to $1.74 ; \mathrm{P}=0.88$; participants $=117$; Analysis 1.1 ), favouring neither gemcitabine nor non-gemcitabine regimens.

\section{Time to progression of the tumour (reported as median time to progression)}

There was no mention of time to progression of the tumour in any of the groups of this comparison.

\section{Tumour response assessments}

Tumour response was evaluated in accordance with the response evaluation in solid tumours criteria in this comparison. The RR for overall response rate (combination of complete response with partial response) was $5.40(95 \% \mathrm{Cl} 1.25$ to 23.29 ; $\mathrm{P}=0.02$; participants $=117$; Analysis 1.2), favouring the gemcitabine-based regimen. Overall response rate was not stratified in this trial by tumour site, tumour stage, or performance status.

\section{Non-serious adverse events}

Non-serious adverse events were categorised in all the included trials according to the National Cancer Institute common terminology criteria (NCl-CTC 2016), and we ranked them accordingly into grades one to four.

RR for all grades of anaemia (grade 1 - 4) was $7.12(95 \% \mathrm{Cl} 0.90$ to 56.08; $P=0.06$; participants $=117$; Analysis 1.3 ), favouring neither gemcitabine nor non-gemcitabine regimens.

RR for high-grade anaemia (grade 3 - 4) was 3.05 (95\% Cl 0.13 to 73.39; $P=0.49$; participants = 117; Analysis 1.4), favouring neither gemcitabine nor non-gemcitabine regimens.

RR for all grades of neutropenia (grade 1 - 4) was $15.25(95 \% \mathrm{Cl}$ 0.89 to $261.11 ; \mathrm{P}=0.06$; participants $=117$; Analysis 1.5 ), favouring neither gemcitabine nor non-gemcitabine regimens.

RR for high-grade neutropenia (grade 3 - 4) was 9.15 ( $95 \% \mathrm{Cl} 0.50$ to $166.27 ; \mathrm{P}=0.13$; participants $=117$; Analysis 1.6 ), favouring neither gemcitabine nor non-gemcitabine regimens.

\section{Gemcitabine versus vandetanib}

One trial included data related to this comparison (Santoro 2015).

\section{All-cause mortality}

There was no mention of all-cause mortality in any of the groups of this comparison.

\section{Health-related quality of life}

There was no mention of health-related quality of life in any of the groups of this comparison.

\section{Serious adverse events}

In Santoro 2015, we found no overt differences between the treatment groups in the proportion of participants who experienced serious adverse events (12 participants in the gemcitabine monotherapy group and 16 participants in the vandetanib monotherapy group). The RR for the probability of serious adverse events was $0.79(95 \% \mathrm{Cl} 0.41$ to $1.52 ; \mathrm{P}=0.48$; 
participants $=115$; Analysis 2.1), favouring neither gemcitabine nor non-gemcitabine regimens.

\section{Time to progression of the tumour (reported as median time to progression)}

There was no mention of time to progression of the tumour in any of the groups of this comparison.

\section{Tumour response assessments}

Tumour response was evaluated in accordance with the response evaluation in solid tumours criteria in this comparison. The RR for overall response rate (combination of complete response with partial response) was $3.77(95 \% \mathrm{Cl} 0.82$ to $17.33 ; \mathrm{P}=0.09$; participants $=108$; Analysis 2.2), favouring neither gemcitabine nor non-gemcitabine regimens. Overall response rate was not stratified in this trial by tumour site, tumour stage, or performance status.

\section{Non-serious adverse events}

Non-serious adverse events were categorised according to the National Cancer Institute common terminology criteria ( $\mathrm{NCl}-\mathrm{CTC}$ 2016), and we ranked them accordingly into grades one to four.

RR for all grades of anaemia (grade 1 - 4) was $7.38(95 \% \mathrm{Cl} 0.94$ to 58.05; $\mathrm{P}=0.06$; participants $=115$; Analysis 2.3), favouring neither gemcitabine nor non-gemcitabine regimens.

RR for high-grade anaemia (grade 3 - 4) was 3.16 (95\% Cl 0.13 to 75.94; $\mathrm{P}=0.48$; participants = 115; Analysis 2.4), favouring neither gemcitabine nor non-gemcitabine regimens.

RR for all grades of neutropenia (grade 1 - 4) was $22.11(95 \% \mathrm{Cl}$ 1.33 to $368.56 ; \mathrm{P}=0.03$; participants $=115$; Analysis 2.5 ), favouring neither gemcitabine nor non-gemcitabine regimens.

RR for high-grade neutropenia (grade 3 - 4) was $11.58(95 \% \mathrm{Cl}$ 0.66 to 204.68; $\mathrm{P}=0.09$; participants $=115$; Analysis 2.6), favouring neither gemcitabine nor non-gemcitabine regimens.

\section{Gemcitabine plus cisplatin versus S-1 plus cisplatin}

One trial contributed data related to this comparison (Kang 2012).

\section{All-cause mortality}

The RR for all-cause mortality at one year was $0.76(95 \% \mathrm{Cl}$ 0.58 to $0.98 ; \mathrm{P}=0.04$; participants $=96$; Analysis 3.1), favouring gemcitabine-based chemotherapy. All-cause mortality was not stratified by tumour site, tumour stage, or performance status. In Kang 2012, all-cause mortality was reported in the text at eight months, and we extracted the one-year mortality from the survival curve in order for the result to be consistent with all-cause mortality from other comparisons.

\section{Health-related quality of life}

There was no mention of health-related quality of life in any of the groups of this comparison.

\section{Serious adverse events}

There was no mention of serious adverse events in any of the groups of this comparison.
Time to progression of the tumour (reported as median time to progression)

There was no mention of time to progression of the tumour in any of the groups of this comparison.

\section{Tumour response assessments}

Tumour response was evaluated in accordance with the response evaluation in solid tumours criteria in this comparison. The RR for overall response rate (complete response and partial response) was $0.82(95 \% \mathrm{Cl} 0.37$ to $1.82 ; \mathrm{P}=0.63$; participants $=88$; Analysis 3.2), favouring neither gemcitabine nor non-gemcitabine regimens. Overall response rate was not stratified in this trial by tumour site, tumour stage, or performance status.

\section{Non-serious adverse events}

Non-serious adverse events were categorised in all the included trials according to the National Cancer Institute common terminology criteria ( $\mathrm{NCl}-\mathrm{CTC}$ 2016), and we ranked them accordingly into grades one to four.

RR for all grades of anaemia (grade 1 - 4) was 11.27 (95\% Cl 4.41 to 28.83 ; $\mathrm{P}<0.001$; participants $=96$; Analysis 3.3 ), favouring nongemcitabine-based regimens.

RR for high-grade anaemia (grade 3 - 4) was 10.55 (95\% Cl 1.42 to $78.56 ; \mathrm{P}=0.02$; participants $=96$; Analysis 3.4 ), favouring nongemcitabine regimens.

RR for all grades of thrombocytopenia (grade 1 - 4) was 6.71 (95\% $\mathrm{Cl} 2.55$ to $17.68 ; \mathrm{P}<0.001$; participants $=96$; Analysis 3.5 ), favouring non-gemcitabine regimens.

RR for high-grade thrombocytopenia (grade 3 - 4) was 5.28 (95\% $\mathrm{Cl} 1.23$ to $22.55 ; \mathrm{P}=0.02$; participants $=96$; Analysis 3.6), favouring non-gemcitabine regimens.

RR for all grades of neutropenia (grade 1 - 4) was 1.28 (95\% Cl 0.95 to $1.72 ; P=0.11 ;$ participants $=96$; Analysis 3.7 ), favouring neither gemcitabine nor non-gemcitabine regimens.

RR for high-grade neutropenia (grade 3 - 4) was $1.64,95 \% \mathrm{Cl} 0.97$ to $2.78 ; \mathrm{P}=0.06$; Analysis 3.8 ), favouring neither gemcitabine nor non-gemcitabine regimens.

RR for febrile neutropenia was $4.80(95 \% \mathrm{Cl} 0.24$ to 97.42 ; $\mathrm{P}=0.31$; participants =96; Analysis 3.9), favouring neither gemcitabine nor non-gemcitabine regimens.

\section{Gemcitabine plus S-1 versus S-1}

Two trials included data related to this comparison (Morizane 2013; Li 2016).

\section{All-cause mortality}

The RR for all-cause mortality at one year was $0.61(95 \% \mathrm{Cl} 0.33$ to $1.13 ; \mathrm{P}=0.12$; participants $=151 ;$ trials $=2 ; \mathrm{I}^{2}=76 \%$ (significant heterogeneity); Analysis 4.1), favouring neither gemcitabine nor non-gemcitabine-based chemotherapy. All-cause mortality was not stratified in this trial by tumour site, tumour stage, or performance status. In both trials, all-cause mortality was reported at one year. In order to detect or reject a risk reduction of $20 \%$, the diversity-adjusted required information size was $n=2655$ trial participants, based upon a proportion of death of $70 \%$ of participants in S-1 group, an alpha (type I error) of $2.5 \%$, a beta (type II error) of $10 \%$, and a diversity of $78 \%$. Using the randomeffects model Trial Sequential Analysis, the resulting cumulative test statistic (Z-score) did not cross the adjusted threshold for 
statistical significance (Figure 4). The Trial Sequential Analysisadjusted $\mathrm{Cl}$ was 0.27 to 1.40 .

Figure 4. Trial Sequential Analysis comparing gemcitabine plus S-1 versus S-1 alone on the outcome 'all-cause mortality'. The diversity-adjusted required information size (DARIS) of $\mathbf{n}=\mathbf{2 6 5 5}$ trial participants was calculated based upon a proportion of mortality of $70 \%$ of the trial participants in the $\mathbf{S - 1}$ group, a relative risk reduction of $20 \%$ in the gemcitabine + S-1 group, an alpha (type I error) of $2.5 \%$, a beta (type II error) of $10 \%$, and a diversity of $78 \%$. The blue curve presents the cumulative meta-analysis Z-score, and the inward-sloping dotted red curves present the adjusted threshold for statistical significance according to the two-sided trial sequential monitoring boundaries. The Trial Sequential Analysis-adjusted CI was 0.27 to 1.40.

DARIS Pc $70 \%$; RRR $20 \%$; alpha $2.5 \%$; beta $10.0 \%$; Diversity $78 \%$ is a Two-sided graph

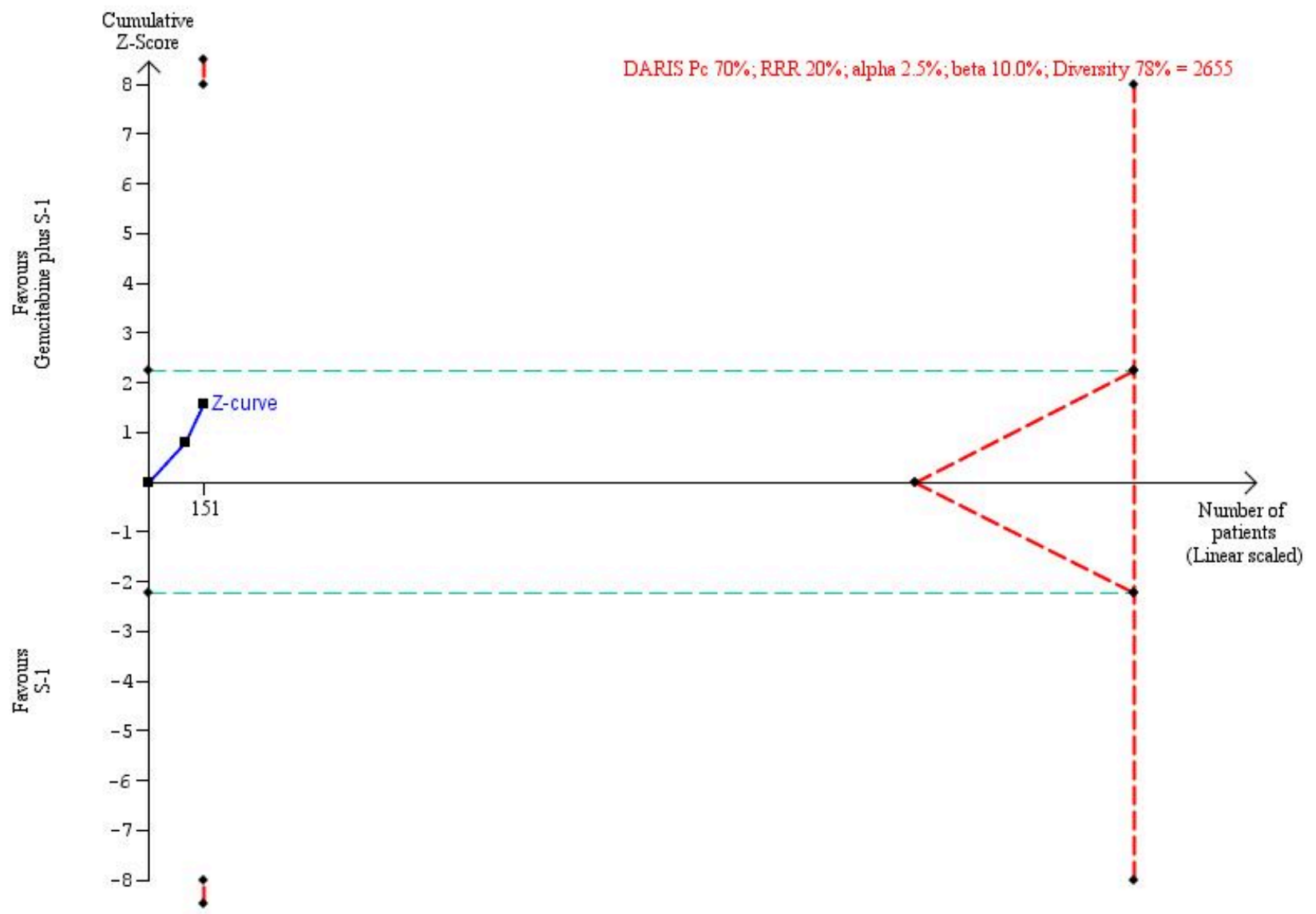

\section{Health-related quality of life}

There was no mention of health-related quality of life in any of the groups of this comparison.

\section{Serious adverse events}

This was covered only by the Morizane 2013 trial, in which two serious adverse events were reported in each group (gemcitabine/ S-1 group and S-1 monotherapy group). Types of serious adverse events in this study included pneumonia, myocardial infarction, and hyponatraemia. The RR for the probability of serious adverse events was: 1.05 ( $95 \% \mathrm{Cl} 0.15$ to 7.10; $\mathrm{P}=0.96$; participants = 90; Analysis 4.2), favouring neither gemcitabine nor non-gemcitabine regimens.
Time to progression of the tumour (reported as median time to progression)

There was no mention of time to progression of the tumour in any of the groups of this comparison.

\section{Tumour response assessments}

Tumour response was evaluated in accordance with the response evaluation in solid tumours criteria in this comparison. The RR for overall response rate (complete response and partial response) was $2.46\left(95 \% \mathrm{Cl} 1.27\right.$ to $4.75 ; \mathrm{P}=0.007 ; \mathrm{I}^{2}=0 \%$; participants = 140; Analysis 4.3), favouring the gemcitabine-based regimen. The overall response rate was stratified according to tumour site only in the Morizane 2013 trial, in which the participants with gall bladder carcinomas achieved an overall response rate of $12.5 \%(2 / 16)$ in the gemcitabine plus S-1 group and $16.7 \%(3 / 18)$ in the S-1 alone group. The overall response rate for participants with non-gall bladder 
carcinomas was 50\% (14/28) in the gemcitabine plus S-1 group and $17.9 \%(5 / 28)$ in the $\mathrm{S}-1$ alone group.

\section{Non-serious adverse events}

Non-serious adverse events were categorised in all included trials according to the National Cancer Institute common terminology criteria ( $\mathrm{NCl}-\mathrm{CTC} 2016$ ), and we ranked them accordingly into grades one to four.

RR for all grades of anaemia (grade 1 - 4) was $1.26(95 \% \mathrm{Cl} 1.00$ to 1.59; $P=0.05$; participants $=151 ;\left.\right|^{2}=0 \%$; Analysis 4.4$)$, favouring neither gemcitabine nor non-gemcitabine regimens.

RR for high-grade anaemia (grade 3 - 4) was 2.94 (95\% Cl 0.62 to 13.89; $P=0.17$; participants $=101$; Analysis 4.5), favouring neither gemcitabine nor non-gemcitabine regimens.

RR for all grades of thrombocytopenia (grade 1 - 4) was 2.45 (95\%

Cl 1.39 to $4.32 ; \mathrm{P}=0.002 ; 1^{2}=0 \%$; participants $=151$; Analysis 4.6$)$, favouring non-gemcitabine regimens.

RR for high-grade thrombocytopenia (grade 3 - 4) was $2.94(95 \% \mathrm{Cl}$ 0.62 to $13.89 ; \mathrm{P}=0.17$; participants $=101$; Analysis 4.7 ), favouring neither gemcitabine nor non-gemcitabine regimens.

RR for all grades of neutropenia (grade 1 - 4) was $3.30(95 \% \mathrm{Cl} 1.04$ to $10.50 ; P=0.04 ; 1^{2}=66 \%$; participants = 151; Analysis 4.8), favouring non-gemcitabine regimens.

RR for high-grade neutropenia (grade 3 - 4) was $15.20(95 \% \mathrm{Cl}$ 3.84 to $60.14 ; \mathrm{P}<0.001$; Analysis 4.9), favouring non-gemcitabine regimens.

RR for febrile neutropenia was 2.97 (95\% Cl 0.32 to 27.87 ; $\mathrm{P}=$ $0.34 ;\left.\right|^{2}=0 \%$; participants $=151$; Analysis 4.10$)$, favouring neither gemcitabine nor non-gemcitabine regimens.

\section{Gemcitabine plus oxaliplatin versus best supportive care}

One trial included data related to this comparison (Sharma 2010).

\section{All-cause mortality}

The RR for all-cause mortality at one year was $0.78(95 \% \mathrm{Cl} 0.53$ to $1.15 ; P=0.20$; participants $=40$; Analysis 5.1 ), favouring neither gemcitabine nor non-gemcitabine-based chemotherapy. All-cause mortality was not stratified in this trial by tumour site, tumour stage, or performance status. The trial reports all-cause mortality at one year.

\section{Health-related quality of life}

There was no mention of health-related quality of life in any of the groups of this comparison.

\section{Serious adverse events}

There was no mention of serious adverse events in any of the groups of this comparison.

\section{Time to progression of the tumour (reported as median time to progression)}

There was no mention of time to progression of the tumour in any of the groups of this comparison.

\section{Tumour response assessments}

Tumour response was evaluated in accordance with the response evaluation in solid tumours criteria in this comparison. The RR for overall response rate (complete response and partial response) was
34.00 (95\% Cl2.11 to 547.54; $\mathrm{P}=0.01$; participants = 40; Analysis 5.2), favouring the gemcitabine-based regimen.

\section{Non-serious adverse events}

There was no mention of non-serious adverse events in any of the groups of this comparison.

\section{Gemcitabine plus oxaliplatin versus 5-fluorouracil plus folinic acid}

One trial included data related to this comparison (Sharma 2010).

\section{All-cause mortality}

The RR for all-cause mortality at one year was $0.81(95 \% \mathrm{Cl} 0.55$ to $1.20 ; P=0.29$; participants $=41$; Analysis 6.1 ), favouring neither gemcitabine nor non-gemcitabine regimens. All-cause mortality was not stratified in this trial by tumour site, tumour stage, or performance status. The trial reports all-cause mortality at one year.

\section{Health-related quality of life}

There was no mention of health-related quality of life in any of the groups of this comparison.

\section{Serious adverse events}

There was no mention of serious adverse events in any of the groups of this comparison.

\section{Time to progression of the tumour (reported as median time to progression)}

There was no mention of time to progression of the tumour in any of the groups of this comparison.

\section{Tumour response assessments}

Tumour response was evaluated in accordance with the response evaluation in solid tumours criteria in this comparison. The RR for overall response rate (complete response and partial response) was $2.15(95 \% \mathrm{Cl} 0.64$ to $7.29 ; \mathrm{P}=0.22$; participants $=41$; Analysis 6.2$)$, favouring neither gemcitabine nor non-gemcitabine regimens.

\section{Non-serious adverse events}

There was no mention of non-serious adverse events in any of the groups of this comparison.

Following our protocol, we have also evaluated the harmful effects from Lee 2015, which is a retrospective study comparing gemcitabine plus cisplatin to capecitabine plus cisplatin. There were no cases of chemotherapy-related death or febrile neutropenia reported in this study. The most common haematologic grade $3-4$ toxicity was neutropenia in both the gemcitabine and non-gemcitabine groups (15\% and $14.4 \%$, respectively). We have also evaluated the harmful effects from Raderer 1999, which is an observational non-randomised study evaluating 5-fluorouracil plus mitomycin C (cohort A) or gemcitabine monotherapy (cohort B). Haematologic adverse effects attributable to treatment were modest with both treatment regimens. Grade IV granulocytopenia was seen in $5 \%$ of the participants, severe thrombocytopenia occurred in $15 \%$ of the participants, and grade III anaemia was seen in $10 \%$ of 19 evaluable participants in cohort A. Among the 17 participants of cohort B 
who were considered evaluable for toxicity, thrombocytopenia was the most commonly-observed haematologic side effect, with $12 \%$ of participants having grade III and $6 \%$ with grade IV thrombocytopenia. Only $6 \%$ had leukocytopenia grade II, and $6 \%$ had anaemia grade $\mathrm{I}$.

\section{Gemcitabine plus oxaliplatin versus 5-fluorouracil plus cisplatin plus radiotherapy}

One trial included data related to this comparison (Phelip 2014).

\section{All-cause mortality}

The RR for all-cause mortality at one year was $0.56(95 \% \mathrm{Cl} 0.21$ to $1.52 ; \mathrm{P}=0.26$; participants $=34$; Analysis 7.1 ), favouring neither gemcitabine nor non-gemcitabine regimens.

All-cause mortality was not stratified in this trial by tumour site, tumour stage, or performance status. The trial reports all-cause mortality at one year.

\section{Health-related quality of life}

There was no mention of health-related quality of life in any of the groups of this comparison.

\section{Serious adverse events}

In Phelip 2014, eight participants suffered serious adverse events in the chemotherapy group versus six participants in the chemoradiotherapy group. The cause of serious adverse events was upper gastrointestinal bleeding in one case, with no mention of the details of hospitalisation of the other 13 participants. The RR for the probability of serious adverse events was 1.50 (95\% Cl 0.66 to $3.39 ; \mathrm{P}=0.33$; participants $=34$; Analysis 7.2 ), favouring neither gemcitabine nor non-gemcitabine regimens.

\section{Time to progression of the tumour (reported as median time to progression)}

There was no mention of time to progression of the tumour in any of the groups of this comparison.

\section{Tumour response assessments}

There was no mention of tumour response in any of the groups of this comparison.

\section{Non-serious adverse events}

Non-serious adverse events were categorised in all the included trials according to the National Cancer Institute common terminology criteria (NCI-CTC 2016), and we ranked them accordingly into grades one to four.

RR for high-grade neutropenia (grade 3 - 4) was 10.06 (95\% Cl 0.58 to $173.47 ; \mathrm{P}=0.11$; participants $=34$; Analysis 7.3 ), favouring neither gemcitabine nor non-gemcitabine regimens.

\section{Gemcitabine plus mitomycin C versus capecitabine plus mitomycin C}

One trial included data related to this comparison (Kornek 2004).

\section{All-cause mortality}

The RR for all-cause mortality at one year was $1.14(95 \% \mathrm{Cl} 0.89$ to $1.48 ; \mathrm{P}=0.30$; participants $=51$; Analysis 8.1 ), favouring neither gemcitabine nor non-gemcitabine regimens. All-cause mortality was not stratified in this trial by tumour site, tumour stage, or performance status. The trial reports all-cause mortality at one year.

\section{Health-related quality of life}

There was no mention of health-related quality of life in any of the groups of this comparison.

\section{Serious adverse events}

There was no mention of serious adverse events in any of the groups of this comparison.

\section{Time to progression of the tumour (reported as median time to progression)}

There was no mention of time to progression of the tumour in any of the groups of this comparison.

\section{Tumour response assessments}

Tumour response was evaluated in this study in accordance with the World Health Organization criteria. The RR for overall response rate (complete response and partial response) was 0.65 (95\% Cl 0.25 to $1.72 ; \mathrm{P}=0.39$; participants $=51$; Analysis 8.2 ), favouring neither gemcitabine nor non-gemcitabine regimens. Overall response rate was not stratified in this trial by tumour site, tumour stage, or performance status.

\section{Non-serious adverse events}

Non-serious adverse events were categorised in all the included trials according to the National Cancer Institute common terminology criteria (NCl-CTC 2016), and we ranked them accordingly into grades one to four.

RR for all grades of thrombocytopenia (grade 1 - 4) was $0.56(95 \%$ $\mathrm{Cl} 0.29$ to $1.06 ; \mathrm{P}=0.07$; participants $=47$; Analysis 8.3 ), favouring neither gemcitabine nor non-gemcitabine regimens.

RR for high-grade thrombocytopenia (grade 3 - 4) was 0.78 (95\% $\mathrm{Cl} 0.20$ to 3.12; $\mathrm{P}=0.73$; participants $=47$; Analysis 8.4 ), favouring neither gemcitabine nor non-gemcitabine regimens.

\section{Summary of findings}

Summary of findings for the main comparison; Summary of findings 2; Summary of findings 3; Summary of findings 4; Summary of findings 5; Summary of findings 6; Summary of findings 7; and Summary of findings 8 present our findings on the outcomes: allcause mortality, serious adverse events, health-related quality of life, time to progression of the tumour, and non-serious adverse events. We downgraded the quality of the evidence by three levels because of within-study risk of bias due to high risk of bias; publication bias as it could not be assessed; and because of imprecision due to the small number of trials (only one trial or two trials contributing data). The certainty of the evidence of all the presented outcomes is therefore graded as very low.

\section{DISCUSSION}

\section{Summary of main results}

Based on the included trials, gemcitabine plus cisplatin combination may be associated with lower all-cause mortality compared with S-1 plus cisplatin combination. Gemcitabine plus vandetanib combination may be associated with higher response rates compared with vandetanib alone. Gemcitabine plus S-1 combination may be associated with higher response 
rates compared with S-1 alone, and gemcitabine plus oxaliplatin may be associated with higher response rates compared with best supportive care. On the other hand, gemcitabine plus cisplatin combination may be associated with a higher risk of all grades and high-grade anaemia and thrombocytopenia. Similarly, gemcitabine plus S-1 combination may be associated with a higher risk of all grades of thrombocytopenia, all grades of neutropenia, and high-grade neutropenia. However, it has to be noted that the included trials were highly heterogeneous in their design, mixing single-agent chemo- or targeted therapy, radiochemotherapy, and supportive care. Thus, taking into consideration the overall low quality of data, we cannot draw definite conclusions. We note also that there were no properly-performed placebo-controlled studies in this review. This might have affected the assessment of intervention effects for all outcomes, with the possible exception of mortality.

We await the results of three ongoing randomised trials to provide data for this intervention with or without additional treatments for advanced biliary tract carcinoma (NCT02591030; NCT01470443; NCT03044587).

\section{Overall completeness and applicability of evidence}

The search strategy for randomised clinical trials was very wide, and additionally, by searching the reference lists of the included trials and by checking recent review articles, we made sure that we covered all relevant trials. However, we note that not all of the included trials provided data on all the primary outcomes of interest in this review; moreover, the control regimens are quite variable, which limits the applicability of the evidence. We have not searched the European Medicines Agency (EMA), the US Food and Drug Administration (FDA), or the World Health Organiztion (WHO) clinical registry, and we did not contact pharmaceutical companies for unpublished trials. By focusing mainly on randomised clinical trials and not searching for observational studies reporting adverse events, we are well aware that we bias the review towards focusing more on potential benefits than on potential harms.

\section{Quality of the evidence}

The body of collected evidence does not allow a robust conclusion regarding the objectives of the review. We assessed the overall quality of the evidence as being of very low certainty, using the GRADE approach (GRADEpro 2008; Balshem 2011). This is because of the high risk of bias, small number of trials (imprecision), as well as marked heterogeneity (inconsistency). Details of the risk of bias assessment of included trials were as follows: there was a low risk of reporting bias in all trials except for Phelip 2014, and a low risk of attrition bias in all the included trials except for Li 2016. There was a low risk of performance bias in Santoro 2015; unclear risk in Kornek 2004 trial; and a high risk in Sharma 2010; Kang 2012; Morizane 2013; Phelip 2014 and Li 2016. There was a low risk of detection bias in Santoro 2015 trial; unclear risk in Kornek 2004; Kang 2012; and Phelip 2014 trials; and a high risk of detection bias in Morizane 2013 and Li 2016 trials. Detection bias (including allocation sequence generation and allocation concealment) was clearly reported by four trials (Kornek 2004; Morizane 2013; Santoro 2015; Li 2016); while it was unclearly reported by three trials (Sharma 2010; Kang 2012; Phelip 2014).

\section{Potential biases in the review process}

Publication bias might be an issue here; however, due to the fact that there were only one or two trials for each comparison, we were not able to assess this formally.

\section{Agreements and disagreements with other studies or reviews}

A meta-analysis of individual patient data combining the UK ABC-02 study (Valle 2010) and the Japanese BT22 study (Okusaka 2010) has been published (Valle 2014). However, the main research question of this meta-analysis was whether or not gemcitabine plus cisplatin combination is better than gemcitabine monotherapy.

Another meta-analysis has evaluated the efficacy and safety of gemcitabine-based chemotherapies in biliary tract cancer (Liu 2014), and included seven randomised trials (Kornek 2004; Okusaka 2010; Sharma 2010; Valle 2010; Kang 2012; Morizane 2013; Sasaki 2013); the conclusions indicated that gemcitabine-based combination chemotherapy is a potential first-line treatment for advanced biliary tract cancer, based on improved survival, albeit with additional toxicity.

\section{AUTHORS' CONCLUSIONS}

\section{Implications for practice}

In adults with advanced biliary tract carcinomas, the effects of gemcitabine or gemcitabine-based chemotherapy are uncertain on mortality and on overall response, compared with a range of inactive or active controls. The very low certainty of evidence is due to risks of bias, lack of information in the analyses and hence large imprecision, and possible publication bias. The confidence intervals exclude neither meaningful benefits nor lack of effect in all comparisons but one on mortality where gemcitabine plus cisplatin is compared with S-1 plus cisplatin. Gemcitabine-based regimens showed an increase in non-serious adverse events (particularly haematological toxicities).

\section{Implications for research}

There is a need for large, high-quality randomised clinical trials of gemcitabine- and non-gemcitabine-based systemic therapy regimens for people with advanced biliary tract carcinomas. It is also important that the randomisation process is clearly described, as well as the interventions. The participant flow and data handling should be well specified. The trials must be designed and described following the SPIRIT statement (Standard Protocol Items: Recommendations for Interventional Trials; www.spiritstatement.org/) and the CONSORT statement (Consolidated Standards of Reporting Trials: www.consort-statement.org).

There is also a particular need for properly-conducted placebocontrolled randomised clinical trials, in order to provide better assessment of clinically-important outcomes.

\section{A C K N O WLEDGEMENTS}

We wish to thank the Cochrane Hepato-Biliary Group and its supporting Editorial Team.

Cochrane Review Group funding acknowledgement: The Danish State is the largest single funder of the Cochrane Hepato-Biliary Group through its investment in The Copenhagen Trial Unit, Centre 
for Clinical Intervention Research, Rigshospitalet, Copenhagen University Hospital, Denmark.

Disclaimer: The views and opinions expressed in this review are those of the authors and do not necessarily reflect those of the Danish State or The Copenhagen Trial Unit.
Peer reviewers: Cindy Neuzillet, France; Joshua Rose-Hansen Feinberg, Denmark

Contact editors: Lise Lotte Gluud, Denmark; Frederik Keus, The Netherlands

Sign-off editor: Christian Gluud, Denmark 


\section{R E F E R E N C E S}

\section{References to studies included in this review}

\section{Kang 2012 \{published data only\}}

Kang MJ, Lee JL, Kim TW, Lee SS, Ahn S, Park do H, et al. Randomized phase II trial of S-1 and cisplatin versus gemcitabine and cisplatin in patients with advanced biliary tract adenocarcinoma. Acta Oncologica 2012;51:860-6.

\section{Kornek 2004 \{published data only\}}

Kornek GV, Schuell B, Laengle F, Gruenberger T, Penz M, Karall K, et al. Mitomycin $\mathrm{C}$ in combination with capecitabine or biweekly high-dose gemcitabine in patients with advanced biliary tract cancer: a randomised phase II trial. Annals of Oncology 2004;15(3):478-83.

\section{Li 2016 \{published data only\}}

Li H, Zhang Z, Zhou Z, Guan J, Tong D, Zhou G. Combined gemcitabine and S-1 chemotherapy for treating unresectable hilar cholangiocarcinoma: a randomized open-label clinical trial. Oncotarget 2016;7(18):26888-97.

\section{Morizane 2013 \{published data only\}}

Morizane C, Okusaka T, Mizusawa J, Takashima A, Ueno M, Ikeda $\mathrm{M}$, et al. Randomized phase II study of gemcitabine plus S- 1 versus S-1 in advanced biliary tract cancer: a Japan Clinical Oncology Group trial (JCOG 0805). Cancer Science 2013;104(9):1211-6.

\section{Phelip 2014 \{published data only\}}

Phelip J-M, Vendrely V, Rostain F, Subtil F, Jouve J-L, Gasmi M, et al. Gemcitabine plus cisplatin versus chemoradiotherapy in locally advanced biliary tract cancer: Fédération Francophone de Cancérologie Digestive 9902 phase II randomised study. European Journal of Cancer 2014;50(17):2975-82.

\section{Santoro 2015 \{published data only\}}

Santoro A, Gebbia V, Pressiani T, Testa A, Personeni N, Arrivas Bajardi $\mathrm{E}$, et al. A randomized, multicenter, phase II study of vandetanib monotherapy versus vandetanib in combination with gemcitabine versus gemcitabine plus placebo in subjects with advanced biliary tract cancer: the VanGogh study. Annals of Oncology 2015;26:542-7.

\section{Sharma 2010 \{published data only\}}

Sharma A, Dwary AD, Mohanti BK, Deo SV, Pal S, Sreenivas V, et al. Best supportive care compared with chemotherapy for unresectable gall bladder cancer: a randomized controlled study. Journal of Clinical Oncology 2010;28(30):4581-6.

\section{References to studies excluded from this review}

\section{Chen 2015 \{published data only\}}

Chen JS, Hsu C, Chiang NJ, Tsai CS, Tsou HH, Huang SF, et al. A KRAS mutation status-stratified randomized phase II trial of gemcitabine and oxaliplatin alone or in combination with cetuximab in advanced biliary tract cancer. Annals of Oncology 2015;26(5):943-9.
Lee 2012 \{published data only\}

Lee J, Park SH, Chang HM, Kim JS, Choi HJ, Lee MA, et al. Gemcitabine and oxaliplatin with or without erlotinib in advanced biliary-tract cancer: a multicentre, open-label, randomised, phase 3 study. Lancet Oncology 2012;13(2):181-8.

\section{Lee 2015 \{published data only\}}

Lee J, Hong TH, Lee IS, You YK, Lee MA. Comparison of the efficacy between gemcitabine-cisplatin and capecitabinecisplatin combination chemotherapy for advanced biliary tract cancer. Cancer Research and Treatment 2015;47(2):259-65.

\section{Leone 2016 \{published data only\}}

Leone F, Marino D, Cereda S, Filippi R, Belli C, Spadi R, et al. Panitumumab in combination with gemcitabine and oxaliplatin does not prolong survival in wild-type KRAS advanced biliary tract cancer: a randomized phase 2 trial (Vecti-BIL study). Cancer 2016;122(4):574-81.

\section{Malka 2014 \{published data only\}}

Malka D, Cervera P, Foulon S, Trarbach T, De la Fouchardiere C, Boucher E, et al. Gemcitabine and oxaliplatin with or without cetuximab in advanced biliary-tract cancer (BINGO): a randomised, open-label, non-comparative phase 2 trial. Lancet Oncology 2014;15(8):819-28.

\section{Moehler 2014 \{published data only\}}

Moehler M, Maderer A, Schimanski C, Kanzler S, Denzer U, Kolligs FT, et al. Gemcitabine plus sorafenib versus gemcitabine alone in advanced biliary tract cancer: a double-blind placebo-controlled multicentre phase II Aio study with biomarker and serum programme. European Journal of Cancer 2014;50(18):3125-35.

\section{Okusaka 2010 \{published data only\}}

Okusaka T, Nakachi K, Fukutomi A, Mizuno N, Ohkawa S, Funakoshi A, et al. Gemcitabine alone or in combination with cisplatin in patients with biliary tract cancer: a comparative multicentre study in Japan. British Journal of Cancer 2010;103(4):469-74.

\section{Raderer 1999 \{published data only\}}

Raderer M, Hejna MH, Valencak JB, Kornek GV, Weinländer GS, Bareck E, et al. Two consecutive phase II studies of 5fluorouracil/leucovorin/mitomycin C and of gemcitabine in patients with advanced biliary cancer. Oncology 1999;56(3):177-80.

\section{Sasaki 2013 \{published data only\}}

Sasaki T, Isayama H, Nakai Y, Ito Y, Yasuda I, Toda N, et al. A randomized phase II study of gemcitabine and S-1 combination therapy versus gemcitabine monotherapy for advanced biliary tract cancer. Cancer Chemotherapy and Pharmacology 2013;71(4):973-9.

\section{Valle 2009 \{published data only\}}

Valle JW, Wasan H, Johnson P, Jones E, Dixon L, Swindell R, et al. Gemcitabine alone or in combination with cisplatin in patients with advanced or metastatic cholangiocarcinomas 
or other biliary tract tumours: a multicentre randomised phase II study - the UK ABC-01 Study. British Journal of Cancer 2009;101(4):621-7.

\section{Valle 2010 \{published data only\}}

Valle J, Wasan H, Palmar D, Cunningham D, Anthoney A, Maraveyas A, et al. Cisplatin plus gemcitabine versus cisplatin for biliary tract cancer. New England Journal of Medicine 2010;362(14):1273-8.

\section{Valle 2015 \{published data only\}}

Valle JW, Wasan H, Lopes A, Backen AC, Palmer DH, Morris K, et al. Cediranib or placebo in combination with cisplatin and gemcitabine chemotherapy for patients with advanced biliary tract cancer (ABC-03): a randomised phase 2 trial. Lancet Oncology 2015;16(8):967-78.

\section{Wan 2014 \{published data only\}}

Wan Y, Hui H, Wang X, Liu H. Random and control study comparing gemcitabine administered in fixed dose rate with a more standard infusion combined with oxaliplatin regimens in advanced biliary tract cancer patients. Chinese Journal of Clinical Oncology 2014;41:1098-102.

\section{References to ongoing studies}

\section{NCT01470443 \{published data only\}}

NCT01470443. Study of GEMOX(gemcitabine/oxaliplatin) versus XELOX(xeloda/oxaliplatin) in advanced biliary tract carcinoma [A randomized, multicenter, open-label, phase 3 study to compare the efficacy and safety of GEMOX (gemcitabine/ oxaliplatin) vs XELOX(xeloda/Oxaliplatin) in advanced biliary tract carcinoma]. clinicaltrials.gov/ct2/show/NCT01470443 (first received 11 November 2011).

\section{NCT02591030 \{published data only\}}

NCT02591030. Safety and efficacy of modified folfirinox versus gemcis in bile duct tumours (AMEBICA) [Randomised phase II/III study, assessing the safety and efficacy of modified folfirinox versus gemcis in locally advanced, unresectable and/ or metastatic bile duct tumours]. clinicaltrials.gov/ct2/show/ NCT02591030 (first received 29 October 2015).

\section{NCT03044587 \{published data only\}}

NCT03044587. Nal-IRI with 5-fluorouracil (5-FU) and leucovorin or gemcitabine plus cisplatin in advanced biliary-tract cancer (NIFE) [Nal-IRI with 5-fluorouracil (5-FU) and leucovorin or gemcitabine plus cisplatin in advanced biliary-tract cancer - an open label, non-comparative, randomized, multicenter phase II Trial]. clinicaltrials.gov/ct2/show/NCT03044587 (first received 7 February 2017).

\section{Additional references}

\section{Albores-Saavedra 2009}

Albores-Saavedra J, Schwartz AM, Batich K, Henson DE. Cancers of the ampulla of vater: demographics, morphology, and survival based on 5,625 cases from the SEER program. Journal of Surgical Oncology 2009;100(7):598-605.

\section{Anderson 2004}

Anderson CD, Pinson CW, Berlin J, Chari RS. Diagnosis and treatment of cholangiocarcinoma. Oncologist 2004;9(1):43-57.

\section{Balshem 2011}

Balshem H, Helfand M, Schünemann HJ, Oxman AD, Kunz R, Brozek J, et al. GRADE guidelines 3: rating the quality of evidence - introduction. Journal of Clinical Epidemiology 2011;64(4):401-6.

\section{Brok 2008}

Brok J, Thorlund K, Gluud C, Wetterslev J. Trial sequential analysis reveals insufficient information size and potentially false positive results in many meta-analyses. Journal of Clinical Epidemiology 2008;61(8):763-9.

\section{Brok 2009}

Brok J, Thorlund K, Wetterslev J, Gluud C. Apparently conclusive meta-analyses may be inconclusive - trial sequential analysis adjustment of random error risk due to repetitive testing of accumulating data in apparently conclusive neonatal meta-analyses. International Journal of Epidemiology 2009;38(1):287-98

\section{Burris 1997}

Burris HA 3rd, Moore MJ, Andersen J, Green MR, Rothenberg ML, Modiano MR, et al. Improvements in survival and clinical benefit with gemcitabine as first-line therapy for patients with advanced pancreas cancer: a randomized trial. Journal of Clinical Oncology 1997;15(6):2403-13.

\section{Chapman 1999}

Chapman RW. Risk factors for biliary tract carcinogenesis. Annals of Oncology 1999;10(Suppl 4):308-11.

\section{Chen 2016}

Chen L, Chen C, Yen Y, Tam KW. Chemotherapy for advanced biliary tract carcinoma: a meta-analysis of randomized controlled trials. Medicine 2016;95(33):e4584.

\section{CTCAE 2010}

Common terminology criteria of adverse events. evs.nci.nih.gov/ftp1/CTCAE/About.html (accessed 21 February 2017).

\section{De Groen 1999}

De Groen PC, Gores GJ, Larusso NF, Gunderson LL, Nagorney DM. Biliary tract cancers. New England Journal of Medicine 1999;341(18):1368-78.

\section{DeMets 1987}

DeMets DL. Methods of combining randomised clinical trials: strengths and limitations. Statistics in Medicine 1987;6(3):341-50

\section{DeOliveira 2007}

DeOliveira ML, Cunningham SC, Cameron JL, Kamangar F, Winter JM, Lillemoe KD, et al. Cholangiocarcinoma: thirty-oneyear experience with 564 patients at a single institution. Annals of Surgery 2007;245(5):755-62. 


\section{DerSimonian 1986}

DerSimonian R, Laird N. Meta-analysis in clinical trials. Controlled Clinical Trials 1986;7(3):177-88.

\section{Eckel 2007}

Eckel F, Schmid RM. Chemotherapy in advanced biliary tract carcinoma: a pooled analysis of clinical trials. British Journal of Cancer 2007;96(6):896-902.

\section{Eckel 2014}

Eckel F, Schmid RM. Chemotherapy and targeted therapy in advanced biliary tract carcinoma: a pooled analysis of clinical trials. Chemotherapy 2014;60(1):13-23.

\section{Egger 1997}

Egger M, Davey Smith G, Schneider M, Minder C. Bias in metaanalysis detected by a simple, graphical test. BMJ (Clinical Research Ed.) 1997;315:629-34.

\section{Eisenhauer 2009}

Eisenhauer EA, Therasse P, Bogaerts J, Schwartz LH, Sargent D, Ford R, et al. New response evaluation criteria in solid tumours: revised RECIST guideline (version 1.1). European Journal of Cancer 2009;45(2):228-47.

\section{Gebbia 2001}

Gebbia V, Giuliani F, Maiello E, Colucci G, Verderame F, Borsellino N, et al. Treatment of inoperable and/or metastatic biliary tree carcinomas with single-agent gemcitabine or in combination with levofolinic acid and infusional fluorouracil: results of a multicenter phase II study. Journal of Clinical Oncology 2001;19(20):4089-91.

\section{Gluud 2018}

Gluud C, Nikolova D, Klingenberg SL. Cochrane Hepato-Biliary Group. About Cochrane (Cochrane Review Groups (CRGs)) 2018, Issue 3. Art. No.: LIVER.

\section{GRADEpro 2008 [Computer program]}

Brozek J, Oxman A, Schünemann H. GRADEpro. Version 3.2 for Windows. Grade Working Group 2004-2007, 2008.

\section{Guyatt 2011a}

Guyatt GH, Oxman AD, Kunz R, Brozek J, Alonso-Coello P, Rind $D$, et al. GRADE guidelines 6 . Rating the quality of evidence -- imprecision. Journal of Clinical Epidemiology 2011;64(12):1283-93. [PUBMED: 21839614]

\section{Guyatt 2011b}

Guyatt GH, Oxman AD, Montori V, Vist G, Kunz R, Brozek J, et al. GRADE guidelines: 5 . Rating the quality of evidence -- publication bias. Journal of Clinical Epidemiology 2011;64(12):1277-82. [PUBMED: 21802904]

\section{Guyatt 2011c}

Guyatt GH, Oxman AD, Sultan S, Glasziou P, Akl EA, AlonsoCoello P, et al. GRADE guidelines: 9. Rating up the quality of evidence. Journal of Clinical Epidemiology 2011;64(12):1311-6. [PUBMED: 21802902]

\section{Guyatt 2011d}

Guyatt GH, Oxman AD, Kunz R, Woodcock J, Brozek J, Helfand M, et al. GRADE guidelines: 7. Rating the quality of evidence -- inconsistency. Journal of Clinical Epidemiology 2011;64(12):1294-302. [PUBMED: 21803546]

\section{Guyatt 2011e}

Guyatt GH, Oxman AD, Kunz R, Woodcock J, Brozek J, Helfand M, et al. GRADE guidelines: 8. Rating the quality of evidence -- indirectness. Journal of Clinical Epidemiology 2011;64(12):1303-10. [PUBMED: 21802903]

\section{Guyatt 2011 f}

Guyatt GH, Oxman AD, Kunz R, Atkins D, Brozek J, Vist G, et al. GRADE guidelines: 2. Framing the question and deciding on important outcomes. Journal of Clinical Epidemiology 2011;64(4):395-400. [PUBMED: 21194891]

\section{Guyatt 2011g}

Guyatt GH, Oxman AD, Vist G, Kunz R, Brozek J, Alonso-Coello P, et al. GRADE guidelines: 4 . Rating the quality of evidence -study limitations (risk of bias). Journal of Clinical Epidemiology 2011;64(4):407-15. [PUBMED: 21247734]

\section{Guyatt 2011h}

Guyatt G, Oxman AD, Akl EA, Kunz R, Vist G, Brozek J, et al. GRADE guidelines: 1 . Introduction - GRADE evidence profiles and summary of findings tables. Journal of Clinical Epidemiology 2011;64(4):383-94. [PUBMED: 21195583]

\section{Guyatt 2013a}

Guyatt G, Oxman AD, Sultan S, Brozek J, Glasziou P, AlonsoCoello P, et al. GRADE guidelines: 11. Making an overall rating of confidence in effect estimates for a single outcome and for all outcomes. Journal of Clinical Epidemiology 2013;66(2):151-7. [PUBMED: 22542023]

\section{Guyatt 2013b}

Guyatt GH, Oxman AD, Santesso N, Helfand M, Vist G, Kunz R, et al. GRADE guidelines: 12 . Preparing summary of findings tables-binary outcomes. Journal of Clinical Epidemiology 2013;66(2):158-72. [PUBMED: 22609141]

\section{Guyatt 2013c}

Guyatt GH, Thorlund K, Oxman AD, Walter SD, Patrick D, Furukawa TA, et al. GRADE guidelines: 13. Preparing summary of findings tables and evidence profiles-continuous outcomes. Journal of Clinical Epidemiology 2013;66(2):173-83. [PUBMED: 23116689]

\section{Guyatt 2013d}

Guyatt G, Andrews J, Oxman AD, Alderson P, Dahm P, FalckYtter Y, et al. GRADE guidelines: 15. Going from evidence to recommendations: the significance and presentation of recommendations. Journal of Clinical Epidemiology 2013;66(7):719-25

\section{Guyatt 2017}

Guyatt GH, Ebrahim S, Alonso-Coello P, Johnston BC, Mathioudakis AG, Briel M, et al. GRADE guidelines: 17. Assessing the risk of bias associated with missing participant outcome 
data in a body of evidence. Journal of Clinical Epidemiology 2017;87:14-22. [PUBMED: 28529188]

\section{Higgins 2011}

Higgins JPT, Green S, editor(s). Cochrane Handbook for Systematic Reviews of Interventions Version 5.1.0 (updated March 2011). The Cochrane Collaboration, 2011. Available from www.cochrane-handbook.org.

\section{Hollis 1999}

Hollis S, Campbell F. What is meant by intention to treat analysis? Survey of published randomised controlled trials. $B M J$ (Clinical Research Ed.) 1999;319(7211):670-4.

\section{ICH-GCP 1997}

International Conference on Harmonisation Expert Working Group. International Conference on Harmonisation of Technical Requirements for Registration of Pharmaceuticals for Human Use. ICH harmonised tripartite guideline. Guideline for good clinical practice CFR \& ICH Guidelines. Vol. 1, Philadelphia (PA): Barnett International/PAREXEL, 1997.

\section{Jain 2016}

Jain A, Kwong LN, Javle M. Genomic profiling of biliary tract cancers and implications for clinical practice. Current Treatment Options in Oncology 2016;17(11):58.

\section{Jakobsen 2014}

Jakobsen J, Wetterslev J, Winkel P, Lange T, Gluud C. Thresholds for statistical and clinical significance in systematic reviews with meta-analytic methods. BMC Medical Research Methodology 2014;14:120

\section{Khan 2008}

Khan SA, Toledano MB, Taylor-Robinson SD. Epidemiology, risk factors, and pathogenesis of cholangiocarcinoma. $H P B$ : the Official Journal of the International Hepato Pancreato Biliary Association 2008;10(2):77-82.

\section{Kjaergard 2001}

Kjaergard LL, Villumsen J, Gluud C. Reported methodologic quality and discrepancies between large and small randomized trials in meta-analyses. Annals of Internal Medicine 2001;135(11):982-9.

\section{Kubicka 2001}

Kubicka S, Rudolph KL, Tietze MK, Lorenz M, Manns M. Phase II study of systemic gemcitabine chemotherapy for advanced unresectable hepatobiliary carcinomas. Hepatogastroenterology 2001;48(39):783-9.

\section{Lamarca 2014}

Lamarca A, Hubner RA, David Ryder W, Valle JW. Second-line chemotherapy in advanced biliary cancer: a systematic review. Annals of Oncology 2014;25(12):2328-38.

\section{Liu 2014}

Liu H, Zhang Q-D, Li Z-H, Zhang Q-Q, Lu L-G. Efficacy and safety of gemcitabine-based chemotherapies in biliary tract cancer: a meta-analysis. World Journal of Gastroenterology 2014;20(47):18001-12.

\section{Lundh 2017}

Lundh A, Lexchin J, Mintzes B, Schroll JB, Bero L. Industry sponsorship and research outcome. Cochrane Database of Systematic Reviews 2017, Issue 2. [DOI: 10.1002/14651858.MR000033.pub3]

\section{Macaskill 2001}

Macaskill P, Walter SD, Irwig L. A comparison of methods to detect publication bias in meta-analysis. Statistics in Medicine 2001;20(4):641-54.

\section{Mantel 1959}

Mantel N, Haenszel W. Statistical aspects of the analysis of data from retrospective studies of disease. Journal of the National Cancer Institute 1959;2(4):719-48.

\section{Marino 2013}

Marino D, Leone F, Cavalloni G, Cagnazzo C, Aglietta M. Biliary tract carcinomas: from chemotherapy to targeted therapy. Critical Reviews in Oncology/Hematology 2013;85(2):136-48.

\section{Mini 2006}

Mini E, Nobili S, Caciagli B, Landini I, Mazzei T. Cellular pharmacology of gemcitabine. Annals of Oncology 2006;17(Suppl 5):v7-v12.

\section{Moher 1998}

Moher D, Pham B, Jones A, Cook DJ, Jadad AR, Moher M, et al. Does quality of reports of randomised trials affect estimates of intervention efficacy reported in meta-analyses?. Lancet 1998;352(9128):609-13.

\section{Mustafa 2013}

Mustafa RA, Santesso N, Brozek J, Akl EA, Walter SD, Norman G et al. The GRADE approach is reproducible in assessing the quality of evidence of quantitative evidence syntheses. Journal of Clinical Epidemiology 2013;66(7):736-42; quiz 742.e1-5. [PUBMED: 23623694]

\section{Nakanuma 2015}

Nakanuma Y, Kakuda Y. Pathologic classification of cholangiocarcinoma: new concepts. Best Practice \& Research. Clinical Gastroenterology 2015;29(2):277-93.

\section{NCI-CTC 2016}

National Cancer Instiute. Common Terminology Criteria for Adverse Events (CTCAE). ctep.cancer.gov/protocolDevelopment/ electronic_applications/ctc.htm (accessed 1 June 2016).

\section{Park 2005}

Park JS, Oh SY, Kim SH, Kwon HC, Kim JS, Jin-Kim H, et al. Single-agent gemcitabine in the treatment of advanced biliary tract cancers: a phase II study. Japanese Journal of Clinical Oncology 2005;35(2):68-73.

\section{Parmar 1998}

Parmar MK, Torri V, Stewart L. Extracting summary statistics to perform meta-analyses of the published literature for survival endpoints. Statistics in Medicine 1998;17(24):2815-34. 


\section{Patel 2001}

Patel T. Increasing incidence and mortality of primary intrahepatic cholangiocarcinoma in the United States. Hepatology (Baltimore, Md.) 2001;33(6):1353-7.

\section{Patel 2002}

Patel T. Worldwide trends in mortality from biliary tract malignancies. BMC Cancer 2002;2:10.

\section{Penz 2001}

Penz M, Kornek GV, Raderer M, Ulrich-Pur H, Fiebiger W, Lenauer $\mathrm{A}$, et al. Phase II trial of two-weekly gemcitabine in patients with advanced biliary tract cancer. Annals of Oncology 2001;12(2):183-6.

\section{Randi 2006}

Randi G, Franceschi S, La Vecchia C. Gallbladder cancer worldwide: geographical distribution and risk factors. International Journal of Cancer 2006;118(7):1591-602.

\section{RevMan 2014 [Computer program]}

The Nordic Cochrane Centre, The Cochrane Collaboration. Review Manager (RevMan). Version 5.3. Copenhagen: The Nordic Cochrane Centre, The Cochrane Collaboration, 2014.

\section{Royle 2003}

Royle P, Milne R. Literature searching for randomised controlled trials used in Cochrane reviews: rapid versus exhaustive searches. International Journal of Technology Assessment in Health Care 2003;19(4):591-603.

\section{Savović 2012a}

Savović J, Jones HE, Altman DG, Harris RJ, Jüni P, Pildal J, et al. Influence of reported study design characteristics on intervention effect estimates from randomized, controlled trials. Annals of Internal Medicine 2012;157(6):429-38.

\section{Savović 2012b}

Savović J, Jones HE, Altman DG, Harris RJ, Jüni P, Pildal J, et al. Influence of reported study design characteristics on intervention effect estimates from randomized, controlled trials. Health Technology Assessment 2012;16(35):1-82.

\section{Schulz 1995}

Schulz KF, Chalmers I, Hayes RJ, Altman DG. Empirical evidence of bias. Dimensions of methodological quality associated with estimates of treatment effects in controlled trials. JAMA 1995;273(5):408-12.

\section{Schweitzer 2015}

Schweitzer N, Vogel A. Systemic therapy of cholangiocarcinoma: From chemotherapy to targeted therapies. Best Practice \& Research. Clinical Gastroenterology 2015;29(2):345-53.

\section{Shaib 2004}

Shaib YH, Davila JA, McGlynn K, El-Serag HB. Rising incidence of intrahepatic cholangiocarcinoma in the United States: a true increase?. Journal of Hepatology 2004;40(3):472-7.

\section{Strom 1995}

Strom BL, Soloway RD, Rios-Dalenz JL, Rodriguez-Martinez HA West SL, Kinman JL, et al. Risk factors for gallbladder cancer. An international collaborative case-control study. Cancer 1995;76(10):1747-56.

\section{Suzuki 2010}

Suzuki E, Furuse J, Ikeda M, Okusaka T, Nakachi K, Mitsunaga S, et al. Treatment efficacy/safety and prognostic factors in patients with advanced biliary tract cancer receiving gemcitabine monotherapy: an analysis of 100 cases. Oncology 2010;79(1-2):39-45.

\section{Thorlund 2009}

Thorlund K, Devereaux PJ, Wetterslev J, Guyatt G, loannidis JP, Thabane $L$, et al. Can trial sequential monitoring boundaries reduce spurious inferences from meta-analyses. International Journal of Epidemiology 2009;38(1):276-86.

\section{Thorlund 2010}

Thorlund K, Anema A, Mills E. Interpreting meta-analysis according to the adequacy of sample size. An example using isoniazid chemoprophylaxis for tuberculosis in purified protein derivative negative HIV-infected individuals. Clinical Epidemiology 2010;2:57-66.

\section{Thorlund 2011}

Thorlund K, Engstrøm J, Wetterslev J, Brok J, Imberger G, Gluud C. User manual for Trial Sequential Analysis (TSA). ctu.dk/ tsa/files/tsa_manual.pdf 2011 (accessed 21 February 2017).

\section{TSA 2011 [Computer program]}

Copenhagen Trial Unit. TSA - Trial Sequential Analysis. Version 0.9 Beta. Copenhagen: Copenhagen Trial Unit, 2011.

\section{Tyson 2011}

Tyson BL, El-Serag BH. Risk factors of cholangiocarcinoma. Hepatology (Baltimore, Md.) 2011;54(1):173-84.

\section{Valle 2014}

Valle JW, Furuse J, Jitlal M, Beare S, Mizuno N, Wasan H, et al. Cisplatin and gemcitabine for advanced biliary tract cancer: a meta-analysis of two randomised trials. Annals of Oncology 2014;25(2):391-8.

\section{Venook 2011}

Venook A. Treatment options for advanced biliary tract cancers. 10th Annual Clinical Cancer Update Course, Lake Tahoe, CA January 28-29, 2011.

\section{Welzel 2006}

Welzel TM, McGlynn KA, Hsing AW, O'Brien TR, Pfeiffer RM. Impact of classification of hilar cholangiocarcinomas (Klatskin tumors) on the incidence of intra- and extrahepatic cholangiocarcinoma in the United States. Journal of National Cancer Institute 2006;98(12):873-5.

\section{West 2001}

West J, Wood H, Logan RF, Quinn M, Aithal GP. Trends in the incidence of primary liver and biliary tract cancers in 
England and Wales 1971-2001. British Journal of Cancer 2001;94(11):1751-8.

\section{Westgaard 2008}

Westgaard A, Tafjord S, Farstad IN, Cvancarova M, Eide TJ, Mathisen $\mathrm{O}$, et al. Pancreatobiliary versus intestinal histologic type of differentiation is an independent prognostic factor in resected periampullary adenocarcinoma. BMC Cancer 2008;8:170.

\section{Wetterslev 2008}

Wetterslev J, Thorlund K, Brok J, Gluud C. Trial sequential analysis may establish when firm evidence is reached in cumulative meta-analysis. Journal of Clinical Epidemiology 2008;61(1):64-75.

\section{Wetterslev 2009}

Wetterslev J, Thorlund K, Brok J, Gluud C. Estimating required information size by quantifying diversity in a random-effects meta-analysis. BMC Medical Research Methodology 2009;9:86.

\section{Wetterslev 2017}

Wetterslev J, Jakobsen JC, Gluud C. Trial Sequential Analysis in systematic reviews with meta-analysis. BMC Medical Research Methodology 2017;17(1):39.

\section{CHARACTERISTICS OF STUDIES}

Characteristics of included studies [ordered by study ID]

\section{Wood 2008}

Wood L, Egger M, Gluud LL, Schulz KF, Jüni P, Altman DG, et al. Empirical evidence of bias in treatment effect estimates in controlled trials with different interventions and outcomes: meta-epidemiological study. BMJ (Clinical Research Ed.) 2008;336(7644):601-5.

\section{Yonemoto 2007}

Yonemoto N, Furuse J, Okusaka T, Yamao K, Funakoshi A, Ohkawa $\mathrm{S}$, et al. A multi-center retrospective analysis of survival benefits of chemotherapy for unresectable biliary tract cancer. Japanese Journal of Clinical Oncology 2007;37(11):843-51.

\section{Zhu 2010}

Zhu AX, Hong TS, Hezel AF, Kooby DA. Current management of gallbladder carcinoma. Oncologist 2010;15(2):168-81.

\section{References to other published versions of this review Abdel-Rahman 2015}

Abdel-Rahman OM, Elsayed Z. Gemcitabine-based chemotherapy for advanced biliary tract carcinomas. Cochrane Database of Systematic Reviews 2015, Issue 6. [DOI: 10.1002/14651858.CD011746]

Kang 2012

Methods The investigators conducted a single-centre randomised parallel-group phase II trial of S-1 plus cisplatin versus gemcitabine plus cisplatin as first-line therapy in people with advanced biliary tract carcinoma.

The study population consisted of people who had advanced biliary tract carcinoma not amenable to
potentially curative surgery or definitive chemoradiotherapy and who had never received systemic
chemotherapy.
96 participants were enrolled from March 2008 to March 2009.
Male/female ratio: $62 / 34$
Median age: 59 years

Interventions
IV at $\left.10 \mathrm{mg} / \mathrm{m}^{2} / \mathrm{min}\right)$ on days 1 and 8 every 3 weeks) group;
47 to cisplatin $\left(60 \mathrm{mg} / \mathrm{m}^{2} \mathrm{IV}\right.$ on day 1$)$ plus $\mathrm{S}-1\left(40 \mathrm{mg} / \mathrm{m}^{2}\right)$ twice a day orally on days $\left.1-14\right)$

\begin{tabular}{ll}
\hline Outcomes & Progression-free survival, response rate, overall survival, and toxicity \\
\hline Notes & Country of study: South Korea \\
& We contacted the authors for further details on 25 January 2016 but received no reply. \\
& $\begin{array}{l}\text { Funding: this trial was supported by a grant of the Korea Healthcare Technology R\&D Project, Ministry } \\
\text { of Health, Welfare and Family Affairs, Republic of Korea. (Grant Number: A070001). }\end{array}$ \\
\hline
\end{tabular}

\section{Risk of bias}


Kang 2012 (Continued) $\begin{array}{ll}\text { Random sequence genera- } & \text { Unclear risk }\end{array} \quad \begin{aligned} & \text { Trial participants were randomly assigned to } 1 \text { of the } 2 \text { groups. However, the } \\ & \text { tion (selection bias) }\end{aligned} \quad \begin{array}{ll}\text { method of sequence generation was not specified. }\end{array}$

Allocation concealment $\quad$ Unclear risk
(selection bias)

(selection bias)

\begin{tabular}{|c|c|c|}
\hline $\begin{array}{l}\text { Blinding of participants } \\
\text { and personnel (perfor- }\end{array}$ & High risk & $\begin{array}{l}\text { The following quote is from the original paper: "The present trial was an open- } \\
\text { label, single-center, randomised phase II study" }\end{array}$ \\
\hline
\end{tabular}

mance bias)

All outcomes

\begin{tabular}{lll}
\hline $\begin{array}{l}\text { Blinding of outcome as- } \\
\text { sessment (detection bias) } \\
\text { All outcomes }\end{array}$ & Unclear risk & Blinding of outcome assessment was not described. \\
\hline $\begin{array}{l}\text { Incomplete outcome data } \\
\text { (attrition bias) }\end{array}$ & Low risk & $\begin{array}{l}\text { Statistical methods were clearly described and all participants were included } \\
\text { in the analyses. }\end{array}$ \\
\hline
\end{tabular}

\begin{tabular}{lll}
\hline $\begin{array}{l}\text { Selective reporting (re- } \\
\text { porting bias) }\end{array}$ & Low risk & $\begin{array}{l}\text { All-cause mortality, tumour response, and adverse events were reported. It } \\
\text { is to be noted, however, that the trial protocol was registered after the study } \\
\text { started. }\end{array}$ \\
\hline For-profit bias & Low risk & $\begin{array}{l}\text { No evidence of industry sponsorship. The following quote is from the original } \\
\text { paper: "This study was supported by a grant of the Korea Healthcare Technol- } \\
\text { ogy R\&D Project, Ministry of Health, Welfare and Family Affairs, Republic of Ko- } \\
\text { rea. (Grant Number: A070001)" }\end{array}$ \\
\hline
\end{tabular}

\begin{tabular}{ll}
\hline Other bias $\quad$ Unclear risk & Unclear risk of other biases \\
\hline
\end{tabular}

\section{Kornek 2004}

The phase II randomised parallel-group controlled trial aimed to investigate the therapeutic efficacy
and tolerance of mitomycin C in combination with gemcitabine or capecitabine in previously untreat-
ed people with non-resectable metastatic biliary tract cancer. The exact time of recruitment of partici-
pants was not stated in the published report of the trial.

\begin{tabular}{|c|c|}
\hline \multirow[t]{3}{*}{ Participants } & $\begin{array}{l}51 \text { trial participants eligible for the study had, histologically or cytologically ascertained, non-re- } \\
\text { sectable metastatic adenocarcinoma of the biliary tract. }\end{array}$ \\
\hline & Male/female: $18 / 33$ \\
\hline & Median age: 66 years \\
\hline \multirow[t]{2}{*}{ Interventions } & $\begin{array}{l}\text { Group A ( } 25 \text { participants): mitomycin C } 8 \mathrm{mg} / \mathrm{m}^{2} \text { on day } 1 \text { in combination with gemcitabine } 2000 \mathrm{mg} / \\
\mathrm{m}^{2} \text { on days } 1 \text { and } 15 \text { every } 4 \text { weeks; }\end{array}$ \\
\hline & $\begin{array}{l}\text { Group B ( } 26 \text { participants): mitomycin C } 8 \mathrm{mg} / \mathrm{m}^{2} \text { on day } 1 \text { plus capecitabine } 2000 \mathrm{mg} / \mathrm{m}^{2} / \mathrm{day} \text { on days } \\
\text { 1-14, every } 4 \text { weeks. } \\
\text { In both groups, chemotherapy was administered for } 6 \text { months unless progressive disease occurred } \\
\text { earlier. }\end{array}$ \\
\hline
\end{tabular}

Outcomes Progression-free survival, response rate, overall survival, and treatment tolerance.

\begin{tabular}{|c|c|}
\hline Notes & Country of the study: Austria \\
\hline
\end{tabular}


Kornek 2004 (Continued)

Risk of bias

\begin{tabular}{lll}
\hline Bias & Authors' judgement & Support for judgement \\
\hline $\begin{array}{l}\text { Random sequence genera- } \\
\text { tion (selection bias) }\end{array}$ & Low risk & $\begin{array}{l}\text { Trial participants were randomly assigned to } 1 \text { of the } 2 \text { groups and allocation } \\
\text { was done though a central unit. }\end{array}$ \\
& $\begin{array}{l}\text { The following is a quote from the original paper: "Patients were then assigned } \\
\text { to one treatment regimen by the central office located at the University of Vi- } \\
\text { enna." }\end{array}$
\end{tabular}

\begin{tabular}{|c|c|c|}
\hline $\begin{array}{l}\text { Allocation concealment } \\
\text { (selection bias) }\end{array}$ & Low risk & Allocation concealment was done by a central unit. \\
\hline $\begin{array}{l}\text { Blinding of participants } \\
\text { and personnel (perfor- } \\
\text { mance bias) } \\
\text { All outcomes }\end{array}$ & Unclear risk & $\begin{array}{l}\text { Trial participants were then assigned to } 1 \text { treatment regimen by the central } \\
\text { office located at the University of Vienna. However, it is not clear whether the } \\
\text { participants and personnel were blinded or not. }\end{array}$ \\
\hline $\begin{array}{l}\text { Blinding of outcome as- } \\
\text { sessment (detection bias) } \\
\text { All outcomes }\end{array}$ & Unclear risk & $\begin{array}{l}\text { Trial participants were then assigned to } 1 \text { treatment regimen by the central } \\
\text { office located at the University of Vienna. However, it is not clear whether the } \\
\text { outcome assessors were blinded or not. }\end{array}$ \\
\hline
\end{tabular}

\begin{tabular}{|c|c|c|}
\hline $\begin{array}{l}\text { Incomplete outcome data } \\
\text { (attrition bias) }\end{array}$ & Low risk & $\begin{array}{l}\text { The authors clearly described their analyses (ITT) and included information } \\
\text { about losses to follow-up/withdrawals. }\end{array}$ \\
\hline
\end{tabular}

All outcomes

The authors clearly described their analyses (ITT) and included information about losses to follow-up/withdrawals.

\begin{tabular}{lll}
\hline $\begin{array}{l}\text { Selective reporting (re- } \\
\text { porting bias) }\end{array}$ & Low risk & All-cause mortality, tumour response, and adverse events were reported. \\
\hline For-profit bias & Unclear risk & We found no evidence on how the trial was funded. \\
\hline Other bias & Unclear risk & Unclear risk of other biases \\
\hline
\end{tabular}

\section{Li 2016}

$\begin{array}{ll}\text { Methods } & \text { This randomised open-label clinical trial aimed to evaluate the efficacy and safety of the gemcitabine } \\ \text { plus S-1 (GEM-S-1) combination for treating unresectable hilar cholangiocarcinoma. The trial was con- } \\ \text { ducted between February } 2009 \text { to November } 2012 .\end{array}$

\begin{tabular}{ll}
\hline Participants & 79 participants with unresectable hilar cholangiocarcinoma were randomised to the study groups. \\
& Male/female: $54 / 21$ \\
& Mean age: $56.3 \pm 7.83$ \\
\hline Interventions & $\begin{array}{l}79 \text { participants were allocated into } 3 \text { study groups (gemcitabine group, S-1 group, and gemc- } \\
\text { itabine+S-1 group respectively). Four participants discontinued the treatment because of financial } \\
\text { hardship or unwillingness to continue the treatment because of advanced disease, and } 75 \text { participants } \\
\text { out of } 79 \text { completed the study and were analysed ( } 25 \text { participants in each of the three arms). }\end{array}$
\end{tabular}

\begin{tabular}{ll}
\hline Outcomes & 1-year overall survival, progression-free survival, response rate, toxicity and side effects \\
\hline Notes & $\begin{array}{l}\text { For data analysis purposes, the gemcitabine plus S-1 group were considered as the intervention group, } \\
\text { and outcomes from this group were compared against the S-1 monotherapy (i.e. non-gemcitabine-con- } \\
\text { taining comparator) group. }\end{array}$
\end{tabular}




\section{Country of the study: China}

We contacted the authors for further details on 4 July 2017 but received no reply.

Funding: this trial was supported in part by the National Natural Science Foundations of China

(81170721) and Shanghai Pujiang Program (14PJ1407300).

\section{Risk of bias}

\begin{tabular}{lll}
\hline Bias & Authors' judgement & Support for judgement \\
\hline $\begin{array}{l}\text { Random sequence genera- } \\
\text { tion (selection bias) }\end{array}$ & Low risk & $\begin{array}{l}\text { Trial participants were randomly assigned to } 1 \text { of the } 3 \text { groups, as quoted from } \\
\text { the original paper: "Eligible patients were randomly assigned to the gemc- } \\
\text { itabine/S-1, gemcitabine and S-1 groups via a computer-generated randomi- } \\
\text { sation list." }\end{array}$ \\
\hline $\begin{array}{l}\text { Allocation concealment } \\
\text { (selection bias) }\end{array}$ & Low risk & $\begin{array}{l}\text { The following quote is from the original paper: "To conceal individual patient } \\
\text { group assignments, a trial/data manager who was not involved in patient re- } \\
\text { cruitment generated the patient random allocation sequence via computer." }\end{array}$ \\
\hline
\end{tabular}

Blinding of participants High risk $\quad$ The study was an open-label clinical trial.
and personnel (perfor-
mance bias)
All outcomes

\begin{tabular}{lll}
\hline $\begin{array}{l}\text { Blinding of outcome as- } \\
\text { sessment (detection bias) } \\
\text { All outcomes }\end{array}$ & High risk & The study was an open-label clinical trial. \\
\hline $\begin{array}{l}\text { Incomplete outcome data } \\
\text { (attrition bias) }\end{array}$ & High risk & $\begin{array}{l}\text { The following quote is from the original paper: "79 patients were randomly al- } \\
\text { located to the study groups. However, four patients discontinued the treat- } \\
\text { ment because of financial hardship or the unwillingness to continue the treat- } \\
\text { ment because of advanced disease", "Seventy-five out of } 79 \text { patients (94.9\%) } \\
\text { completed the analysis, with } 25 \text { subjects in each treatment group (gemc- } \\
\text { itabine, S-1, and gemcitabine-S-1)". There were no available outcome data } \\
\text { about these remaining 4 patients. }\end{array}$ \\
\hline
\end{tabular}

\begin{tabular}{ll}
\hline $\begin{array}{l}\text { Selective reporting (re- } \\
\text { porting bias) }\end{array}$ & Low risk \\
& $\begin{array}{l}\text { Although the study protocol cannot be accessed, the authors reported prima- } \\
\text { ry (OS and PFS) and secondary (objective RR and safety of chemotherapeutic } \\
\text { agents) outcomes in the published results. }\end{array}$
\end{tabular}

For-profit bias Low risk No evidence of industry sponsorship. The following quote is from the
original paper: "This study was supported in part by the National Natural Science Foundations of China (81170721) and Shanghai Pujiang Program (14PJ1407300)"

Other bias Unclear risk Unclear risk of other bias

\section{Morizane 2013}

$\begin{array}{ll}\text { Methods } & \text { Phase II randomised parallel-group controlled trial; to evaluate the safety and efficacy of } 2 \text { regimens } \\ \text { (S-1 alone or S-1 with gemcitabine) in the management of advanced biliary tract cancers }\end{array}$

Participants

From February 2009 to April 2010, 101 trial participants were enrolled with unresectable or recurrent disease; histologically-proven adenocarcinoma or adenosquamous carcinoma in people with extrahepatic biliary duct, gall bladder or intrahepatic biliary duct carcinomas 
Morizane 2013 (Continued)

Male/female: 55/46

Median age: 64 years

$\begin{array}{ll}\text { Interventions } & \text { Gemcitabine plus S-1 (gemcitabine: } 1000 \mathrm{mg} / \mathrm{m}^{2} \text {, day } 1 \text { and day } 8 ; \mathrm{S}-1: 60 \mathrm{mg} / \mathrm{m}^{2} \text {, twice daily on days } 1 \\ & -14 \text {, repeated every } 3 \text { weeks) ( } 51 \text { participants); } \\ & \text { S- } 1\left(80 \mathrm{mg} / \mathrm{m}^{2} \text {, days } 1-28 \text {, given orally twice daily for } 4 \text { weeks, followed by a 2-week rest, repeated }\right. \\ & \text { every } 6 \text { weeks) (50 participants). }\end{array}$

Outcomes

Progression-free survival, overall survival, response rate in participants with measurable lesions, the incidence of adverse events, and of serious adverse events

Notes Country of the study: Japan

We contacted the authors for further details 25 January 2016 but received no reply.

Funding: the sponsor of the study was the Ministry of Health, Labour and Welfare, Japan, which had no role in the study design, data collection, data analysis, data interpretation, or writing of the report.

\section{Risk of bias}

Bias Authors' judgement Support for judgement

Random sequence genera- Low risk tion (selection bias)
Trial participants were randomly allocated to either the gemcitabine/S-1 or S-1 treatment groups, using a minimisation method with an algorithm (concealed from the investigator) to balance the following stratification factors: institution; primary site (gall bladder, others); and clinical stage (II, III, IV or recurrent).

The following quote is from the original paper: "The data managers checked the eligibility, completed registration if appropriate, and randomly allocated the patient to either the GS or S-1 treatment group, using a minimization method with an algorithm (concealed to the investigator)"

Allocation concealment Low risk
(selection bias)

Trial participants were randomly allocated to either the gemcitabine/S-1 or S-1 treatment groups, using a minimisation method with an algorithm (concealed from the investigator) to balance the following stratification factors: institution; primary site (gall bladder, others); and clinical stage (II, III, IV or recurrent).

The following quote is from the original paper: "The data managers checked the eligibility, completed registration if appropriate, and randomly allocated the patient to either the GS or S-1 treatment group, using a minimization method with an algorithm (concealed to the investigator)"

\begin{tabular}{|c|c|c|}
\hline $\begin{array}{l}\text { Blinding of participants } \\
\text { and personnel (perfor- } \\
\text { mance bias) } \\
\text { All outcomes }\end{array}$ & High risk & $\begin{array}{l}\text { The following quote is from the original paper: "The treatment allocation was } \\
\text { not masked from the investigators or the patients" }\end{array}$ \\
\hline $\begin{array}{l}\text { Blinding of outcome as- } \\
\text { sessment (detection bias) } \\
\text { All outcomes }\end{array}$ & High risk & $\begin{array}{l}\text { The following quote is from the original paper: "The treatment allocation was } \\
\text { not masked from the investigators or the patients" }\end{array}$ \\
\hline $\begin{array}{l}\text { Incomplete outcome data } \\
\text { (attrition bias) } \\
\text { All outcomes }\end{array}$ & Low risk & $\begin{array}{l}\text { The follow-up and statistical methods were clearly described and all partici- } \\
\text { pants were included in the analyses. }\end{array}$ \\
\hline $\begin{array}{l}\text { Selective reporting (re- } \\
\text { porting bias) }\end{array}$ & Low risk & $\begin{array}{l}\text { The study authors stated that "This study was registered at the UMIN Clinical } \\
\text { Trials registry UMIN } 000001685 \text { (http://www.umin.ac.jp/ctr/index.htm)", but }\end{array}$ \\
\hline
\end{tabular}


Morizane 2013 (Continued)

we could not access the protocol. All-cause mortality, tumour response, and adverse events were reported.

\begin{tabular}{ll}
\hline For-profit bias & Low risk \\
& $\begin{array}{l}\text { No evidence of industry sponsorship. The following quote is from the original } \\
\text { paper: "The sponsor of the study was the Ministry of Health, Labour and Wel- } \\
\text { fare, Japan, which had no role in the study design, data collection, data analy- } \\
\text { sis, data interpretation, or writing of the report" }\end{array}$ \\
\hline
\end{tabular}

Other bias Unclear risk Unclear risk of other biases

Phelip 2014

\begin{tabular}{|c|c|}
\hline Methods & An open-label, multicentre, randomised, parallel-group, 2-group controlled phase II trial \\
\hline \multirow[t]{3}{*}{ Participants } & $\begin{array}{l}\text { Between July } 2006 \text { and December 2010, } 34 \text { people with locally-advanced biliary tract cancers were in- } \\
\text { cluded in } 12 \text { centres ( } 18 \text { in the chemoradiotherapy and } 16 \text { in the chemotherapy group). }\end{array}$ \\
\hline & Male/female ratio: not reported \\
\hline & Median age: not reported \\
\hline Interventions & $\begin{array}{l}\text { Chemoradiotherapy (fluorouracil infusion and cisplatin were given in association with radiotherapy (50 } \\
\text { Gray)); } \\
\text { Chemotherapy (gemcitabine + oxaliplatin for } 6 \text { months) }\end{array}$ \\
\hline Outcomes & $\begin{array}{l}\text { Progression-free survival, overall survival, toxicity, rate of biliary complications, and duration of hospi- } \\
\text { talisation }\end{array}$ \\
\hline \multirow[t]{3}{*}{ Notes } & Country of the study: France \\
\hline & We contacted the authors for further details 25 January 2016 but received no reply. \\
\hline & $\begin{array}{l}\text { Funding: this work was supported by 'Programme Hospitalier de Recherche Clinique } 2001 \text { ' from the } \\
\text { French National Institute of Cancer (INCA) and sponsored by Centre Georges Leclerc, Dijon. Lilly compa- } \\
\text { ny supplied gemcitabine and Sanofi company supplied oxaliplatin. }\end{array}$ \\
\hline
\end{tabular}

\section{Risk of bias}

\begin{tabular}{lll}
\hline Bias & Authors' judgement & Support for judgement \\
\hline $\begin{array}{l}\text { Random sequence genera- } \\
\text { tion (selection bias) }\end{array}$ & Unclear risk & $\begin{array}{l}\text { The method of sequence generation was not specified. The following quote is } \\
\text { from the original paper: "eligible patients were randomised at the 'Federation } \\
\text { Francophonie de Cancerologie Digestive (FFCD)' data centre" }\end{array}$ \\
\hline $\begin{array}{l}\text { Allocation concealment } \\
\text { (selection bias) }\end{array}$ & Unclear risk & $\begin{array}{l}\text { The method used to conceal the allocation was not described. The following } \\
\text { quote is from the original paper: "eligible patients were randomised at the }\end{array}$ \\
'Federation Francophonie de Cancerologie Digestive (FFCD)' data centre"
\end{tabular}

Blinding of outcome as- Unclear risk Blinding of outcome assessment was not described.


Phelip 2014 (Continued)

Incomplete outcome data Low risk Figure 1 of the original paper contains a detailed account of all participants in (attrition bias) the study.

All outcomes

$\begin{array}{ll}\begin{array}{l}\text { Selective reporting (re- } \\ \begin{array}{l}\text { porting bias) } \\ \end{array}\end{array} & \text { Tumour response was not reported. } \\ & \text { The trial was registered after the start of the study at clinicaltrials.gov } \\ \text { (NCT00304135). }\end{array}$

\begin{tabular}{ll}
\hline For-profit bias & High risk \\
& $\begin{array}{l}\text { The following quotes are from the original paper: "This work was supported by } \\
\text { 'Programme Hospitalier de Recherche Clinique 2001' from the French National } \\
\text { Institute of Cancer (INCA) and sponsored by Centre Georges Leclerc, Dijon." }\end{array}$ \\
& $\begin{array}{l}\text { "We thank Lilly for supplying gemcitabine and Sanofi for supplying oxali- } \\
\text { platin". }\end{array}$
\end{tabular}

\begin{tabular}{lll}
\hline Other bias & Unclear risk & Unclear risk of other biases \\
\hline
\end{tabular}

\section{Santoro 2015}

\begin{tabular}{ll}
\hline Methods & $\begin{array}{l}\text { This phase II multicentre parallel-group randomised controlled trial evaluated the efficacy and tolera- } \\
\text { bility of vandetanib alone compared with vandetanib plus gemcitabine or gemcitabine plus placebo in } \\
\text { people with advanced biliary tract carcinoma. }\end{array}$ \\
\hline
\end{tabular}

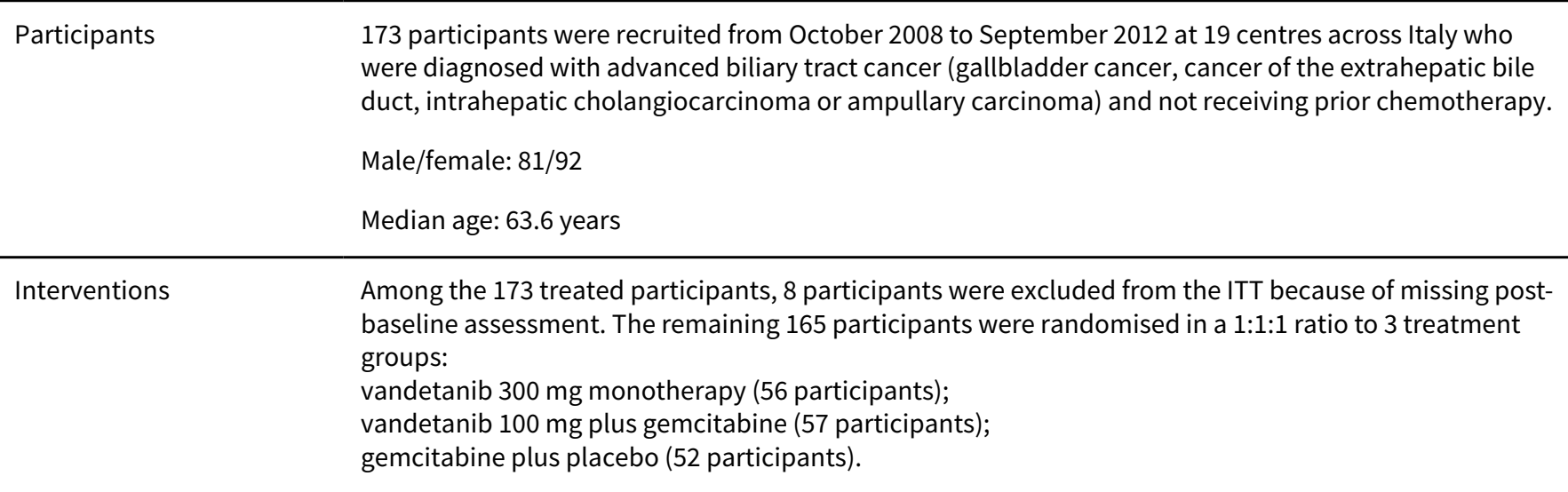

Outcomes

Progression-free survival, overall survival, response rate, disease control rate, duration of response, performance status and safety outcomes

Notes

For data analysis purposes, the (vandetanib plus gemcitabine) group and the (gemcitabine plus placebo) group were considered as the intervention group and outcomes from these 2 groups were compared against the vandetanib alone (i.e. non-gemcitabine-containing comparator) group.

Country of the study: Italy

We contacted the authors for further details 25 January2016 but received no reply.

Funding: AstraZeneca

\section{Risk of bias}

\begin{tabular}{lll}
\hline Bias & Authors' judgement & Support for judgement \\
\hline $\begin{array}{l}\text { Random sequence genera- } \\
\text { tion (selection bias) }\end{array}$ & Low risk & $\begin{array}{l}\text { The following 2 quotes are from the original paper "Randomisation was based } \\
\text { on concealed treatment allocation using sequentially numbered opaque, }\end{array}$ \\
\hline
\end{tabular}


Santoro 2015 (Continued)

sealed envelopes". "The actual treatment given to individual patients was determined by a computer-generated randomisation scheme"

\begin{tabular}{|c|c|c|}
\hline $\begin{array}{l}\text { Allocation concealment } \\
\text { (selection bias) }\end{array}$ & Low risk & $\begin{array}{l}\text { The following quote is from the original paper: "Randomisation was based on } \\
\text { concealed treatment allocation using sequentially numbered opaque, sealed } \\
\text { envelopes" }\end{array}$ \\
\hline
\end{tabular}

\begin{tabular}{ll}
\hline $\begin{array}{l}\text { Blinding of participants } \\
\text { and personnel (perfor- }\end{array}$ & Low risk
\end{tabular}$\quad \begin{aligned} & \text { The following quote is from the clinicaltrials.gov record of the study: "Double } \\
& \text { Blind (Participant, Investigator, Outcomes Assessor)" }\end{aligned}$
Blind (Participant, Investigator, Outcomes Assessor)" mance bias)

All outcomes

\begin{tabular}{|c|c|c|}
\hline $\begin{array}{l}\text { Blinding of outcome as- } \\
\text { sessment (detection bias) }\end{array}$ & Low risk & $\begin{array}{l}\text { The following quote is from the clinicaltrials.gov record of the study: "Double } \\
\text { Blind (Participant, Investigator, Outcomes Assessor)" }\end{array}$ \\
\hline
\end{tabular}

All outcomes

Incomplete outcome data Low risk
(attrition bias)

All outcomes

There was a flow chart, detailing the included participants and their progress through the study "Figure-1 of the original paper".

\begin{tabular}{|c|c|c|}
\hline $\begin{array}{l}\text { Selective reporting (re- } \\
\text { porting bias) }\end{array}$ & Unclear risk & $\begin{array}{l}\text { According to clinicaltrials.gov record of the trial, there are data on overall sur- } \\
\text { vival which were collected but not analysed. }\end{array}$ \\
\hline
\end{tabular}

\begin{tabular}{ll}
\hline For-profit bias & High risk \\
& The following quote is from the original paper "This study was sponsored by \\
& AstraZeneca".
\end{tabular}

\begin{tabular}{ll}
\hline Other bias $\quad$ Unclear risk $\quad$ Unclear risk of other biases \\
\hline
\end{tabular}

\section{Sharma 2010}

\begin{tabular}{|c|c|}
\hline Methods & Single-centre randomised parallel-group 3-groups trial \\
\hline \multirow[t]{3}{*}{ Participants } & $\begin{array}{l}99 \text { trial participants with cytologically-proven unresectable or metastatic adenocarcinoma of gallblad- } \\
\text { der were screened from June } 2006 \text { to October } 2008.81 \text { participants were then randomised into one of } \\
\text { the three treatment groups and received treatment. }\end{array}$ \\
\hline & Male/female:15/84 \\
\hline & Median age: 49 years \\
\hline Interventions & $\begin{array}{l}\text { Group A: best supportive care ( } 27 \text { participants); } \\
\text { Group B: fluorouracil /folinic acid (FUFA) ( } 28 \text { participants); } \\
\text { Group C: gemcitabine/oxaliplatin ( } 26 \text { participants), for a maximum of } 6 \text { cycles }\end{array}$ \\
\hline Outcomes & Progression-free survival, response rate, overall survival, and toxicity patterns \\
\hline \multirow[t]{3}{*}{ Notes } & $\begin{array}{l}\text { For our analysis, we divided the intervention group into two equal halves and compared each half with } \\
\text { a different comparator group. }\end{array}$ \\
\hline & Country of the study: India \\
\hline & We contacted the authors for further details 25 January 2016 but received no reply. \\
\hline
\end{tabular}

\section{Risk of bias}


Sharma 2010 (Continued)

\begin{tabular}{|c|c|c|}
\hline Bias & Authors' judgement & Support for judgement \\
\hline $\begin{array}{l}\text { Random sequence genera- } \\
\text { tion (selection bias) }\end{array}$ & Unclear risk & $\begin{array}{l}\text { Trial participants were randomly assigned to } 1 \text { of } 3 \text { groups, but the method of } \\
\text { sequence generation was not specified. }\end{array}$ \\
\hline $\begin{array}{l}\text { Allocation concealment } \\
\text { (selection bias) }\end{array}$ & Unclear risk & Allocation concealment was not stated in the publication. \\
\hline $\begin{array}{l}\text { Blinding of participants } \\
\text { and personnel (perfor- } \\
\text { mance bias) } \\
\text { All outcomes }\end{array}$ & High risk & $\begin{array}{l}\text { The following quote is from the original paper: "This was a randomised, con- } \\
\text { trolled, open-label, single-center study" }\end{array}$ \\
\hline $\begin{array}{l}\text { Blinding of outcome as- } \\
\text { sessment (detection bias) } \\
\text { All outcomes }\end{array}$ & Unclear risk & Blinding of outcome assessment was not described. \\
\hline $\begin{array}{l}\text { Incomplete outcome data } \\
\text { (attrition bias) } \\
\text { All outcomes }\end{array}$ & Low risk & $\begin{array}{l}\text { There was a flow chart, detailing the included participants, and showing that } \\
\text { only one participant was lost to follow-up without therapy "Figure-1 of the } \\
\text { original paper". }\end{array}$ \\
\hline $\begin{array}{l}\text { Selective reporting (re- } \\
\text { porting bias) }\end{array}$ & Low risk & $\begin{array}{l}\text { The authors stated that: "Clinical Trials repository link available on JCO.org"; } \\
\text { but we could not find the link. Otherwise, all-cause mortality, tumour re- } \\
\text { sponse, and adverse events were reported. }\end{array}$ \\
\hline For-profit bias & Unclear risk & It is not clear how the study was funded. \\
\hline Other bias & Unclear risk & Unclear risk of other biases \\
\hline
\end{tabular}

ITT: intention- to treat;IV: intravenous

Characteristics of excluded studies [ordered by study ID]

\begin{tabular}{ll}
\hline Study & Reason for exclusion \\
\hline Chen 2015 & Gemcitabine was used in both randomised groups of the trial \\
\hline Lee 2012 & Gemcitabine was used in both randomised groups of the trial \\
\hline Lee 2015 & This publication was a retrospective analysis of clinical data through reviewing medical records \\
\hline Leone 2016 & Gemcitabine was used in both randomised groups of the trial \\
\hline Malka 2014 & Gemcitabine was used in both randomised groups of the trial \\
\hline Moehler 2014 & Gemcitabine was used in both randomised groups of the trial \\
\hline Okusaka 2010 & Gemcitabine was used in both randomised groups of the trial \\
\hline Raderer 1999 & $\begin{array}{l}\text { Although the experimental gemcitabine group belongs to a prospectively-performed phase II trial, } \\
\text { the comparator cohort was retrospectively assigned }\end{array}$ \\
\hline Sasaki 2013 & Gemcitabine was used in both randomised groups of the trial \\
\hline Valle 2009 & Gemcitabine was used in both randomised groups of the trial \\
\hline
\end{tabular}




\begin{tabular}{ll}
\hline Study & Reason for exclusion \\
\hline Valle 2010 & Gemcitabine was used in both randomised groups of the trial \\
\hline Valle 2015 & Gemcitabine was used in both randomised groups of the trial \\
\hline Wan 2014 & Gemcitabine was used in both randomised groups of the trial \\
\hline
\end{tabular}

Characteristics of ongoing studies [ordered by study ID]

\section{NCT01470443}

Trial name or title

Methods

Participants

Interventions

Interventions

\begin{tabular}{|c|c|}
\hline Outcomes & $\begin{array}{l}\text { Primary outcome measures: } \\
\text { - progression-free survival } \\
\text { Secondary outcome measures: } \\
\text { - safety profile }\end{array}$ \\
\hline Starting date & December 2011 \\
\hline Contact information & $\begin{array}{l}\text { Ho Yeong Lim, Professor of Medicine, Sungkyunkwan University School of Medicine, Department } \\
\text { of Hematology and Oncology, Samsung Medical Center Mi Yeon Kwon, RN, miyeon.kwon@sam- } \\
\text { sung.com }\end{array}$ \\
\hline Notes & Estimated enrolment: 240 participants \\
\hline
\end{tabular}

\section{NCT02591030}

\begin{tabular}{ll}
\hline Trial name or title & Safety and efficacy of modified folfirinox versus gemcis in bile duct tumours (AMEBICA) \\
\hline Methods & Randomised phase II/III study \\
\hline Participants & People with locally-advanced, unresectable and/or metastatic bile duct tumours \\
\hline Interventions & Group I: gemcitabine/cisplatin \\
& Group II: oxaliplatin/Irinotecan/folinic acid/5-fluorouracil \\
\hline Outcomes & Primary outcomes: \\
& - percentage of participants alive without radiological progression (Phase II) \\
\hline
\end{tabular}
tract carcinoma

Randomised, multicentre, open-label, phase III study

People with histologically- or cytologically-confirmed adenocarcinoma of biliary tract (intrahepatic, extrahepatic cholangiocarcinoma, gall bladder cancer) but ampulla of Vater cancer is excluded.

\section{Group I: GEMOX}

Group II: oxaliplatin 
NCT02591030 (Continued)

Secondary outcomes:

- overall survival

- tumour response

- toxicity of the treatment assessed according to NCI-CTC v 4.0

- biliary complications

- quality of life (EORTC QLQ-C30)

\begin{tabular}{ll}
\hline Starting date & November 2015 \\
\hline Contact information & Jean-Marc Phelip, PhD (0)477828320 ext +33 j.marc.phelip@chu-st-etienne.fr \\
& Lila GABA-BERKOUK (0)380393483 ext +33 \\
& lila.gaba@u-bourgogne.fr \\
\hline Notes & Estimated enrolment: 316 participants \\
\hline
\end{tabular}

\section{NCT03044587} $\begin{array}{ll}\text { Trial name or title } & \text { Nal-IRI with 5-fluorouracil (5-FU) and leucovorin or gemcitabine plus cisplatin in advanced bil- } \\ \text { iary-tract cancer (NIFE) }\end{array}$

\begin{tabular}{ll}
\hline Methods & An open-label, non-comparative, randomised, multicentre phase II trial \\
\hline Participants & People with: \\
& adenocarcinoma metastatic biliary tract cancer; \\
& adenocarcinoma of the biliary tract; \\
& adenocarinoma locally-advanced, non-resectable hepatocellular carcinoma; \\
& intrahepatic bile duct carcinoma; \\
& extrahepatic bile duct carcinoma. \\
\hline
\end{tabular}

Interventions Group A: Na I-IRI + 5-FU + leucovorin

Group B: cisplatin + gemcitabine

\begin{tabular}{ll}
\hline Outcomes & Primary outcome measures: \\
& - progression-free survival \\
Secondary outcome measures: \\
- 3 -year overall survival \\
- objective tumour response rate (ORR) \\
- toxicity/safety \\
- health-related quality of life EORTC QLQ-BIL21
\end{tabular}

\begin{tabular}{ll}
\hline Starting date & January 2017. This study is not yet open for participant recruitment. \\
\hline Contact information & Dr Thomas J. Ettrich, Klinik für Innere Medizin I, Universitätsklinikum Ulm \\
\hline
\end{tabular}




\section{DATA AND ANALYSES}

Comparison 1. Gemcitabine plus vandetanib versus vandetanib alone

\begin{tabular}{lllll}
\hline Outcome or subgroup title & No. of studies & $\begin{array}{l}\text { No. of partici- } \\
\text { pants }\end{array}$ & Statistical method & Effect size \\
\hline 1 Serious adverse events & 1 & Risk Ratio (M-H, Random, 95\% Cl) & Totals not selected \\
\hline 2 Overall response rate & 1 & Risk Ratio (M-H, Random, 95\% Cl) & Totals not selected \\
\hline 3 Grade 1 - 4 anaemia & 1 & Risk Ratio (M-H, Random, 95\% Cl) & Totals not selected \\
\hline 4 Grade 3 - 4 anaemia & 1 & Risk Ratio (M-H, Random, 95\% Cl) & Totals not selected \\
\hline 5 Grade 1 - 4 neutropenia & 1 & Risk Ratio (M-H, Random, 95\% Cl) & Totals not selected \\
\hline 6 Grade 3 - 4 neutropenia & 1 & Risk Ratio (M-H, Random, 95\% Cl) & Totals not selected \\
\hline
\end{tabular}

Analysis 1.1. Comparison 1 Gemcitabine plus vandetanib versus vandetanib alone, Outcome 1 Serious adverse events.

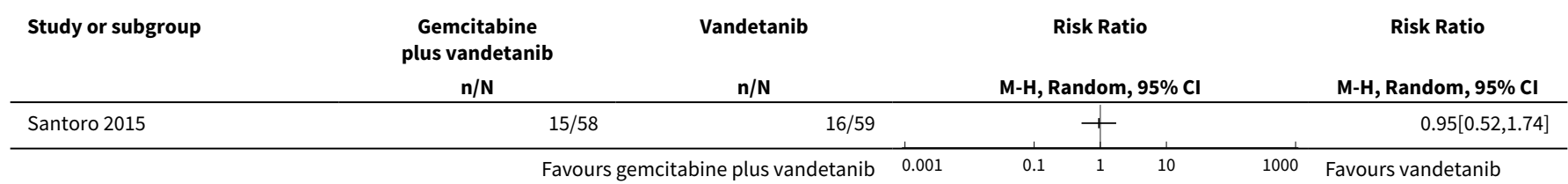

Analysis 1.2. Comparison 1 Gemcitabine plus vandetanib versus vandetanib alone, Outcome 2 Overall response rate.

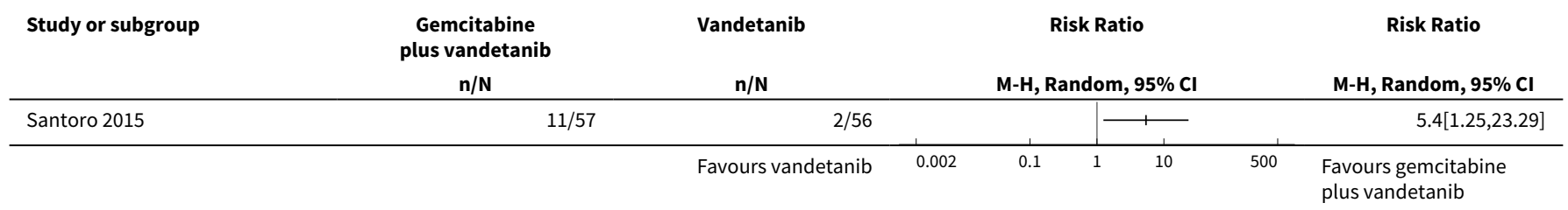

Analysis 1.3. Comparison 1 Gemcitabine plus vandetanib versus vandetanib alone, Outcome 3 Grade 1 - 4 anaemia.

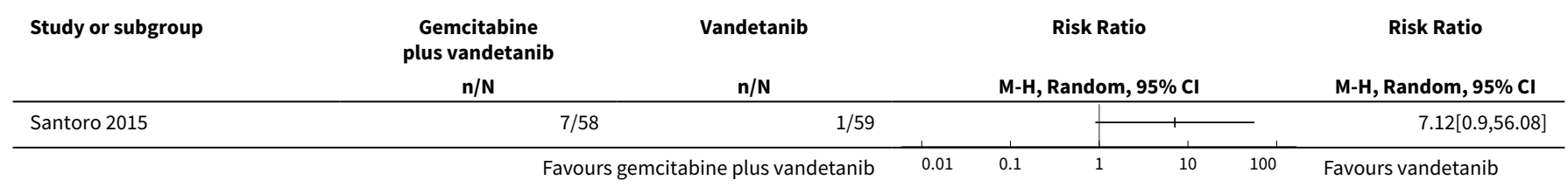


Analysis 1.4. Comparison 1 Gemcitabine plus vandetanib versus vandetanib alone, Outcome 4 Grade 3 - 4 anaemia.

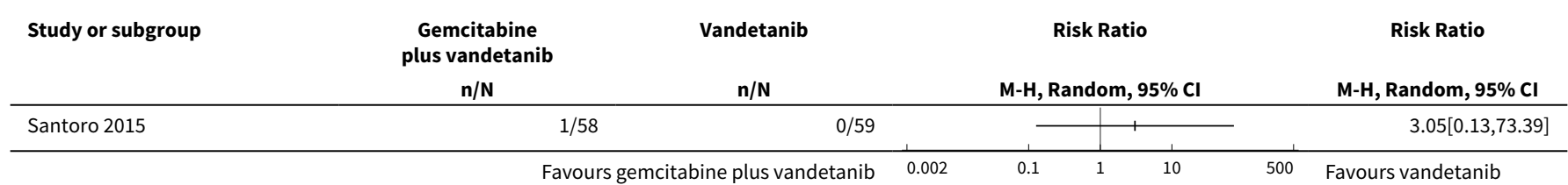

Analysis 1.5. Comparison 1 Gemcitabine plus vandetanib versus vandetanib alone, Outcome 5 Grade 1 - 4 neutropenia.

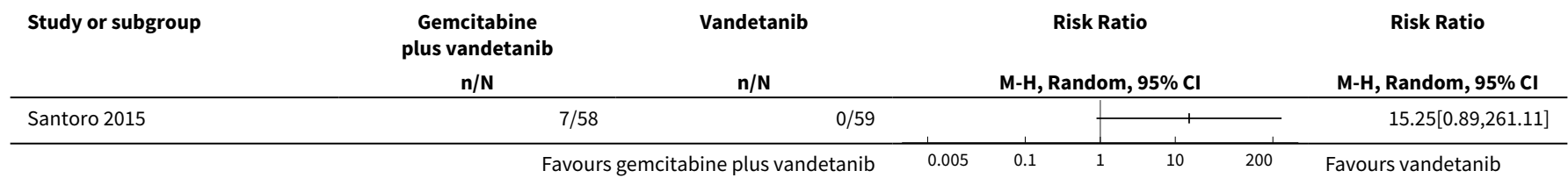

Analysis 1.6. Comparison 1 Gemcitabine plus vandetanib versus vandetanib alone, Outcome 6 Grade 3 - 4 neutropenia.

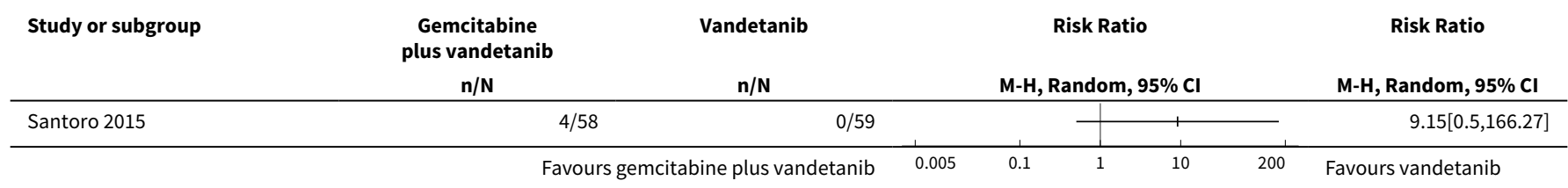

Comparison 2. Gemcitabine versus vandetanib

\begin{tabular}{lllll}
\hline Outcome or subgroup title & No. of studies & $\begin{array}{l}\text { No. of partici- } \\
\text { pants }\end{array}$ & Statistical method & Effect size \\
\hline 1 Serious adverse events & 1 & Risk Ratio (M-H, Random, 95\% Cl) & Totals not selected \\
\hline 2 Overall response rate & 1 & Risk Ratio (M-H, Random, 95\% Cl) & Totals not selected \\
\hline 3 Grade 1 - 4 anaemia & 1 & Risk Ratio (M-H, Random, 95\% Cl) & Totals not selected \\
\hline 4 Grade 3 - 4 anaemia & 1 & Risk Ratio (M-H, Random, 95\% Cl) & Totals not selected \\
\hline 5 Grade 1 - 4 neutropenia & 1 & Risk Ratio (M-H, Random, 95\% Cl) & Totals not selected \\
\hline 6 Grade 3 - 4 neutropenia & 1 & Risk Ratio (M-H, Random, 95\% Cl) & Totals not selected \\
\hline
\end{tabular}


Analysis 2.1. Comparison 2 Gemcitabine versus vandetanib, Outcome 1 Serious adverse events.

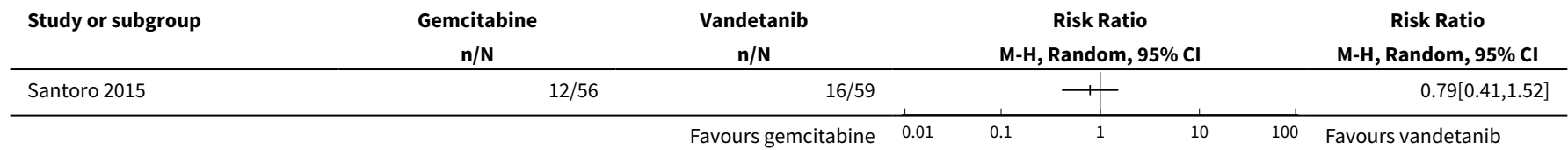

Analysis 2.2. Comparison 2 Gemcitabine versus vandetanib, Outcome 2 Overall response rate.

\begin{tabular}{|c|c|c|c|c|c|c|c|}
\hline Study or subgroup & $\begin{array}{c}\text { Gemcitabine } \\
n / N\end{array}$ & $\begin{array}{c}\text { Vandetanib } \\
\mathbf{n} / \mathbf{N}\end{array}$ & & & Ratio & & $\begin{array}{c}\text { Risk Ratio } \\
\text { M-H, Random, 95\% CI }\end{array}$ \\
\hline Santoro 2015 & $7 / 52$ & $2 / 56$ & & & 1 & & $3.77[0.82,17.33]$ \\
\hline
\end{tabular}

Analysis 2.3. Comparison 2 Gemcitabine versus vandetanib, Outcome 3 Grade 1 - 4 anaemia.

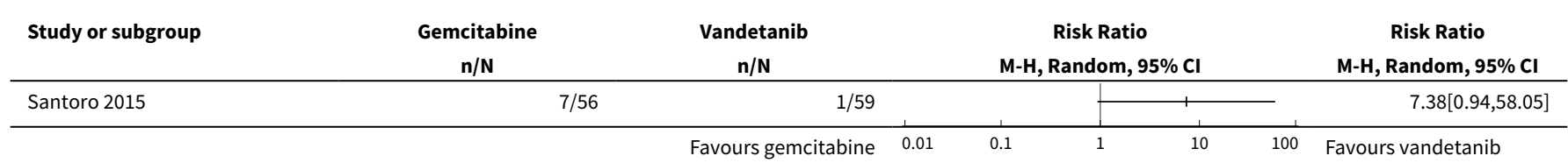

Analysis 2.4. Comparison 2 Gemcitabine versus vandetanib, Outcome 4 Grade 3 - 4 anaemia.

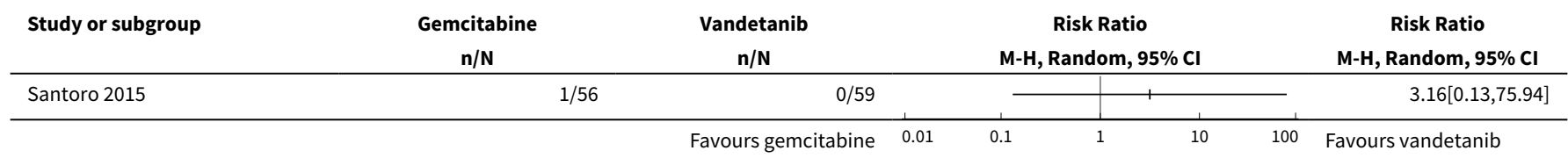

Analysis 2.5. Comparison 2 Gemcitabine versus vandetanib, Outcome 5 Grade 1 - 4 neutropenia.

\begin{tabular}{|c|c|c|c|c|c|c|c|}
\hline \multirow{2}{*}{$\begin{array}{l}\text { Study or subgroup } \\
\text { Santoro } 2015\end{array}$} & $\begin{array}{c}\text { Gemcitabine } \\
\mathbf{n} / \mathbf{N}\end{array}$ & $\begin{array}{c}\text { Vandetanib } \\
\mathbf{n} / \mathbf{N}\end{array}$ & \multicolumn{3}{|c|}{$\begin{array}{c}\text { Risk Ratio } \\
\text { M-H, Random, } 95 \% \mathrm{Cl} \\
\end{array}$} & & \multirow{2}{*}{$\begin{array}{c}\text { Risk Ratio } \\
\text { M-H, Random, 95\% Cl } \\
22.11[1.33,368.56\end{array}$} \\
\hline & $10 / 56$ & $0 / 59$ & & & 1 & & \\
\hline
\end{tabular}

Analysis 2.6. Comparison 2 Gemcitabine versus vandetanib, Outcome 6 Grade 3 - 4 neutropenia.

\begin{tabular}{|c|c|c|c|c|c|c|c|}
\hline Study or subgroup & $\begin{array}{c}\text { Gemcitabine } \\
n / N\end{array}$ & $\begin{array}{c}\text { Vandetanib } \\
\mathbf{n} / \mathbf{N}\end{array}$ & \multicolumn{3}{|c|}{$\begin{array}{c}\text { Risk Ratio } \\
\text { M-H, Random, 95\% Cl }\end{array}$} & & \multirow{2}{*}{$\begin{array}{c}\text { Risk Ratio } \\
\text { M-H, Random, 95\% Cl } \\
11.58[0.66,204.68]\end{array}$} \\
\hline Santoro 2015 & $5 / 56$ & $0 / 59$ & & & 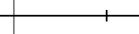 & - & \\
\hline
\end{tabular}


Comparison 3. Gemcitabine plus cisplatin versus S-1 plus cisplatin

\begin{tabular}{|c|c|c|c|c|}
\hline Outcome or subgroup title & No. of studies & $\begin{array}{l}\text { No. of partici- } \\
\text { pants }\end{array}$ & Statistical method & Effect size \\
\hline $\begin{array}{l}1 \text { All-cause mortality at one } \\
\text { year }\end{array}$ & 1 & & Risk Ratio (M-H, Random, 95\% Cl) & Totals not selected \\
\hline 2 Overall response rate & 1 & & Risk Ratio (M-H, Random, 95\% Cl) & Totals not selected \\
\hline 3 Grade 1 - 4 anaemia & 1 & & Risk Ratio (M-H, Random, 95\% Cl) & Totals not selected \\
\hline 4 Grade 3 - 4 anaemia & 1 & & Risk Ratio (M-H, Random, 95\% Cl) & Totals not selected \\
\hline $\begin{array}{l}5 \text { Grade } 1 \text { - } 4 \text { thrombocy- } \\
\text { topenia }\end{array}$ & 1 & & Risk Ratio (M-H, Random, 95\% Cl) & Totals not selected \\
\hline $\begin{array}{l}6 \text { Grade } 3 \text { - } 4 \text { thrombocy- } \\
\text { topenia }\end{array}$ & 1 & & Risk Ratio (M-H, Random, 95\% Cl) & Totals not selected \\
\hline 7 Grade 1 - 4 neutropenia & 1 & & Risk Ratio (M-H, Random, 95\% Cl) & Totals not selected \\
\hline 8 Grade 3 - 4 neutropenia & 1 & & Risk Ratio (M-H, Random, 95\% Cl) & Totals not selected \\
\hline 9 Febrile neutropenia & 1 & & Risk Ratio (M-H, Random, 95\% Cl) & Totals not selected \\
\hline
\end{tabular}

Analysis 3.1. Comparison 3 Gemcitabine plus cisplatin versus S-1 plus cisplatin, Outcome 1 All-cause mortality at one year.

\begin{tabular}{|c|c|c|c|c|c|c|}
\hline \multirow[t]{2}{*}{ Study or subgroup } & $\begin{array}{l}\text { Gemcitabine } \\
\text { plus cisplatin }\end{array}$ & S-1 plus cisplatin & \multicolumn{3}{|c|}{ Risk Ratio } & \multirow{2}{*}{$\begin{array}{c}\text { Risk Ratio } \\
\text { M-H, Random, } 95 \% \mathrm{Cl}\end{array}$} \\
\hline & $n / N$ & $\mathrm{n} / \mathrm{N}$ & & M-H, Rando & $5 \% \mathrm{Cl}$ & \\
\hline \multirow[t]{2}{*}{ Kang 2012} & $30 / 49$ & $38 / 47$ & & 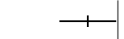 & & $0.76[0.58,0.98]$ \\
\hline & Fav & citabine plus cisplatin & 0.2 & 0.5 & 2 & $\begin{array}{l}\text { Favours S-1 plus cis- } \\
\text { platin }\end{array}$ \\
\hline
\end{tabular}

Analysis 3.2. Comparison 3 Gemcitabine plus cisplatin versus S-1 plus cisplatin, Outcome 2 Overall response rate.

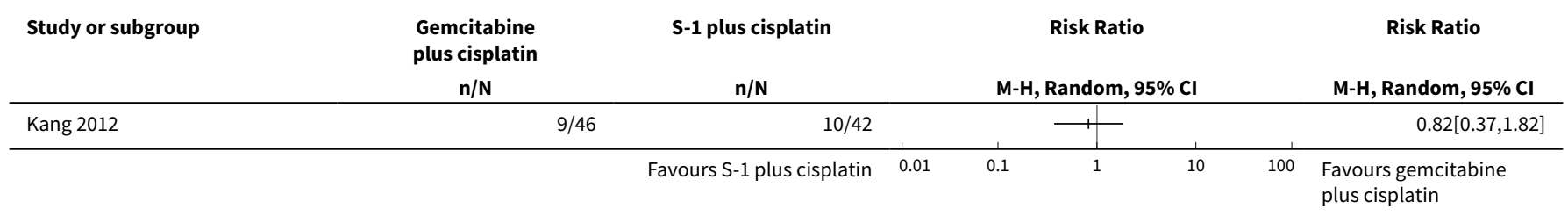


Analysis 3.3. Comparison 3 Gemcitabine plus cisplatin versus S-1 plus cisplatin, Outcome 3 Grade 1 - 4 anaemia.

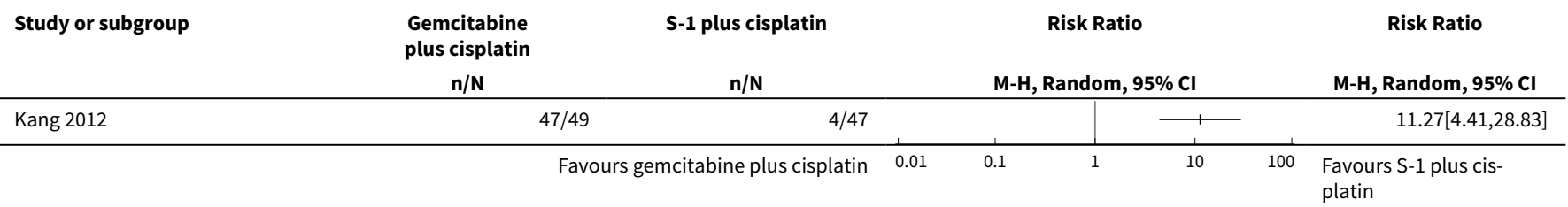

Analysis 3.4. Comparison 3 Gemcitabine plus cisplatin versus S-1 plus cisplatin, Outcome 4 Grade 3 - 4 anaemia.

\begin{tabular}{|c|c|c|c|c|c|c|c|}
\hline \multirow[t]{2}{*}{ Study or subgroup } & $\begin{array}{l}\text { Gemcitabine } \\
\text { plus cisplatin }\end{array}$ & S-1 plus cisplatin & & & Ratio & & \multirow{2}{*}{$\begin{array}{c}\text { Risk Ratio } \\
\text { M-H, Random, 95\% Cl }\end{array}$} \\
\hline & $n / N$ & $n / N$ & \multicolumn{4}{|c|}{ M-H, Random, $95 \% \mathrm{Cl}$} & \\
\hline \multirow[t]{2}{*}{ Kang 2012} & $11 / 49$ & $1 / 47$ & & & 1 & - & $10.55[1.42,78.56]$ \\
\hline & Favo & ncitabine plus cisplatin & 0.01 & 0.1 & 10 & 100 & $\begin{array}{l}\text { Favours S-1 plus cis- } \\
\text { platin }\end{array}$ \\
\hline
\end{tabular}

Analysis 3.5. Comparison 3 Gemcitabine plus cisplatin versus S-1 plus cisplatin, Outcome 5 Grade 1 - 4 thrombocytopenia.

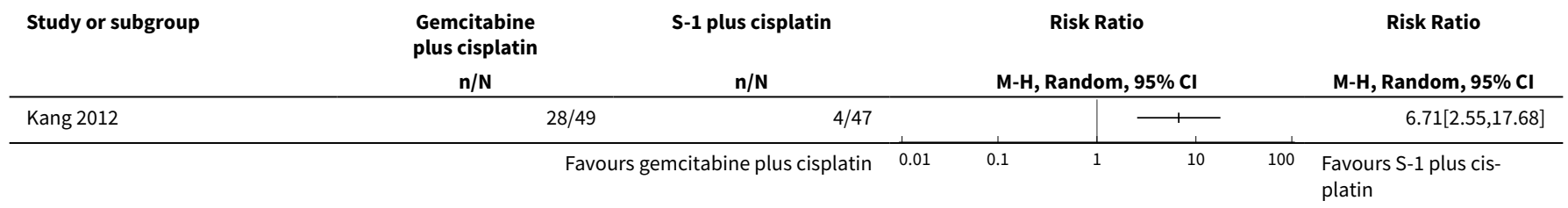

Analysis 3.6. Comparison 3 Gemcitabine plus cisplatin versus S-1 plus cisplatin, Outcome 6 Grade 3 - 4 thrombocytopenia.

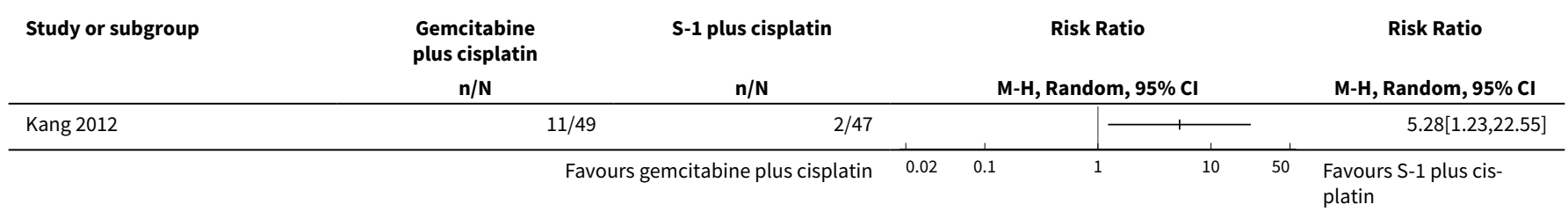

Analysis 3.7. Comparison 3 Gemcitabine plus cisplatin versus S-1 plus cisplatin, Outcome 7 Grade 1 - 4 neutropenia.

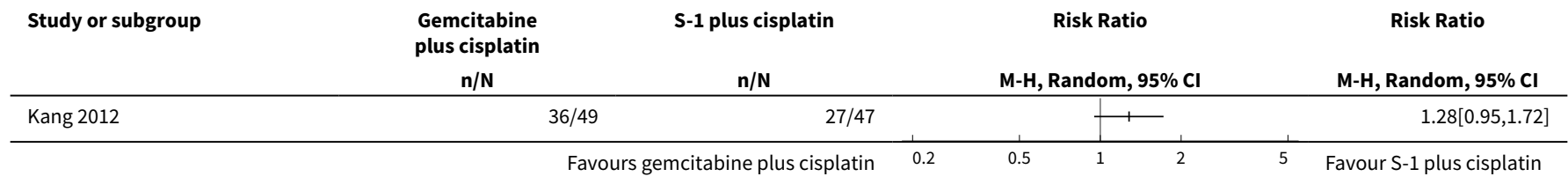


Analysis 3.8. Comparison 3 Gemcitabine plus cisplatin versus S-1 plus cisplatin, Outcome 8 Grade 3 - 4 neutropenia.

\begin{tabular}{|c|c|c|c|c|c|c|c|}
\hline \multirow[t]{2}{*}{ Study or subgroup } & $\begin{array}{l}\text { Gemcitabine } \\
\text { plus cisplatin }\end{array}$ & \multicolumn{2}{|l|}{ S-1 plus cisplatin } & & Ratio & & \multirow[t]{2}{*}{$\begin{array}{c}\text { Risk Ratio } \\
\text { M-H, Random, 95\% Cl }\end{array}$} \\
\hline & $n / N$ & $n / N$ & \multicolumn{3}{|c|}{ M-H, Random, $95 \% \mathrm{Cl}$} & & \\
\hline Kang 2012 & $24 / 49$ & $14 / 47$ & & & - & & $1.64[0.97,2.78]$ \\
\hline & Favo & ncitabine plus cisplatin & 0.01 & 0.1 & 10 & 100 & $\begin{array}{l}\text { Favours S-1 plus cis- } \\
\text { platin }\end{array}$ \\
\hline
\end{tabular}

Analysis 3.9. Comparison 3 Gemcitabine plus cisplatin versus S-1 plus cisplatin, Outcome 9 Febrile neutropenia.

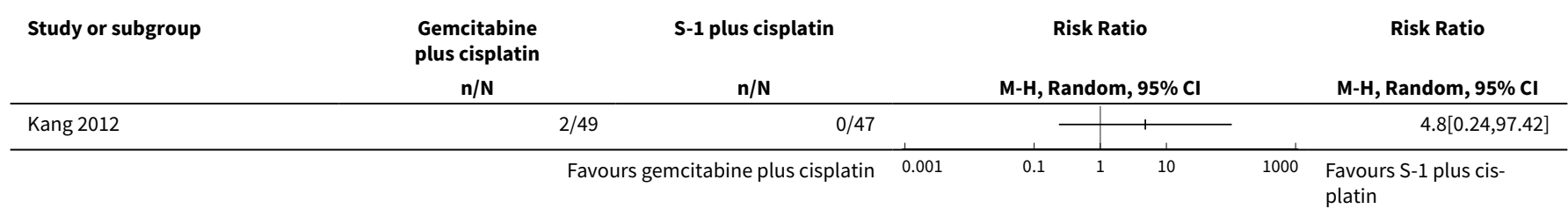

\section{Comparison 4. Gemcitabine plus S-1 versus S-1}

\begin{tabular}{|c|c|c|c|c|}
\hline Outcome or subgroup title & No. of studies & $\begin{array}{l}\text { No. of partici- } \\
\text { pants }\end{array}$ & Statistical method & Effect size \\
\hline $\begin{array}{l}1 \text { All-cause mortality at one } \\
\text { year }\end{array}$ & 2 & 151 & Risk Ratio $(\mathrm{M}-\mathrm{H}$, Random, $95 \% \mathrm{Cl})$ & $0.61[0.33,1.13]$ \\
\hline 2 Serious adverse events & 1 & & Risk Ratio (M-H, Random, 95\% Cl) & Totals not selected \\
\hline 3 Overall response rate & 2 & 140 & Risk Ratio (M-H, Random, 95\% Cl) & $2.46[1.27,4.75]$ \\
\hline 4 Grade 1 - 4 anaemia & 2 & 151 & Risk Ratio (M-H, Random, 95\% Cl) & $1.26[1.00,1.59]$ \\
\hline 5 Grade 3 - 4 anaemia & 1 & & Risk Ratio (M-H, Random, 95\% Cl) & Totals not selected \\
\hline $\begin{array}{l}6 \text { Grade } 1 \text { - } 4 \text { thrombocy- } \\
\text { topenia }\end{array}$ & 2 & 151 & Risk Ratio $(\mathrm{M}-\mathrm{H}$, Random, 95\% Cl) & $2.45[1.39,4.32]$ \\
\hline $\begin{array}{l}7 \text { Grade } 3 \text { - } 4 \text { thrombocy- } \\
\text { topenia }\end{array}$ & 1 & & Risk Ratio (M-H, Random, 95\% Cl) & Totals not selected \\
\hline 8 Grade 1 - 4 neutropenia & 2 & 151 & Risk Ratio (M-H, Random, 95\% Cl) & $3.30[1.04,10.50]$ \\
\hline 9 Grade 3 - 4 neutropenia & 1 & & Risk Ratio (M-H, Random, 95\% Cl) & Totals not selected \\
\hline 10 Febrile neutropenia & 2 & 151 & Risk Ratio (M-H, Random, 95\% Cl) & $2.97[0.32,27.87]$ \\
\hline
\end{tabular}


Analysis 4.1. Comparison 4 Gemcitabine plus S-1 versus S-1, Outcome 1 All-cause mortality at one year.

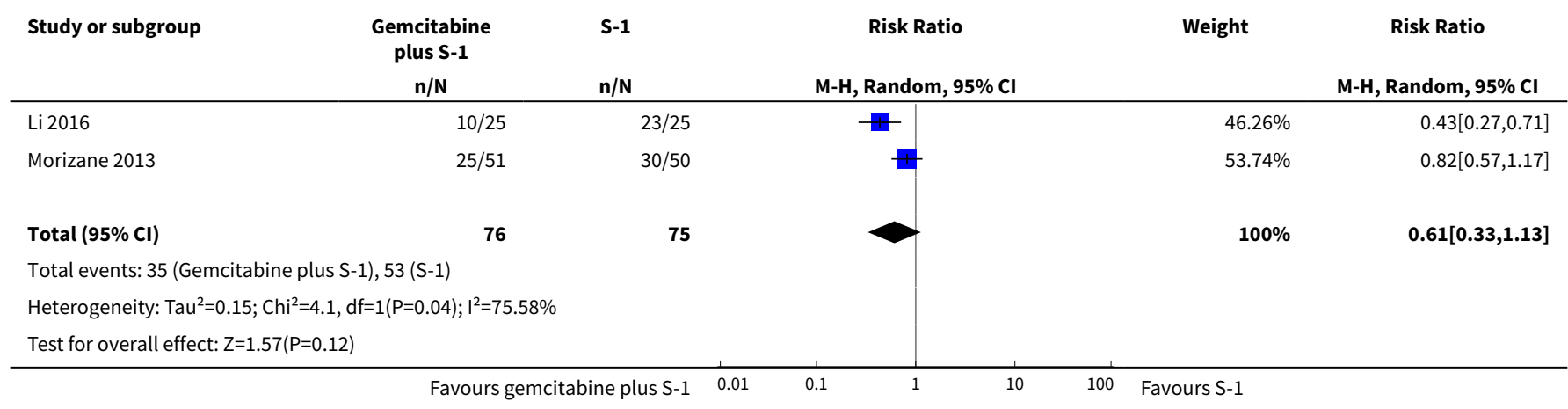

Analysis 4.2. Comparison 4 Gemcitabine plus S-1 versus S-1, Outcome 2 Serious adverse events.

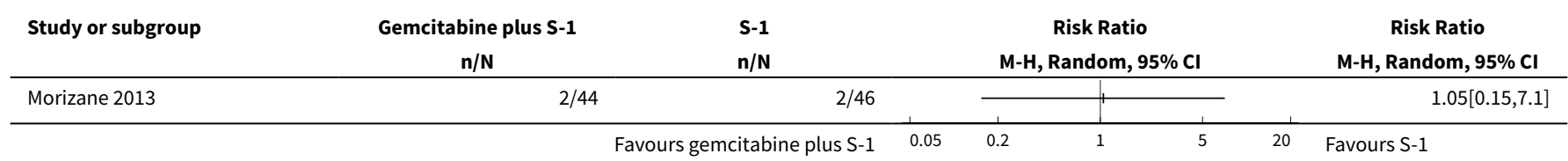

Analysis 4.3. Comparison 4 Gemcitabine plus S-1 versus S-1, Outcome 3 Overall response rate.

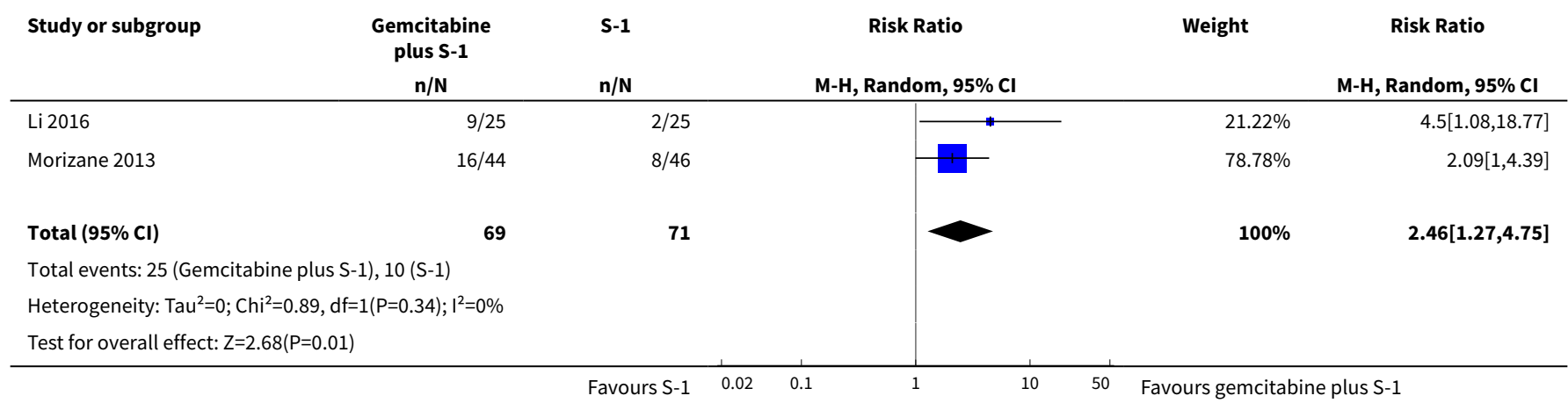

Analysis 4.4. Comparison 4 Gemcitabine plus S-1 versus S-1, Outcome 4 Grade 1 - 4 anaemia.

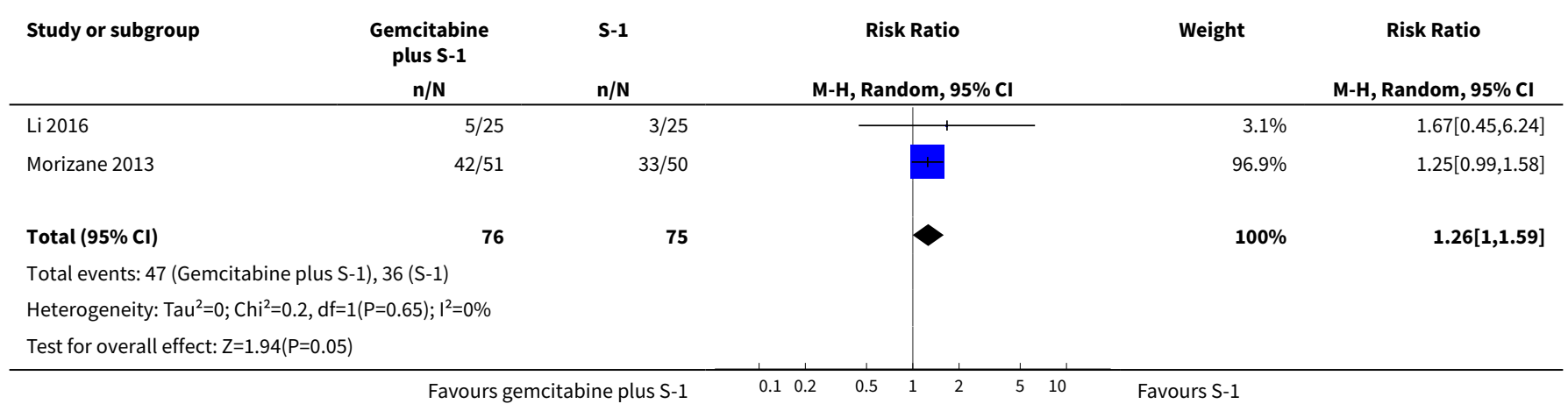


Analysis 4.5. Comparison 4 Gemcitabine plus S-1 versus S-1, Outcome 5 Grade 3 - 4 anaemia.

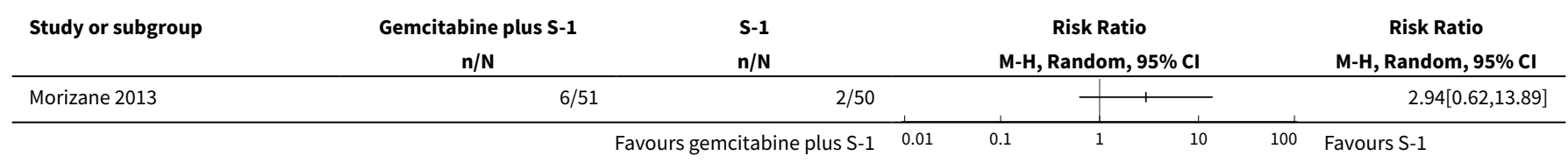

Analysis 4.6. Comparison 4 Gemcitabine plus S-1 versus S-1, Outcome 6 Grade 1 - 4 thrombocytopenia.

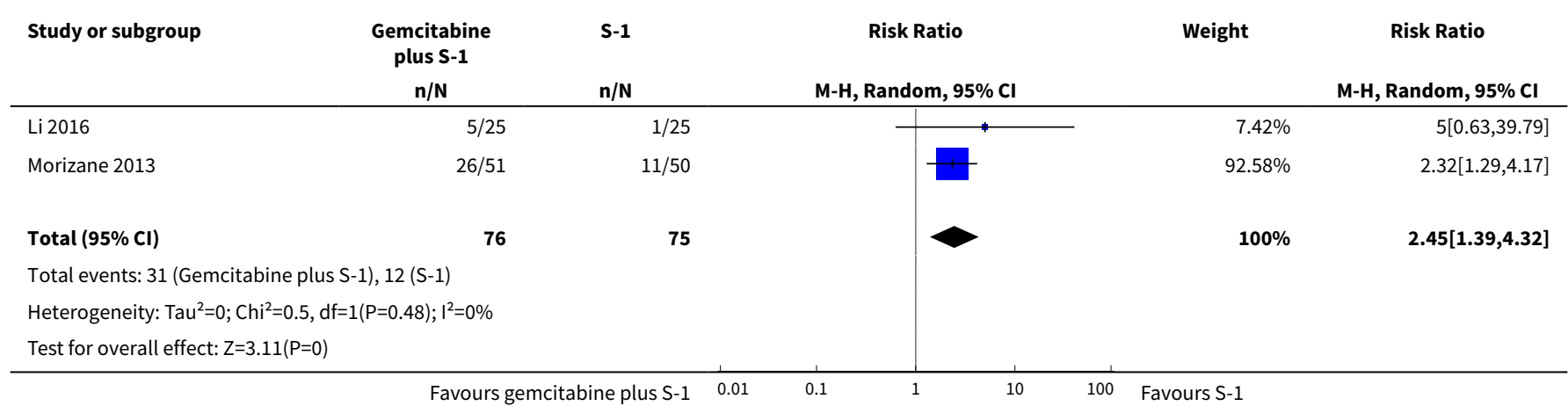

Analysis 4.7. Comparison 4 Gemcitabine plus S-1 versus S-1, Outcome 7 Grade 3 - 4 thrombocytopenia.

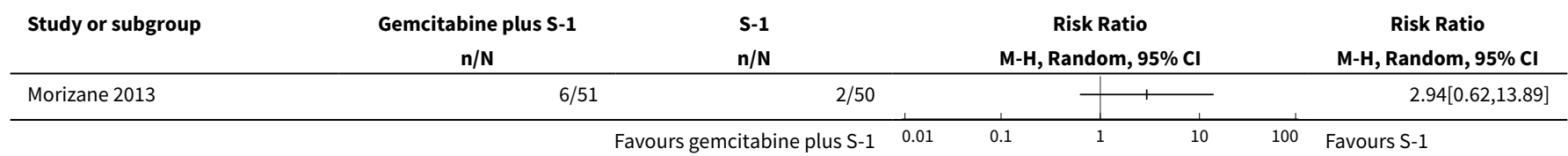

Analysis 4.8. Comparison 4 Gemcitabine plus S-1 versus S-1, Outcome 8 Grade 1 - 4 neutropenia.

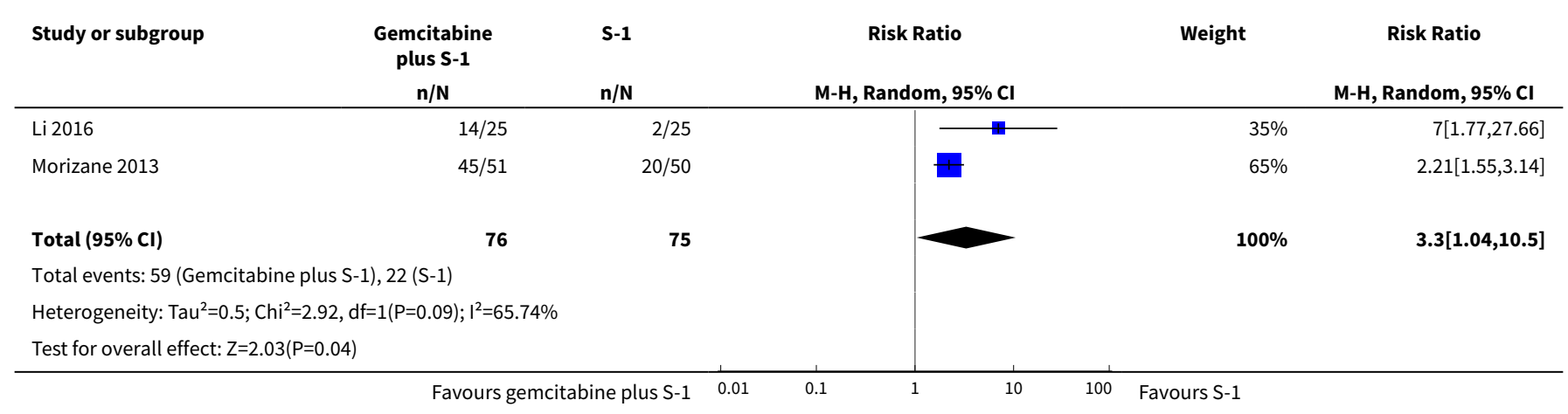


Analysis 4.9. Comparison 4 Gemcitabine plus S-1 versus S-1, Outcome 9 Grade 3 - 4 neutropenia.

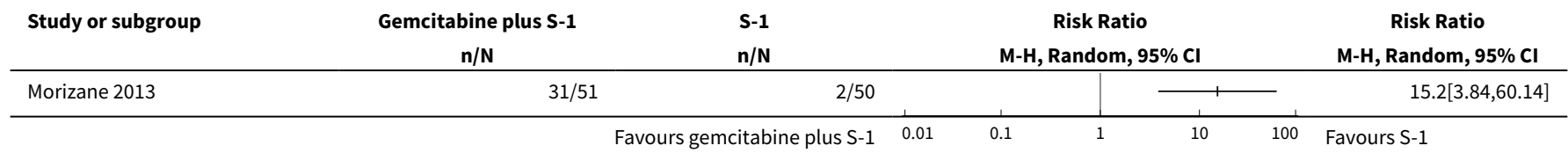

Analysis 4.10. Comparison 4 Gemcitabine plus S-1 versus S-1, Outcome 10 Febrile neutropenia.

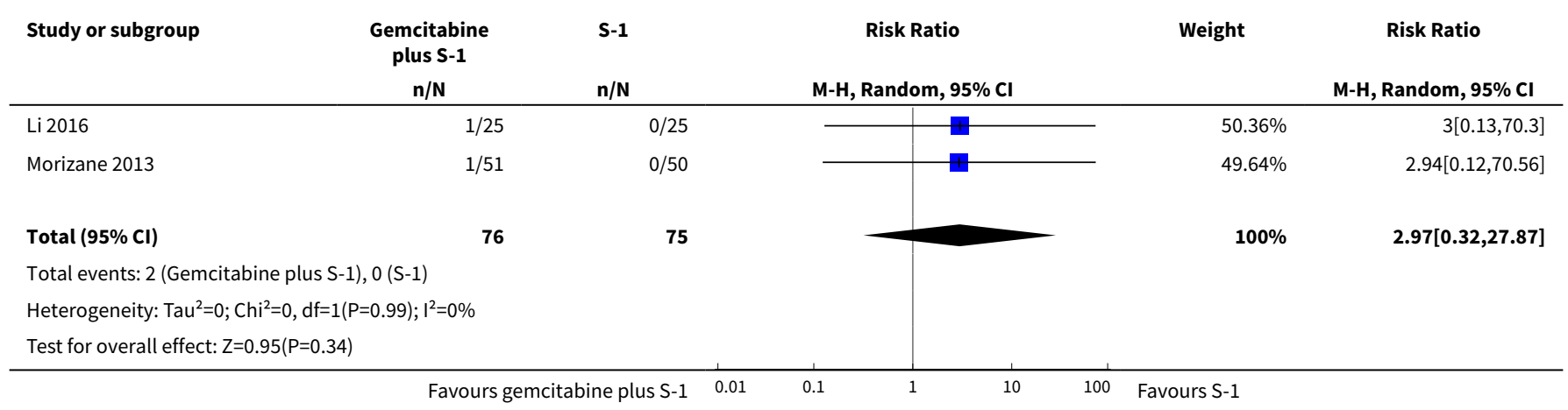

\section{Comparison 5. Gemcitabine plus oxaliplatin versus best supportive care}

\begin{tabular}{lllll}
\hline Outcome or subgroup title & No. of studies & $\begin{array}{l}\text { No. of partici- } \\
\text { pants }\end{array}$ & Statistical method & Effect size \\
\hline 1 All-cause mortality at one year & 1 & & $\begin{array}{l}\text { Risk Ratio (M-H, Random, 95\% } \\
\mathrm{Cl})\end{array}$ & Totals not selected \\
\hline 2 Overall response rate & 1 & $\begin{array}{l}\text { Risk Ratio (M-H, Random, 95\% } \\
\mathrm{Cl})\end{array}$ & Totals not selected \\
\hline
\end{tabular}

Analysis 5.1. Comparison 5 Gemcitabine plus oxaliplatin versus best supportive care, Outcome 1 All-cause mortality at one year.

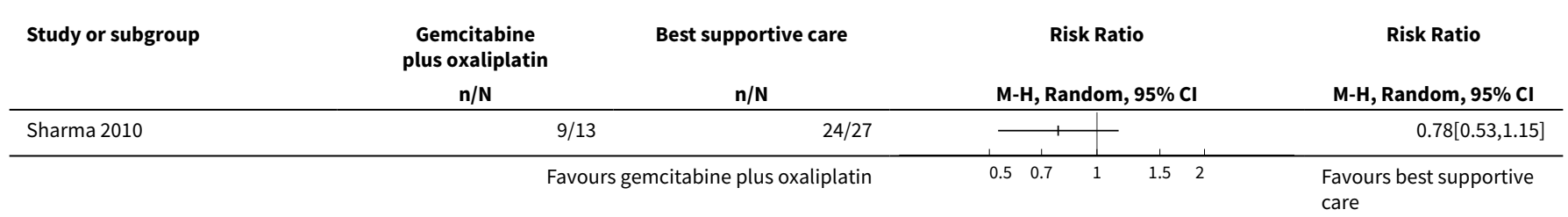


Analysis 5.2. Comparison 5 Gemcitabine plus oxaliplatin versus best supportive care, Outcome 2 Overall response rate.

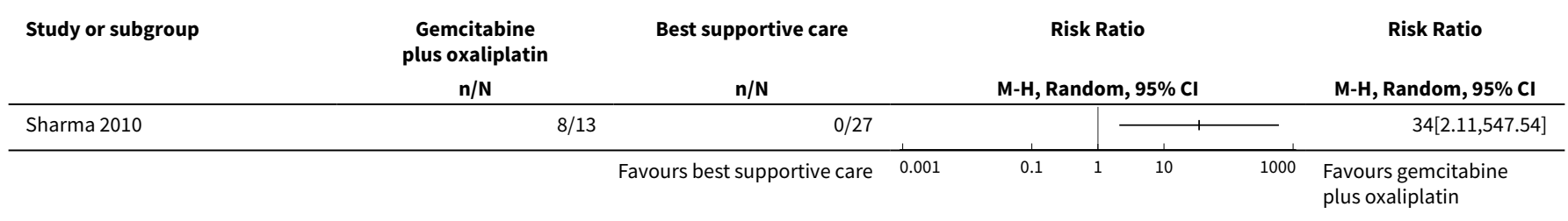

Comparison 6. Gemcitabine plus oxaliplatin versus fluorouracil plus folinic acid

\begin{tabular}{lllll}
\hline Outcome or subgroup title & No. of studies & $\begin{array}{l}\text { No. of partici- } \\
\text { pants }\end{array}$ & Statistical method & Effect size \\
\hline 1 All-cause mortality at one year & 1 & & $\begin{array}{l}\text { Risk Ratio (M-H, Random, 95\% } \\
\text { Cl) }\end{array}$ & Totals not selected \\
\hline 2 Overall response rate & 1 & $\begin{array}{l}\text { Risk Ratio (M-H, Random, 95\% } \\
\text { Cl) }\end{array}$ & Totals not selected \\
\hline
\end{tabular}

Analysis 6.1. Comparison 6 Gemcitabine plus oxaliplatin versus fluorouracil plus folinic acid, Outcome 1 All-cause mortality at one year.

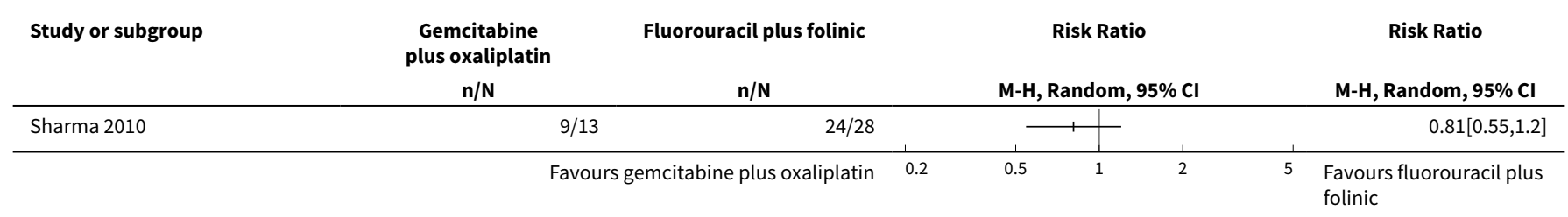

Analysis 6.2. Comparison 6 Gemcitabine plus oxaliplatin versus fluorouracil plus folinic acid, Outcome 2 Overall response rate.

\begin{tabular}{|c|c|c|c|c|c|c|c|}
\hline \multirow{2}{*}{$\begin{array}{l}\text { Study or subgroup } \\
\text { Sharma } 2010\end{array}$} & $\begin{array}{c}\text { Gemcitabine } \\
\text { plus oxaliplatin } \\
\mathbf{n} / \mathbf{N} \\
\end{array}$ & $\begin{array}{l}\text { Fluorouracil plus folinic } \\
\qquad \mathrm{n} / \mathrm{N} \\
\end{array}$ & \multicolumn{4}{|c|}{ Risk Ratio } & \multirow{2}{*}{$\begin{array}{c}\text { Risk Ratio } \\
\text { M-H, Random, 95\% Cl } \\
2.15[0.64,7.29]\end{array}$} \\
\hline & $4 / 13$ & $4 / 28$ & & & 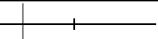 & & \\
\hline & & urs fluorouracil plus folinic & 0.05 & 0.2 & 5 & 20 & $\begin{array}{l}\text { Favours gemcitabine } \\
\text { plus oxaliplatin }\end{array}$ \\
\hline
\end{tabular}

Comparison 7. Gemcitabine plus oxaliplatin versus 5-fluorouracil plus cisplatin plus radiotherapy

\begin{tabular}{llll}
\hline Outcome or subgroup title & No. of studies & $\begin{array}{l}\text { No. of partici- } \\
\text { pants }\end{array}$ & Statistical method \\
\hline $\begin{array}{l}1 \text { All-cause mortality at one } \\
\text { year }\end{array}$ & 1 & Risk Ratio (M-H, Random, 95\% Cl) $\quad$ Totals not selected & Risk Ratio (M-H, Random, 95\% Cl) Totals not selected \\
\hline 2 Serious adverse events & 1 & \\
\hline
\end{tabular}




\begin{tabular}{lllll}
\hline Outcome or subgroup title & No. of studies & $\begin{array}{l}\text { No. of partici- } \\
\text { pants }\end{array}$ & Statistical method & Effect size \\
\hline 3 Grade 3-4 neutropenia & 1 & & Risk Ratio (M-H, Random, 95\% Cl) & Totals not selected
\end{tabular}

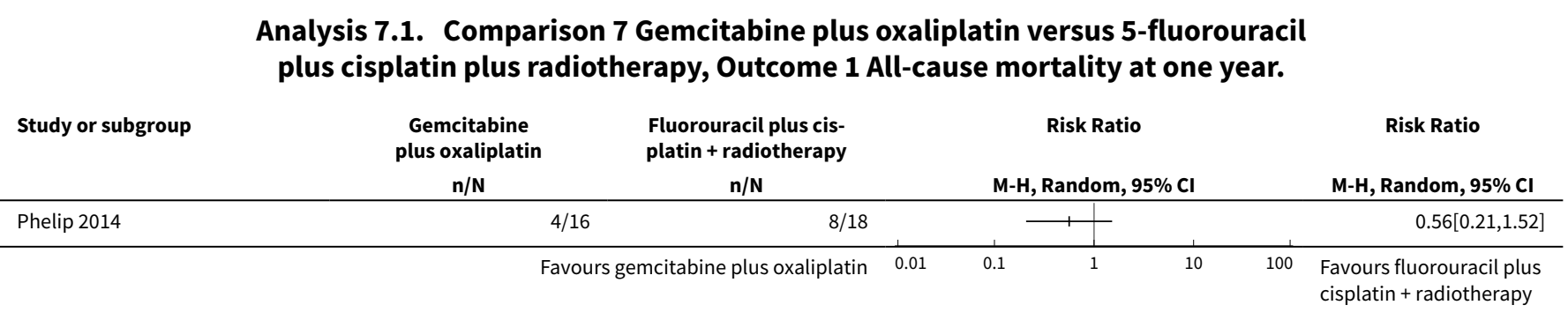

Analysis 7.2. Comparison 7 Gemcitabine plus oxaliplatin versus 5-fluorouracil plus cisplatin plus radiotherapy, Outcome 2 Serious adverse events.

\begin{tabular}{|c|c|c|c|c|c|c|c|}
\hline \multirow[t]{2}{*}{ Study or subgroup } & $\begin{array}{c}\text { Gemcitabine } \\
\text { plus oxaliplatin }\end{array}$ & $\begin{array}{l}\text { Fluorouracil plus cis- } \\
\text { platin + radiotherapy }\end{array}$ & \multicolumn{4}{|c|}{ Risk Ratio } & \multirow{2}{*}{$\begin{array}{c}\text { Risk Ratio } \\
\text { M-H, Random, } 95 \% \mathrm{Cl}\end{array}$} \\
\hline & $n / N$ & $n / N$ & & & dom, $95 \% \mathrm{Cl}$ & & \\
\hline Phelip 2014 & $8 / 16$ & $6 / 18$ & & & $+1-$ & & $1.5[0.66,3.39]$ \\
\hline & Favou & mcitabine plus oxaliplatin & 0.01 & 0.1 & 10 & 100 & $\begin{array}{l}\text { Favours fluorouracil plus } \\
\text { cisplatin + radiotherapy }\end{array}$ \\
\hline
\end{tabular}

Analysis 7.3. Comparison 7 Gemcitabine plus oxaliplatin versus 5 -fluorouracil plus cisplatin plus radiotherapy, Outcome 3 Grade 3 - 4 neutropenia.

\begin{tabular}{|c|c|c|c|c|c|c|c|}
\hline Study or subgroup & $\begin{array}{c}\text { Gemcitabine } \\
\text { plus oxaliplatin } \\
\text { n/N }\end{array}$ & $\begin{array}{c}\text { Fluorouracil plus cis- } \\
\text { platin + radiotherapy } \\
\text { n/N }\end{array}$ & \multicolumn{4}{|c|}{ Risk Ratio } & \multirow{2}{*}{$\begin{array}{c}\text { Risk Ratio } \\
\begin{array}{c}\text { M-H, Random, 95\% Cl } \\
10.06[0.58,173.47]\end{array}\end{array}$} \\
\hline \multirow[t]{2}{*}{ Phelip 2014} & $4 / 16$ & $0 / 18$ & & & 1 & & \\
\hline & Favou & ncitabine plus oxaliplatin & 0.002 & 0.1 & 10 & 500 & $\begin{array}{l}\text { Favours fluorouracil plus } \\
\text { cisplatin + radiotherapy }\end{array}$ \\
\hline
\end{tabular}

Comparison 8. Gemcitabine plus mitomycin $\mathrm{C}$ versus capecitabine plus mitomycin $\mathrm{C}$

\begin{tabular}{lllll}
\hline Outcome or subgroup title & No. of studies & $\begin{array}{l}\text { No. of partici- } \\
\text { pants }\end{array}$ & Statistical method & Effect size \\
\hline $\begin{array}{l}1 \text { All-cause mortality at one } \\
\text { year }\end{array}$ & 1 & Risk Ratio (M-H, Random, 95\% Cl) & Totals not selected \\
\hline 2 Overall response rate & 1 & Risk Ratio (M-H, Random, 95\% Cl) & Totals not selected \\
\hline $\begin{array}{l}\text { 3 Grade 1 - 4 thrombocytope- } \\
\text { nia }\end{array}$ & 1 & Risk Ratio (M-H, Random, 95\% Cl) & Totals not selected \\
\hline
\end{tabular}




\begin{tabular}{lllll}
\hline Outcome or subgroup title & No. of studies & $\begin{array}{l}\text { No. of partici- } \\
\text { pants }\end{array}$ & Statistical method & Effect size \\
\hline $\begin{array}{l}\text { 4 Grade 3-4 thrombocytope- } \\
\text { nia }\end{array}$ & 1 & Risk Ratio (M-H, Random, 95\% Cl) & Totals not selected \\
\hline
\end{tabular}

Analysis 8.1. Comparison 8 Gemcitabine plus mitomycin $C$ versus capecitabine plus mitomycin C, Outcome 1 All-cause mortality at one year.

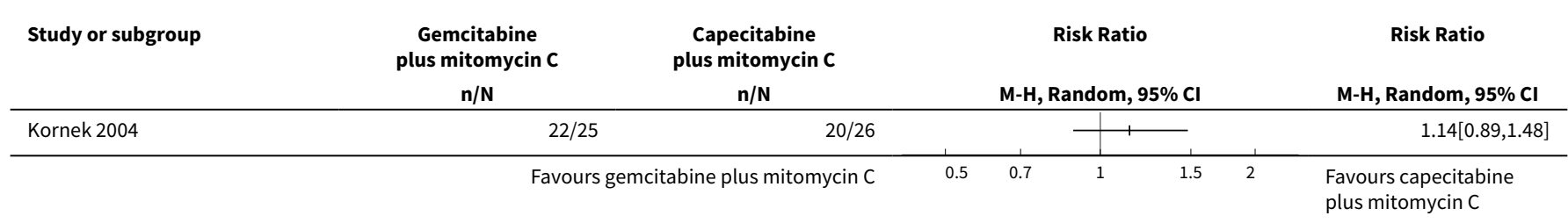

Analysis 8.2. Comparison $8 \mathrm{Gemcitabine} \mathrm{plus} \mathrm{mitomycin} \mathrm{C}$ versus capecitabine plus mitomycin C, Outcome 2 Overall response rate.

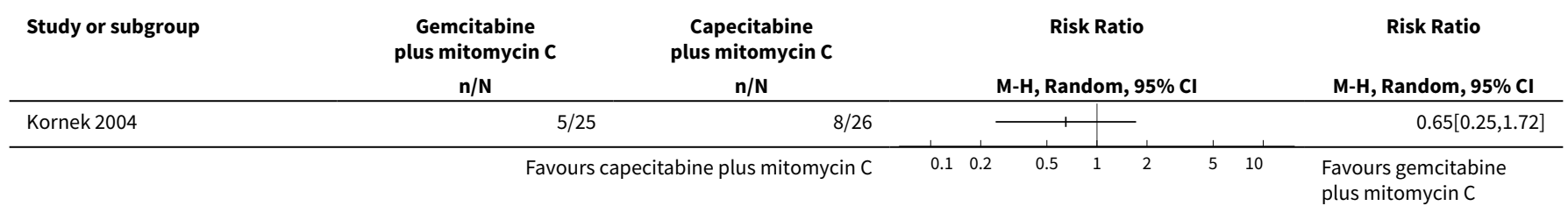

Analysis 8.3. Comparison 8 Gemcitabine plus mitomycin $C$ versus capecitabine plus mitomycin C, Outcome 3 Grade 1 - 4 thrombocytopenia.

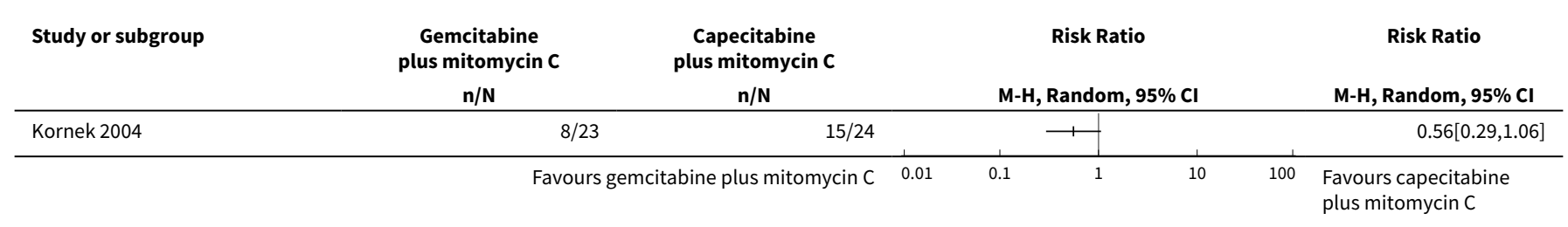

Analysis 8.4. Comparison 8 Gemcitabine plus mitomycin $C$ versus capecitabine plus mitomycin C, Outcome 4 Grade 3 - 4 thrombocytopenia.

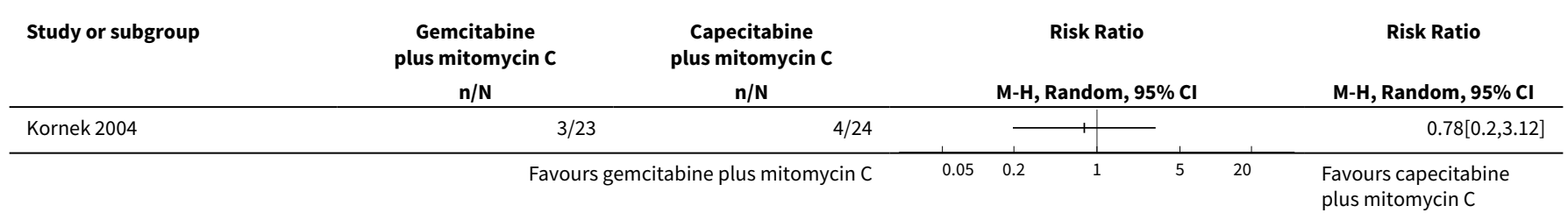

\section{ADDITIONAL TABLES}


Table 1. Explanations for Cochrane 'Summary of findings' tables

\section{Examples from table}

Outcomes

Assumed control group risk

\section{Explanation}

The tables provide the findings for the most important outcomes for someone making a decision. These include potential benefits and harms, whether the included trials provide data for these outcomes or not. Additional findings may be reported elsewhere in the review.

Assumed control group risks can be based either on the control group risks reported in the included trials or on epidemiological data from elsewhere. When only one control group risk is provided, it is normally the median control group risk across the trials that provided data for that outcome.

Risk is the probability of an outcome occurring. The control group risk is the risk of an outcome occurring in the comparison group (without the intervention).

Corresponding intervention group risk
Risk is the probability of an outcome occurring. The intervention group risk is the risk of an outcome occurring in the group receiving the intervention.

Relative effect

\section{Relative effect or RR (risk ratio)}

Relative effects are ratios. Here the relative effect is expressed as a risk ratio.

Risk is the probability of an outcome occurring. An RR is the ratio between the risk in the intervention group and the risk in the control group. If the risk in the control group is $10 \%$ (100 per 1000) and the risk in the intervention group is $1 \%$ (10 per 1000), the RR is $10 / 100$ or 0.10 .

If the RR is exactly 1.0, this means that there is no difference between the occurrence of the outcome in the intervention and the control group. It is unusual for the RR to be exactly 1.0, and understanding what it means if it is above or below this value depends on whether the outcome being counted is judged to be good or bad.

If the RR is greater than 1.0, the intervention increases the risk of the outcome. If it is a good outcome (e.g. the birth of a healthy baby), an RR $>1.0$ indicates a desirable effect for the intervention, whereas if the outcome is bad (e.g. death), an RR $>1.0$ would indicate an undesirable effect.

If the RR is less than 1.0, the intervention decreases the risk of the outcome. This indicates a desirable effect if it is a bad outcome (e.g. death) and an undesirable effect if it is a good outcome (e.g. birth of a healthy baby).

\section{What is the difference between absolute and relative effects?}

The effect of an intervention can be described by comparing the risk of the intervention group with the risk of the control group. Such a comparison can be made in different ways.

One way to compare two risks is to calculate the difference between the risks. This is the absolute effect.

Consider the risk for blindness in a person with diabetes over a five-year period. If the risk for blindness is found to be 20 in $1000(2 \%)$ in a group of people treated conventionally and 10 in $1000(1 \%)$ in people treated with a new drug, the absolute effect is derived by subtracting the intervention group risk from the control group risk: $2 \% / 1 \%=1 \%$. Expressed in this way, it can be said that the new drug reduces the five-year risk for blindness by $1 \%$ (absolute effect is 10 fewer per 1000).

Another way to compare risks is to calculate the ratio of the two risks. Given the data above, the relative effect is derived by dividing the two risks, with the intervention risk being divided by the control risk: $1 \% \div 2 \%=1 / 2(0.50)$. Expressed in this way, as the 'relative effect', the five-year risk for blindness with the new drug is $1 / 2$ the risk with the conventional drug.

Here the table presents risks as x per 1000 (or 100, etc.) instead of $\%$, as this tends to be easier to understand. Whenever possible, the table presents the relative effect as the RR.

Usually the absolute effect is different for groups that are at high and low risk, whereas the relative effect often is the same. Therefore, when it is relevant, we have reported indicative risks for groups at different levels of risk. Two or three indicative control group risks and the corresponding inter- 
Table 1. Explanations for Cochrane 'Summary of findings' tables (Continued)

vention group risks are presented when there are important differences across different populations.

Mean difference

95\% confidence interval

As explained above, the $\mathrm{Cl}$ indicates the extent to which chance may be responsible for the observed numbers. In the simplest terms, a $95 \% \mathrm{Cl}$ means that we can be $95 \%$ confident that the true size of effect is between the lower and upper confidence limit (e.g. 0 and 3 in the blindness drugs example mentioned above). Conversely, there is a $5 \%$ chance that the true effect is outside of this range.

Not statistically significant

Statistically significant means that a result is unlikely to have occurred by chance. The usual threshold for this judgement is that the results, or more extreme results, would occur by chance with a probability of less than 0.05 if the null hypothesis (no effect) were true. When results are not statistically significant, as in this example, this is stated to alert users to the possibility that the results may have occurred by chance.

Number of participants (trials)

The table provides the total number of participants across trials and the number of trials that provided data for that outcome. This indicates how much evidence there is for the outcome.

Certainty of the evidence

The certainty of the evidence is a judgement about the extent to which we can be confident that the estimates of effect are correct. These judgements are made using the GRADE system, and are provided for each outcome. The judgements are based on the type of study design (randomised trials versus observational trials), the risk of bias, the consistency of the results across trials, and the precision of the overall estimate across trials.

For each outcome, the certainty of the evidence is rated as high, moderate, low, or very low using the following definitions:

- High certainty: We are very confident that the true effect lies close to that of the estimate of the effect

- Moderate certainty: We are moderately confident in the effect estimate: The true effect is likely to be close to the estimate of the effect, but there is a possibility that it is substantially different

- Low certainty: Our confidence in the effect estimate is limited: The true effect may be substantially different from the estimate of the effect

- Very low certainty: We have very little confidence in the effect estimate: The true effect is likely to be substantially different from the estimate of effect. 


\section{AP PE N DICES}

\section{Appendix 1. Search strategies}

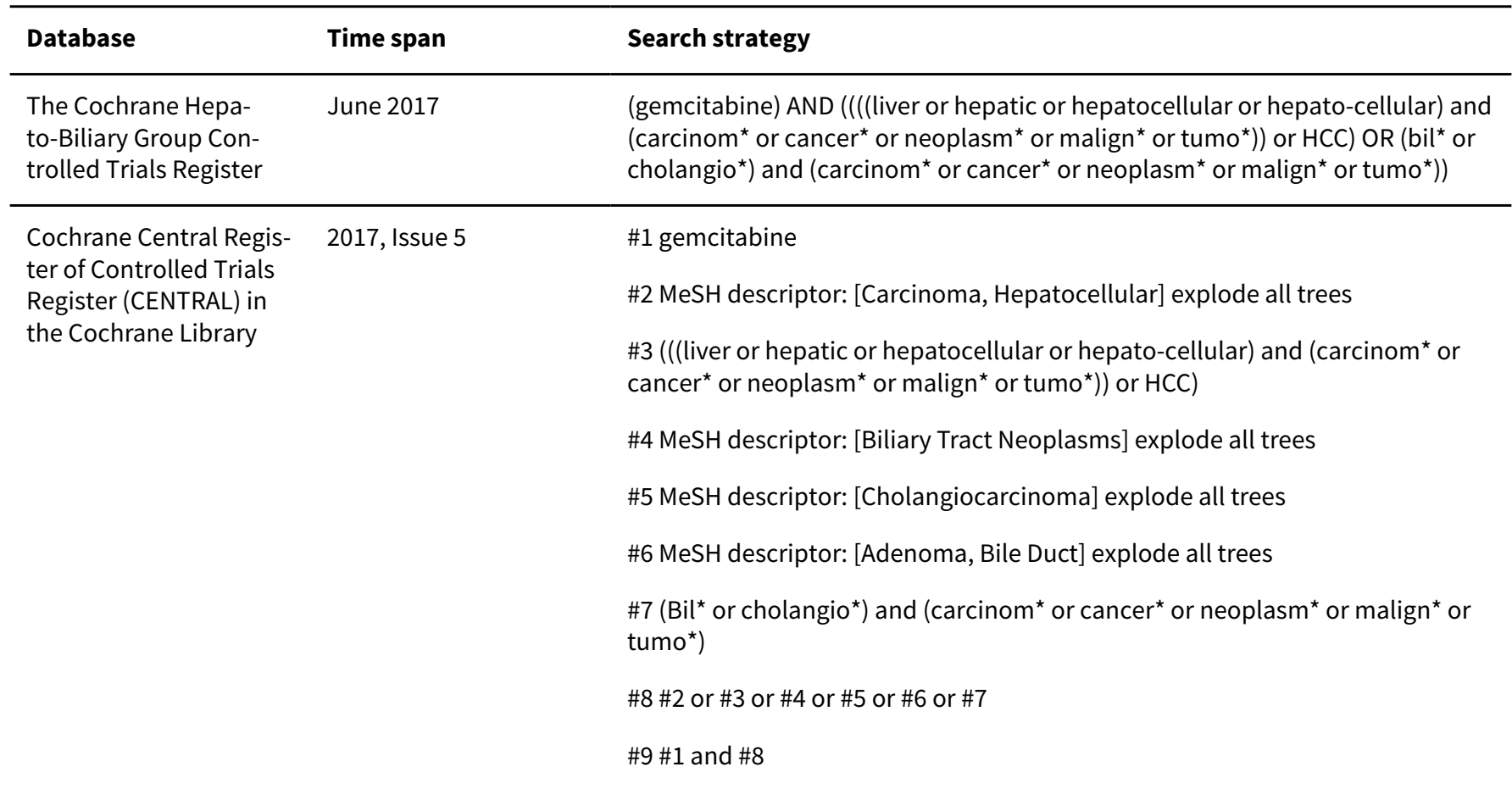

MEDLINE Ovid
From 1946 to June 2017
1. gemcitabine.mp. [ $\mathrm{mp}=$ title, abstract, original title, name of substance word, subject heading word, keyword heading word, protocol supplementary concept word, rare disease supplementary concept word, unique identifier]

\section{2. exp Carcinoma, Hepatocellular/}

3. (((liver or hepatic or hepatocellular or hepato-cellular) and (carcinom* or cancer* or neoplasm * or malign* or tumo*)) or HCC).mp. [mp=title, abstract, original title, name of substance word, subject heading word, keyword heading word, protocol supplementary concept word, rare disease supplementary concept word, unique identifier]

4. exp Biliary Tract Neoplasms/

5. Cholangiocarcinoma/

6. Adenoma, Bile Duct/

7. ((Bil ${ }^{\star}$ or cholangio $\left.{ }^{\star}\right)$ and (carcinom ${ }^{\star}$ or cancer ${ }^{\star}$ or neoplasm ${ }^{\star}$ or malign ${ }^{\star}$ or tumo*)).mp. [mp=title, abstract, original title, name of substance word, subject heading word, keyword heading word, protocol supplementary concept word, rare disease supplementary concept word, unique identifier]

\section{2 or 3 or 4 or 5 or 6 or 7}

\section{1 and 8}

10. $\left(\right.$ random $^{\star}$ or blind ${ }^{*}$ or placebo* or meta-analys $\left.{ }^{\star}\right) . m p$. [mp=title, abstract, original title, name of substance word, subject heading word, keyword heading word, protocol supplementary concept word, rare disease supplementary concept word, unique identifier] 
2. gemcitabine.mp. [mp=title, abstract, subject headings, heading word, drug trade name, original title, device manufacturer, drug manufacturer, device trade name, keyword]

\section{1 or 2}

4. exp liver cell carcinoma/

5. (((liver or hepatic or hepatocellular or hepato-cellular) and (carcinom* or cancer $^{\star}$ or neoplasm* or malign* or tumo*)) or HCC).mp. [mp=title, abstract, subject headings, heading word, drug trade name, original title, device manufacturer, drug manufacturer, device trade name, keyword]

\section{6. exp biliary tract tumor/}

7. exp bile duct carcinoma/

8. ((Bil ${ }^{\star}$ or cholangio*) and (carcinom ${ }^{\star}$ or cancer ${ }^{\star}$ or neoplasm ${ }^{\star}$ or malign ${ }^{\star}$ or tumo*)).mp. [mp=title, abstract, subject headings, heading word, drug trade name, original title, device manufacturer, drug manufacturer, device trade name, keyword]

\section{4 or 5 or 6 or 7 or 8}

10. 3 and 9

11. $\left(\right.$ random $^{\star}$ or blind ${ }^{\star}$ or placebo ${ }^{\star}$ or meta-analys $\left.{ }^{\star}\right) \cdot \mathrm{mp}$. [mp=title, abstract, subject headings, heading word, drug trade name, original title, device manufacturer, drug manufacturer, device trade name, keyword]

\section{10 and 11}

LILACS (Bireme)
From 1982 to June 2017

gemcitabine [Words] and ((( (liver or hepatic or hepatocellular or hepato-cellular) and (carcinom\$ or cancer\$ or neoplasm\$ or malign\$ or tumo\$)) or HCC) OR (bil\$ or cholangio\$) and (carcinom\$ or cancer\$ or neoplasm\$ or malign\$ or tumo\$)) [Words]

Science Citation Index Expanded (Web of Science)

\section{From 1900 to June $2017 \quad$ \#7 \#6 AND \#5}

\#6 TS=(random ${ }^{\star}$ or blind ${ }^{\star}$ or placebo* or meta-analys $\left.{ }^{\star}\right)$

\#5 \#4 AND \#1

\#4 \#3 OR \#2

\#3 TS=((Bil ${ }^{\star}$ or cholangio* $)$ and (carcinom ${ }^{*}$ or cancer ${ }^{*}$ or neoplasm ${ }^{\star}$ or malign * or tumo*))

\#2 TS=(((liver or hepatic or hepatocellular or hepato-cellular) and (carcinom* or cancer* or neoplasm* or malign* or tumo*)) or HCC)

\#1 TS=(gemcitabine)

\begin{tabular}{|c|c|c|}
\hline \multirow{3}{*}{$\begin{array}{l}\text { Conference Proceed- } \\
\text { ings Citation Index } \\
\text { - Science (Web of } \\
\text { Science) }\end{array}$} & From 1990 to June 2017 & $\begin{array}{l}\text { \#7 \#6 AND \#5 } \\
\left.\text { \#6 TS=(random* or blind }{ }^{\star} \text { or placebo* or meta-analys }{ }^{\star}\right)\end{array}$ \\
\hline & & \#5 \#4 AND \#1 \\
\hline & & \#4 \#3 OR \#2 \\
\hline
\end{tabular}


\#3 TS= $\left(\left(\right.\right.$ Bil $^{\star}$ or cholangio $\left.{ }^{\star}\right)$ and (carcinom ${ }^{\star}$ or cancer ${ }^{\star}$ or neoplasm ${ }^{\star}$ or malign ${ }^{\star}$ or tumo*))

\#2 TS=(((liver or hepatic or hepatocellular or hepato-cellular) and (carcinom* or cancer* or neoplasm* or malign* or tumo*)) or HCC)

\#1 TS=(gemcitabine)

\section{CONTRIBUTIONS OFAUTHORS}

Omar Abdel-Rahman: writing and revising the review

Zeinab Elsayed: revising the review

Hesham El Halawani: writing and revising the review

All review authors agreed on the final version of the review.

\section{DECLARATIONS OF INTEREST}

Omar Abdel-Rahman: none known

Zeinab Elsayed: none known

Hesham El Halawani: none known

\section{SOURCES OF SUPPORT}

\section{Internal sources}

- None, Other.

\section{External sources}

- None, Other.

\section{DIFFERENCES BETWEEN PROTOCOLANDREVIEW}

\section{Methods: Types of interventions}

- We dropped the last two points mentioned in the protocol section Types of interventions, which was originally: " high-dose gemcitabinebased chemotherapy versus low-dose gemcitabine-based chemotherapy; one type of gemcitabine-based chemotherapy versus another gemcitabine-based chemotherapy", in order to comply with what we have written in the Types of studies section of the protocol, which reads: "All randomised clinical trials, irrespective of language or publication status, comparing intravenous administration of gemcitabine monotherapy or gemcitabine-based combination to other treatments (excluding gemcitabine) or to placebo or no intervention". Thus, we have not included any studies comparing two different gemcitabine-based regimens.

The Types of interventions now reads in the review as:

Intravenous gemcitabine (monotherapy or combination therapy) versus placebo or no treatment, or treatments other than gemcitabine

- gemcitabine-based chemotherapy versus placebo or no intervention;

- gemcitabine-based chemotherapy versus chemotherapy without gemcitabine.

\section{Results}

- We have introduced (post hoc) the common terminology criteria of adverse events (CTCAE 2010) in the assessment of non-serious adverse events, because this is the most widely accepted and standardised method of assessing toxicity to anticancer agents worldwide.

\section{N DEX TERMS}

\section{Medical Subject Headings (MeSH)}

Ampulla of Vater; Antimetabolites, Antineoplastic [adverse effects] [*therapeutic use]; Antineoplastic Combined Chemotherapy Protocols [adverse effects] [ ${ }^{\star}$ therapeutic use]; Biliary Tract Neoplasms [ ${ }^{\star}$ drug therapy] [mortality] [pathology]; Capecitabine [administration \& dosage] [adverse effects]; Cholangiocarcinoma [*drug therapy] [mortality] [pathology]; Cisplatin [administration \& dosage] [adverse effects]; Deoxycytidine [adverse effects] [*analogs \& derivatives] [therapeutic use]; Drug Combinations; Gallbladder Neoplasms [drug therapy] [mortality] [pathology]; Mitomycin [administration \& dosage] [adverse effects]; Organoplatinum 
Compounds [administration \& dosage] [adverse effects]; Oxaliplatin; Oxonic Acid [administration \& dosage] [adverse effects]; Piperidines [administration \& dosage] [adverse effects]; Quinazolines [administration \& dosage] [adverse effects]; Randomized Controlled Trials as Topic; Tegafur [administration \& dosage] [adverse effects]

\section{MeSH check words}

Female; Humans; Male 